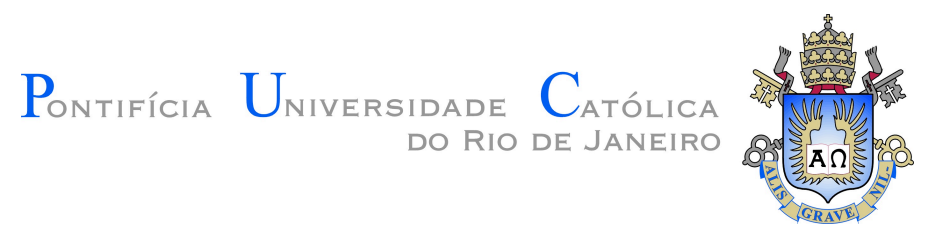

Suzane Pereira dos Santos Nascimento

\title{
Caracterização Experimental da Distribuição da Fuligem nas Proximidades de um Queimador \\ Tipo Bluff -Body
}

Dissertação apresentada como requisito parcial para obtenção do grau de Mestre pelo Programa de Pós-graduação em Engenharia Mecânica do Departamento de Engenharia Mecânica do Centro Técnico Científico da PUC-Rio.

Orientador: Prof. Luis Fernando Figueira da Silva 


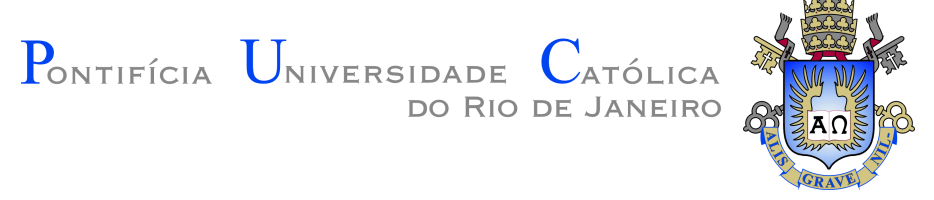

Suzane Pereira dos Santos Nascimento

\title{
Caracterização Experimental da Distribuição da Fuligem nas Proximidades de um Queimador \\ Tipo Bluff-Body
}

Dissertação apresentada como requisito parcial para obtenção do grau de Mestre pelo Programa de Pós-graduação em Engenharia Mecânica do Departamento de Engenharia Mecânica do Centro Técnico Científico da PUC-Rio. Aprovada pela Comissão Examinadora abaixo assinada.

\author{
Prof. Luis Fernando Figueira da Silva \\ Orientador \\ Departamento de Engenharia Mecânica - PUC-Rio
}

Prof. Florian Alain Yannick Pradelle

Departamento de Engenharia Mecânica - PUC-Rio

Dr. Ricardo Serfaty

Petrobras -

Prof. Márcio da Silveira Carvalho

Coordenador Setorial do Centro Técnico Científico - PUC-Rio 
Todos os direitos reservados. É proibida a reprodução total ou parcial do trabalho sem autorização da universidade, do autor e do orientador.

\section{Suzane Pereira dos Santos Nascimento}

Engenheira Química formada pela Pontifícia Universidade Católica do Rio de Janeiro - PUC-Rio, 2016.

Ficha Catalográfica

Nascimento, Suzane Pereira dos Santos

Caracterização Experimental da Distribuição da Fuligem nas Proximidades de um Queimador Tipo Bluff-Body / Suzane Pereira dos Santos Nascimento; orientador: Luis Fernando Figueira da Silva. - Rio de janeiro: PUC-Rio, Departamento de Engenharia Mecânica , 2018.

v., 85 f: il. color. ; $30 \mathrm{~cm}$

Dissertação (mestrado) - Pontifícia Universidade Católica do Rio de Janeiro, Departamento de Engenharia Mecânica .

Inclui bibliografia

1. Engenharia Mecânica - Teses. 2. - Teses. 3. Incandescência induzida por laser;. 4. Fluorescência induzida por laser planar;. 5. Combustão turbulenta;. 6. Estudo experimental. . I. Silva, Luis Fernando Figueira da.. II. Pontifícia Universidade Católica do Rio de Janeiro. Departamento de Engenharia Mecânica. III. Título. 


\section{Agradecimentos}

Ao meu orientador e mentor Professor Luis Fernando Figueira da Silva pela paciência, ensinamentos, dedicação, amizade e confiança em mim depositada durante essa jornada.

A Puc-Rio e ao Departamento de Engenharia Mecânica da PUC-Rio pela concessão do espaço no Laboratório de Combustão e Turbulência que viabilizou a realização deste trabalho.

O presente trabalho foi realizado com o apoio da Coordenação de Aperfeiçoamento de Pessoal de Nível Superior - Brasil (CAPES) - Código de financiamento 001.

Ao Professor Andrés Fuentes Castillo pelas sugestões que contribuiram para a realização deste trabalho.

Ao meu amigo Dr. Juan José Cruz Villanueva pelo acompanhamento e ensinamentos no laboratório de Combustão e Turbulência da PUC-Rio que contribuiram para realização deste trabalho.

A equipe de pesquisa do laboratório de Combustão e Turbulência da Puc-Rio pelo acompanhamento na realização dos testes de laboratório, pelo conhecimento trocado e sobretudo por serem minha força motriz motivacional diária.

Aos meus melhores amigos Thamires Figueiredo, Paloma Ernestine, Matheus Oliveira e Glenda Sousa que me acompanham desde o início dessa jornada pelo suporte, companhia, carinho e incentivo.

As amizades que fortaleci durante o percurso do mestrado: Letícia Piton, Gabriela Nobrega, Louise Ramos, Letícia Ozorio e Omar Horna pelos momentos compartilhados, conselhos, solidariedade, empatia e palavras de incentivo.

Aos meus pais, meus irmãos, Tia Emília e Tia Cléo que sempre me apoiaram e incentivaram a correr atrás dos meus sonhos sejam eles quais fossem. Sem o suporte incondicional deles nada disso seria possível.

Aos meus amigos e colegas da PUC-Rio, da vida e do TETO que mesmo de longe torceram e mandaram pensamentos positivos para mim. A energia de vocês me ajudou a criar essa grande Genki Dama.

A todos o meu singelo Obrigada! 


\section{Resumo}

Nascimento, Suzane Pereira dos Santos; Silva, Luis Fernando Figueira da.. Caracterização Experimental da Distribuição da Fuligem nas Proximidades de um Queimador Tipo Bluff-Body. Rio de Janeiro, 2018. 85p. Dissertação de Mestrado - Departamento de Engenharia Mecânica , Pontifícia Universidade Católica do Rio de Janeiro.

Entender o processo de produção de fuligem é crucial para o projeto de novos queimadores, como os de fornos industriais. Estes queimadores, que utilizam processos de combustão turbulenta, dependem de transferência de calor via radiação das partículas de fuligem para as paredes do forno para seu bom funcionamento. A fuligem formada na região de radiação deve ser oxidada para evitar problemas de saúde e meio ambiente. Mesmo tendo havido significativo progresso no decorrer das duas últimas décadas em relação às chamas laminares, a interação entre a turbulência e a produção de fuligem ainda é um problema em aberto. Este trabalho apresenta resultados experimentais recentes da distribuição instantânea e média da distribuição de fuligem em chamas turbulentas de etileno/ar não prémisturadas estabilizadas em um queimador do tipo bluff-body. A intensidade de turbulência na região de esteira deste queimador é muito alta, levando a uma presença de fuligem intermitente e a estruturas de fuligem altamente distorcidas. A distribuição de fuligem é medida usando incandescência induzida por laser (LII), com uma excitação em $266 \mathrm{~nm}$ a $10 \mathrm{~Hz}$ e fluência de $0,8 \mathrm{~J} / \mathrm{cm}^{2}$ e medição em $400 \mathrm{~nm}$ por uma câmera intensificada. Os resultados da técnica LII são comparados à técnica clássica de extinção da luz. Resultados da distribuição de hidrocarbonetos aromáticos policíclicos também são apresentados. Os resultados obtidos permitem caracterizar a distribuição da função de densidade de probabilidade de fuligem. Nas situações de escoamento onde a turbulência da esteira é controlada pelo escoamento de ar, demonstra-se que a PDF da fração volumétrica de fuligem corresponde a uma distribuição lognormal.

\section{Palavras-chave}

Incandescência induzida por laser; Fluorescência induzida por laser planar; Combustão turbulenta; Estudo experimental. 


\section{Abstract}

Nascimento, Suzane Pereira dos Santos; Silva, Luis Fernando Figueira da. (Advisor). Experimental Characterization of the Soot Distribution at the Turbulent Near Wake of a BluffBody Burner. Rio de Janeiro, 2018. 85p. Dissertação de mestrado - Departamento de Engenharia Mecânica , Pontifícia Universidade Católica do Rio de Janeiro.

Understanding the soot production process is crucial to the design of new burners, such as those in industrial furnaces. Indeed, these burners, which use turbulent combustion processes, rely on radiative heat transfer from the soot particles to the furnace walls to operate properly. The soot formed within the radiation region must the be oxidized in order to avoid health and environment issues. Although there has been significant progress over the past two decades in relation to laminar flames, the interaction between turbulence and soot production is still an open problem. This works presents recent experimental results of the instantaneous and mean soot distribution on non-premixed turbulent ethylene/air flames stabilized at a bluff-body burner. The turbulence intensity in the wake region of this burner is very high, leading to a soot intermittent presence and to highly distorted soot structures. The soot distribution is measured using laserinduced incandescence (LII), with $266 \mathrm{~nm}$ excitation at $10 \mathrm{~Hz}, 0.8 \mathrm{~J} / \mathrm{cm}^{2}$ fluence and collected at $400 \mathrm{~nm}$ by an intensified camera. The results of the LII technique are compared to those of a classical of light extinction technique. Polyciclic aromatic hydrocarbon distribution results are also presented. The results obtained allow to characterize the soot probability density function distribution. In flow situations where the wake turbulence is controlled by the air flow, the soot volume fraction PDF is shown to correspond to a lognormal distribution.

\section{Keywords}

Laser induced incandescence; Planar laser induced fluorescence; Turbulent combustion; Experimental study. 


\section{Sumário}

1 Introdução 14

$\begin{array}{lll}1.1 & \text { Objetivos } & 20\end{array}$

$\begin{array}{lll}1.2 & \text { Organização do Manuscrito } & 20\end{array}$

2 Estado da Arte: Medição de Fuligem em Chamas 22

2.1 Aplicação de Técnicas Ópticas 22

2.2 Estudos em Chamas Laminares 23

2.3 Estudos em Chamas Turbulentas 25

2.4 Sumário do Estado da Arte 33

3 Metodologia Experimental $\quad 35$

3.1 Queimador: Bluff-Body $\quad 35$

3.2 Extinção da Luz (LE) 39

3.2.1 Metodologia de Medição 39

3.2.2 Montagem Experimental 41

3.3 Incandescência Induzida por Laser (LII) 42

3.3.1 Metodologia de Medição 42

3.3.2 Montagem Experimental 44

3.3.3 Calibração LII Por LE 47

3.4 Escalas Características do Movimento Turbulento 48

3.5 Sumário das Incertezas Experimentais 49

3.6 Sumário da Metodologia Experimental 50

4 Resultados e Discussão $\quad 52$

4.1 Considerações Gerais Sobre as Chamas Estudadas 52

4.2 Fração Volumétrica de Fuligem Integrada 54

4.3 Caracterização da Distribuição de Energia do Laser 59

4.4 Estrutura Instantânea da Distribuição Espacial de Fuligem e HPA 60

4.5 Intermitência 64

4.6 Distribuição Espacial Média da Fuligem e de HPA 66

4.7 Função Densidade Probabilidade (PDF) da Distribuição de Fuligem 70

4.7.1 Distribuição de Probabilidade Medida $\quad 71$

$\begin{array}{lll}\text { 4.7.2 Análise Paramétrica da PDF } & 74\end{array}$

5 Conclusões e Perspectivas $\quad 78$ 


\section{Lista de figuras}

Figura 1.1 Consumo energético final por fonte no Brasil. Adaptado de (1).

Figura 1.2 Esquema representativo dos caminhos de reação em chamas de metano incluindo a formação do precursor de fuligem, acetileno $\left(\mathrm{C}_{2} \mathrm{H}_{2}\right)$. Adaptado de (10).

Figura 1.3 Mecanismo HACA de formação de hidrocarbonetos aromáticos de maiores cadeias via adição de etino e dehidrogenação. Adaptado de (10)

Figura 1.4 Etapas de formação de fuligem. Adaptado de (3).

Figura 1.5 Imagens das chamas de etileno/ar estudadas.

Figura 2.2 Evolução temporal da fuligem que cresce em uma forma ligamentar. Representação de cores: $\mathrm{OH}$ em vermelho, HPA em azul e fuligem em preto, adaptado de (30).

Figura 2.1 Regimes característicos de chamas não pré-misturadas estabilizadas num bluff-body, adaptado de (28).

Figura 2.3 Evolução temporal da taxa de ocupação da fuligem na linha central do plano laser em função da posição radial em três posições de medição: (a) formação de fuligem $(h=35 d)$, (b) dominada pela mistura $(h=80 d)$ e $(c)$ regiões de oxidação da fuligem $(h=120 d)$. Representação de cores: $\mathrm{OH}$ em vermelho, HPA em azul e fuligem em preto, adaptado de (30).

Figura 2.4 Imagens instantâneas de uma chama de GLP com adição de $\mathrm{N}_{2}$ na corrente de combustível, adaptado de (31).

Figura 2.5 PDF do extremo instantâneo da fração volumétrica de fuligem obtido de medidas experimentais ao longo de uma chama turbulenta. Adaptado de (32).

Figura 2.6 Estruturas globais de fuligem e radicais $\mathrm{OH}$ em uma chama de difusão turbulenta $(\operatorname{Re}=12.000)$. Cada seção da imagem foi obtida em um tempo diferente e reunida para criar uma representação composta da chama. Adaptado de (33).

Figura 2.7 Perfis axiais das frações volumétrica de fuligem média no eixo de saída do jato, para chamas com vários números de Reynolds. As flutuações de concentração de fuligem variam aproximadamente de $100 \%$ em torno do eixo do jato e atingem até $800 \%$ perto do limite da chama (não mostrado na figura). Adaptado de (33).

Figura 2.8 PDFs conjuntas da fração volumétrica de fuligem colocadas em faixas de temperatura condicionais de $300 \mathrm{~K}, 100$ diâmetros a jusante do tubo de fornecimento de combustível. (a) $0<r / d<1$, (b) $4<r / d<5$ e (c) $10<r / d<11$. Adaptado de (35). 
Figura 3.1 Chama turbulenta do tipo bluff-body apresentando as três regiões: (i) Zona de recirculação, (ii) região de gargalo e (iii) região de propagação, respectivamente, adaptado de (32).

Figura 3.2 Representação esquemática, adaptado de (36) e vista do queimador utilizado.

Figura 3.3 Ilustração do uso do programa de conversão de vazão mássica (37).

Figura 3.4 Aparato experimental extinção da luz

Figura 3.5 Sinal LII pulsado em função de diferentes perfis de feixe laser. Curvas de fluência com 18 ns de gate, iniciando 20 ns após o início do pulso de laser, adaptado de (6).

Figura 3.6 Aparato experimental da técnica de incandescência induzida por laser, LII, disponível no Laboratório de Combustão e Turbulência da PUC-Rio.

Figura 3.7 Imagem esquemática da configuração do Intensificador de imagem. Adaptado de (42).

Figura 3.8 Esquema da evolução temporal da incandescência e fluorescência detectadas na faixa UV-Vísivel e janelas temporais de detecção das câmeras, adaptado de (46).

Figura 3.9 Perfis e campos da energia cinética turbulenta adimensional, $k$. Linhas de corrente em branco, $\operatorname{Re}=45.400$. Adaptado de (49).

Figura 4.1 Fotografias das chamas de etileno/ar estudadas no queimador do tipo bluff-body.

Figura 4.2 Histogramas do sinal de extinção da fuligem superpostos por uma distribuição Normal para diferentes tempos de integração, Caso A.

Figura 4.3 Função densidade probabilidade do sinal de extinção para diferentes tempos de integração, $i_{t}$, Caso A.

Figura 4.4 Histograma de extinção da fuligem para a chama de etileno/ar na altura acima do queimador (HAB) de $27 \mathrm{~mm}$, Caso A.

Figura 4.5 Histograma de extinção da fuligem para a chama de etileno/ar na altura acima do queimador (HAB) de $37 \mathrm{~mm}$, Caso A.

Figura 4.6 Histograma de extinção da fuligem para a chama de etileno/ar na altura acima do queimador (HAB) de $47 \mathrm{~mm}$, Caso A.

Figura 4.7 Perfil transversal do laser para diferentes tipos de feixe, adaptado de (53).

Figura 4.8 Perfis do feixe laser utilizados no estudo, medidos utilizando-se espalhamento Rayleigh. Imagem planar (esquerda) e corte vertical (direita).

Figura 4.9 Estruturas instantâneas de: fuligem + HPA (sinal prompt), e fuligem (sinal delay) para o Caso A.

Figura 4.10 Estruturas instantâneas de: fuligem + HPA (sinal prompt), e fuligem (sinal delay) para o Caso B. 
Figura 4.11 Distribuição do indíce de intermitência da fuligem $(\Omega)$ para chamas de etileno/ar estudadas nos comprimentos de deteção de i) esquerda: $340 \mathrm{~nm}$ prompt, ii) centro: $400 \mathrm{~nm}$ prompt e iii) direita: $400 \mathrm{~nm}$ delay.

Figura 4.12 Distribuição do sinal médio das estruturas de fuligem + HPA para as chamas de etileno/ar nos sinais prompt e delay nos comprimentos de deteção i) esquerda: $340 \mathrm{~nm}$, ii) centro: $400 \mathrm{~nm}$ prompt e iii) direita: $400 \mathrm{~nm}$ delay.

Figura 4.13 Distribuição radial do sinal de fuligem + HPA para as chamas de etileno/ar medidos em $340 \mathrm{~nm}$ prompt para i) esquerda: Caso A e ii) direita: Caso B.

Figura 4.14 Distribuição espacial do sinal de fuligem + HPA para as chamas de etileno/ar nos sinais de $400 \mathrm{~nm}$ prompt para i) esquerda: Caso A e ii) direita: Caso B.

Figura 4.15 Distribuição espacial do sinal de fuligem para as chamas de etileno/ar nos sinais de $400 \mathrm{~nm}$ delay para i) esquerda: Caso A e ii) direita: Caso B.

Figura 4.16 Esquema representativo das regiões de análise $(1,2,3$, 4 e 5) em janelas $10 \times 10$ pixel nas linhas centrais da chama, $z=[16,28,36] \mathrm{mm}$ e $r=[-24,-12,0] \mathrm{mm}$.

Figura 4.17 Dispersão do sinal medido na zona de esteira para os casos estudados, $400 \mathrm{~nm}$ delay.

Figura 4.18 Histogramas da distribuição do sinal LII na zona de esteira para o Caso A.

Figura 4.19 Histogramas da distribuição do sinal LII na linha central do jato para o Caso A.

Figura 4.20 Histogramas da distribuição do sinal LII na zona de esteira para o Caso B.

Figura 4.21 Histogramas da distribuição do sinal LII na linha central do jato para o Caso B.

Figura 4.22 Quantis da função de distribuição de probabilidade da fuligem em $400 \mathrm{~nm}$ delay na zona de esteira para os casos estudados.

Figura 4.23 Função densidade probabilidade da distribuição de fuligem, sinal $400 \mathrm{~nm}$ delay, nas regiões apresentadas na Fig. 4.16 para o Caso A. 


\section{Lista de tabelas}

Tabela 1.1 Limites máximos de emissão para poluentes atmosféricos provenientes de processos de geração de calor a partir da combustão externa de óleo combustível. Adaptado de (2).

Tabela 2.1 Características das técnicas ópticas de diagnóstico laser empregadas neste estudo.

Tabela 3.1 Incertezas associadas a erros experimentais. Adaptado de $(41)$.

Tabela 4.1 Condições de operação para os casos estudados.

Tabela 4.2 Escalas características da turbulência utilizadas.

Tabela 4.4 Fração volumétrica de fuligem obtida para chama de etileno/ar em alturas HAB distintas, $i_{t}=1,5 \mathrm{~m} / \mathrm{s}$, Caso A.

Tabela 4.3 Fração volumétrica de fuligem obtida para chama de etileno/ar para diferentes tempos de integração, $H A B=27 \mathrm{~mm}$, Caso A.

Tabela 4.5 Médias e desvios padrão aritmética e logarítmica das regiões 1, 2, 3, 4 e 5 estudadas para o Caso A.

Tabela 4.6 Médias e desvios padrão aritmética e logarítmica das regiões 1, 2, 3, 4 e 5 estudadas para o Caso B. 


\section{Lista de Símbolos}

$\mathrm{bb}-$ bluff-body

$\mathrm{C}_{n}$ - Número de partículas por unidade de volume

$\mathrm{C}_{p}$ - Calor específico a pressão constante

$c_{0}$ - Velocidade da luz

$d, D$ - Diâmetro

$E(m)$ - Função de absorção em função do índice de refração

$E_{e x}-$ Eficiência de extinção

$\bar{f}_{v}$ - Média temporal da fração volumétrica de fuligem

$\left\langle f_{v}\right\rangle$ - Média de conjunto da fração volumétrica de fuligem

$F_{v}(z)$ - Valor integrado médio da fração volumétrica de fuligem

$h$ - Constante de Planck

$i$ - Integração

$I_{\lambda}$ - Intensidade espectral

$j-$ Jato

$k_{\lambda}$ - Coeficiente de extinção espectral do meio

$k$ - Constante de Boltzman

$k$ - Energia cinética turbulenta

$k$ - Parte imaginária de $m$

$K_{\lambda}$ - Coeficiente de extinção espectral adimensional

$\ell$ - Comprimento

$L$ - Caminho óptico

$m$ - Indíce complexo de refração

$n$ - Indíce de refração do meio

$n$ - Parte real de $m$

$N\left(d_{p}\right)$ - Função distribuição de probabilidade de partículas

$p$ - Partículas

$Q$ - Vazão volumétrica

Re - Número de Reynolds 


\section{Lista de Símbolos}

$\operatorname{Re}_{T}$ - Número de Reynolds da turbulência

$S_{L I I}$ - Sinal de incandescência

$S_{\Delta t}-$ Luz natural da chama

$t-$ Tempo

$\mathrm{T}$ - Temperatura

$u, U$ - Velocidade

$z$ - Coordenada axial

$\eta$ - Referência à escala de Kolmogorov

$\Delta t$ - Intervalo de tempo

$\tau$ - Transmissividade do meio participante

$\nu$ - Viscosidade cinemática

$\nu$ - Frequência

$\epsilon$ - Taxa de dissipação da energia cinética da turbulência

$\Omega$ - Indíce de intermitência da fuligem

$\lambda$ - Comprimento de onda de detecção

$\phi-$ Riqueza

$\mathrm{HAB}$ - Altura acima do queimador

ICCD - Intensified charged coupled device

IO - Índice de oxigênio

Im - Imaginário

LE - Light extinction

LII - Laser induced incandescence

NTLAF - Non-linear excitation regime Two-Line Atomic Fluorescence

PLIF - Planar laser induced fluorescence

PIV - Particle image velocimetry

TEM - Transmission electronic microscopy

TiRe-LII - Time-resolved laser induced incandescence 


\section{Introdução}

O processo de combustão é responsável por $85 \%$ de toda energia produzida mundialmente. A geração de energia a partir da combustão de derivados de petróleo, gás natural, carval vapor e metalúrgico, lenha e derivados da canade-açúcar representa mais de $80 \%$ da energia utilizada no Brasil, de acordo com o balanço energético nacional (ano base 2016) (1) publicado pelo Ministério de Minas e Energia. A Fig. 1.1 apresenta, em percentual, o consumo energético final por fonte no Brasil nas últimas décadas de acordo com o balanço energético nacional, onde se pode observar que derivados de petróleo, lenha e bagaço de cana somam mais de $60 \%$ das fontes de geração de energia no País.

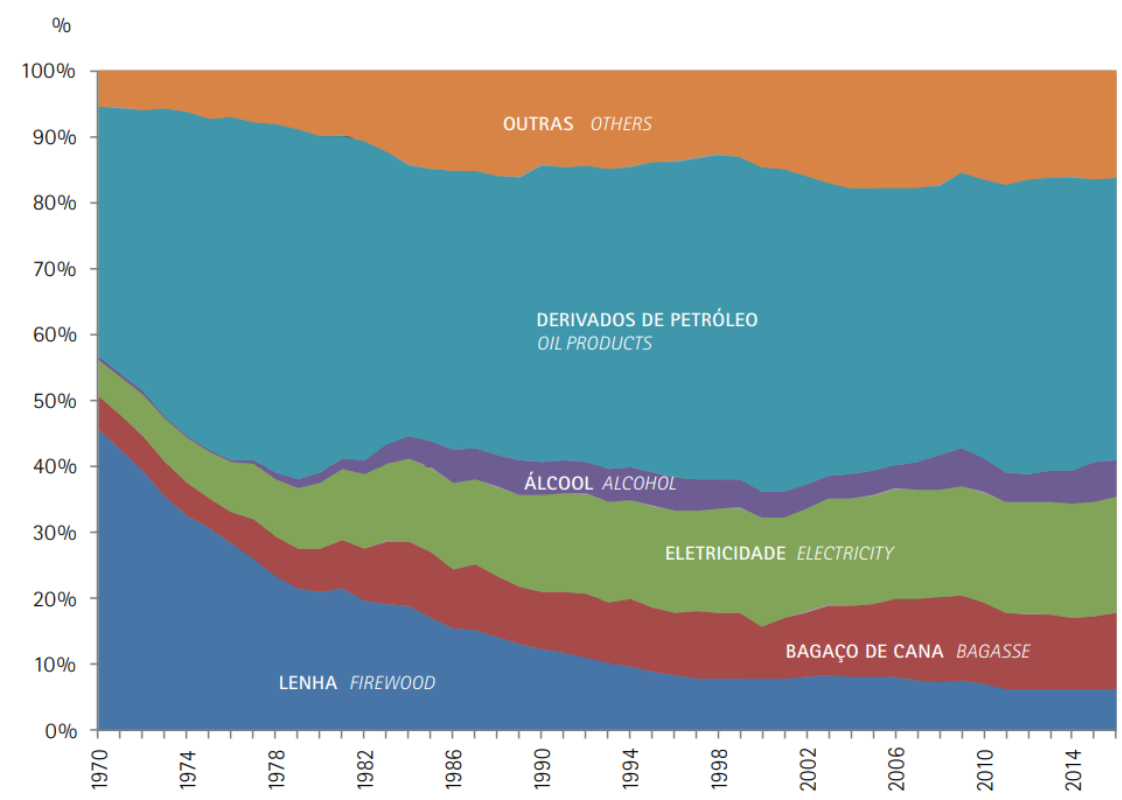

Figura 1.1: Consumo energético final por fonte no Brasil. Adaptado de (1).

A combustão ideal, que produz somente dióxido de carbono $\left(\mathrm{CO}_{2}\right)$, Nitrogênio $\left(\mathrm{N}_{2}\right)$ e água $\left(\mathrm{H}_{2} \mathrm{O}\right)$, tão somente existe na teoria. Sabe-se que, no mundo real, a combustão utilizada em escala industrial libera muitos poluentes, tais quais óxidos de nitrogênio $\left(\mathrm{NO}_{x}\right)$, hidrocarbonetos não queimados, monóxido de carbono $(\mathrm{CO})$, óxidos de enxofre $\left(\mathrm{SO}_{x}\right)$ e material particulado (MP).

Os processos de queima de óleo combustível realizados em qualquer forno ou caldeira cujos produtos de combustão não entram em contato direto 
com o material ou produto processado são chamados de processos de geração de calor por combustão externa (2) de acordo com o Conselho Nacional do Meio Ambiente (CONAMA). Estes poluentes possuem limites máximos de emissão para poluição atmosférica provenientes de tais processos. A Tabela 1.1 apresenta os limites máximos de emissão para os poluentes atmosféricos MP, $\mathrm{NO}_{x}$ e $\mathrm{SO}_{x}$ regulamentadas no Brasil para processos de geração de calor por combustão externa.

Tabela 1.1: Limites máximos de emissão para poluentes atmosféricos provenientes de processos de geração de calor a partir da combustão externa de óleo combustível. Adaptado de (2).

\begin{tabular}{|c|c|c|c|}
\hline $\begin{array}{l}\text { Potência térmica } \\
\text { nominal (MW) }\end{array}$ & $\mathrm{MP}^{(1)}$ & $\begin{array}{ll}\mathrm{NO}_{x}^{(1)} & \text { (Como } \\
\left.\mathrm{NO}_{2}\right) & \\
\end{array}$ & $\begin{array}{ll}\mathrm{SO}_{x}^{(1)} & \text { (Como } \\
\left.\mathrm{SO}_{2}\right) & \\
\end{array}$ \\
\hline Menor que 10 & 300 & 1600 & 2700 \\
\hline Entre 10 e 70 & 250 & 1000 & 2700 \\
\hline Maior que 70 & 100 & 1000 & 1800 \\
\hline
\end{tabular}

(1) os resultados devem ser expressos na unidade de concentração $\mathrm{mg} / \mathrm{Nm}^{3}$, em base seca e $3 \%$ de excesso de $\mathrm{O}_{2}$.

Os efeitos catastróficos no meio ambiente, tais como enchentes, incêndios florestais, secas e tempestades, resultado do aquecimento global gerado pela grande emissão de poluentes no ar $\left(\mathrm{CH}_{4}, \mathrm{CO}_{2}, \mathrm{SO}_{2}, \mathrm{NO}_{x}\right.$ e etc.), têm causado grande preocupação levando os governos a aplicarem uma regulamentação mais rígida aos limites máximos de emissão de poluentes no ar. Por exemplo, a adoção de tecnologias de controle de emissão de poluentes atmosféricos, técnicas economicamente viáveis e acessíveis, e, já desenvolvidas em escala que permitam sua aplicação prática (2). Dentro desse panorama, cientistas e pesquisadores procuram encontrar maneiras de se obter a máxima eficiência energética da combustão, mas causando o menor impacto ambiental possível.

Materiais particulados, também conhecidos como partícula de poluição, são misturas de partículas sólidas e gotas líquidas encontradas no ar. Alguns particulados, como poeira, fuligem ou fumaça, são grandes o suficiente a ponto de serem observadas a olho nu. Já outras partículas são tão pequenas que somente podem ser detectadas utilizando microscópio eletrônico. Dentre estes MP, destaca-se a fuligem, objeto de estudo do presente trabalho.

A fuligem é constituída por aglomerados tridimensionais de nanopartículas de carbono provenientes da queima incompleta de hidrocarbonetos; seu tamanho pode variar de diâmetros que vão desde $10 \mathrm{~nm}$ (partículas 
primárias) até $100 \mathrm{~nm}$ (estruturas fractais) (3). Pela classificação de material particulado, fuligem é classificada como partícula ultrafina $(d<1 \mu \mathrm{m})$, o que a torna extremamente nociva à saúde humana. A inalação de partículas finas pode levar a uma série de efeitos adversos a saúde, incluindo câncer de pulmão, doença de obstrução pulmocar crônica (OPC), e doenças cardiovasculares (4). Estudos mostram que partículas finas e ultrafinas $\left(\leq M P_{2.5}\right)$ possuem maior impacto em mortes por problemas cardiovasculares, pois penetram mais facilmente no organismo (5).

Em algumas aplicações industriais, a formação de fuligem pode ser propícia para os processos de combustão. Por exemplo, em queimadores de fornos industriais, a presença de fuligem pode aumentar a potência emissiva radiante da chama. Já em turbinas a gás, a presença de fuligem pode levar a danos em componentes, tais como as palhetas da turbina .

Sendo assim, é de suma importância compreeender os processos de formação e oxidação de fuligem para um melhor projeto de sistemas práticos. Entretanto, a determinação da quantidade de fuligem formada nos processos de combustão ainda é um problema em aberto (1) (6) (7). Há diversas maneiras de se quantificar e qualificar a existência de fuligem em processos de combustão, tais quais espectroscopia de absorção, na qual é medida a absorção de radiação luminosa pela fuligem, microscopia de transmissão eletrônica (TEM), pirometria de duas cores, na qual é medido a temperatura e distribuição de tamanho de partículas, incandescência induzida por laser (LII), dentre outras (6).

Nas últimas décadas, as técnicas de diagnóstico óptico vêm se desenvolvendo e, atualmente, se tornaram uma ferramenta essencial nos estudos dos processos de combustão (6) (8). Sua seletividade, juntamente, com a alta resolução temporal e espacial, permite a estas técnicas a medição da distribuição local de temperatura e de espécies químicas, por exemplo. Estas técnicas viabilizam que as medidas sejam feitas sem que haja interferência significativa na dinâmica do processo estudado.

A incandescência induzida por laser, LII, tem sido aplicada para determinar a concentração de fuligem em chamas, e baseia-se no aquecimento das partículas de fuligem por irradiação laser (6) (7) (9). Partículas de fuligem absorvem radiação laser provocando um aumento em sua temperatura e culminando na emissão de radiação (incandescência) semelhante à emissão de corpo negro. O sinal de radiação da técnica LII, que comumente é captado por uma câmera intensificadora, pode ser relacionado a fração volumétrica de fuligem, $f_{v}$. 


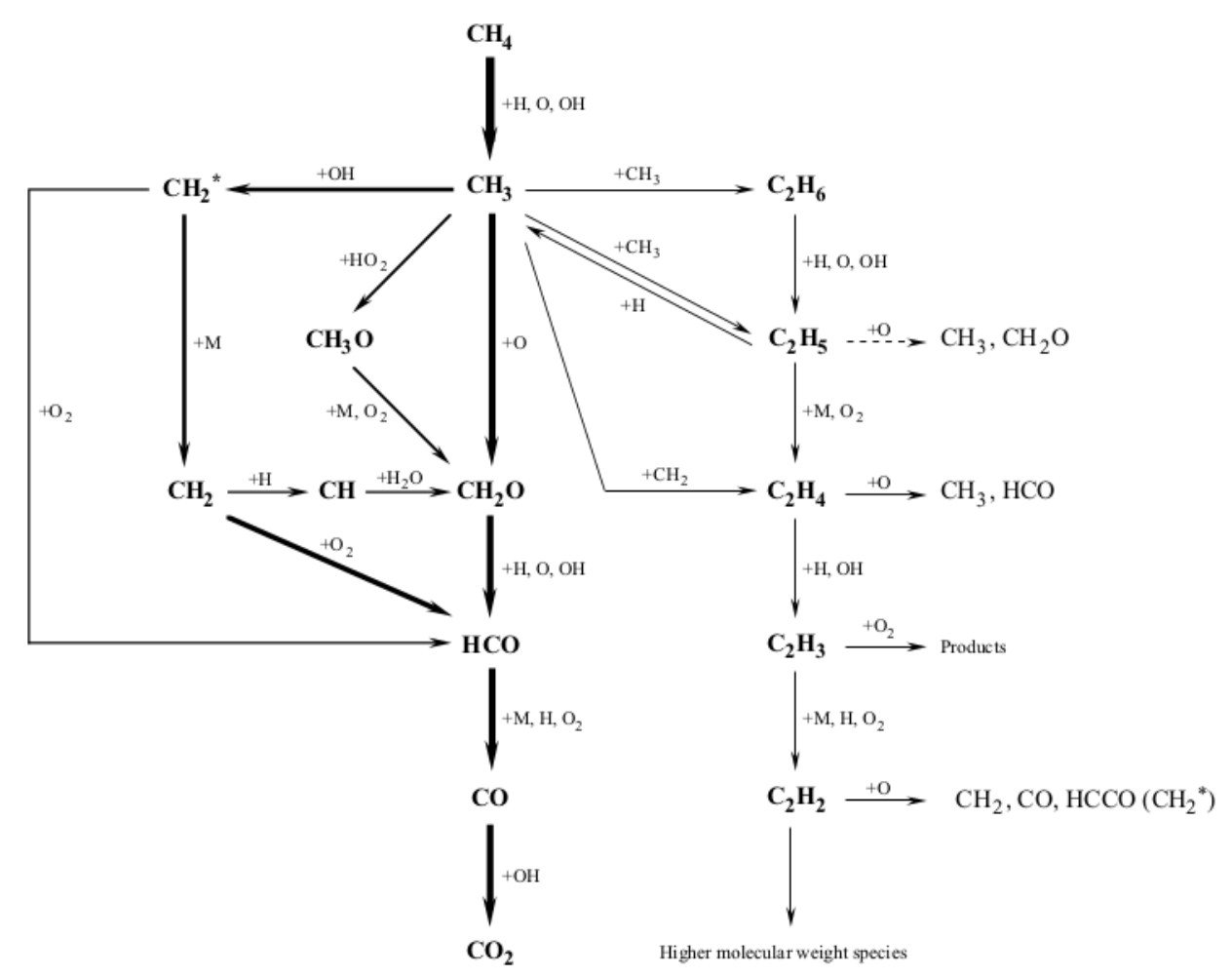

Figura 1.2: Esquema representativo dos caminhos de reação em chamas de metano incluindo a formação do precursor de fuligem, acetileno $\left(\mathrm{C}_{2} \mathrm{H}_{2}\right)$. Adaptado de (10).

Os caminhos de formação de fuligem podem ser melhor compreendidos observando-se as reações de seus precursores. A Fig. 1.2 apresenta os caminhos de reação do combustível metano para processos de combustão em chamas. Em casos de combustão ideal ou completa, isto é, produção total de $\mathrm{CO}_{2}, 4$ caminhos de reação podem ser observados. Para combustão incompleta, característica de sistemas reais, 3 caminhos de reação podem ocorrer, culminando todos na formação da espécie acetileno $\left(\mathrm{C}_{2} \mathrm{H}_{2}\right)$. Este composto é o principal precursor de espécies de maior peso molecular, isto é, o acetileno é a espécie base para formação de outros hidrocarbonetos de maiores cadeias dentro dos produtos de combustão incompleta. Em seguida, forma-se hidrocarbonetos aromáticos de maiores cadeias carbônicas, via o mecanismo HACA (10) (Fig 1.3), de adição de etino, e dehidrogenação. 


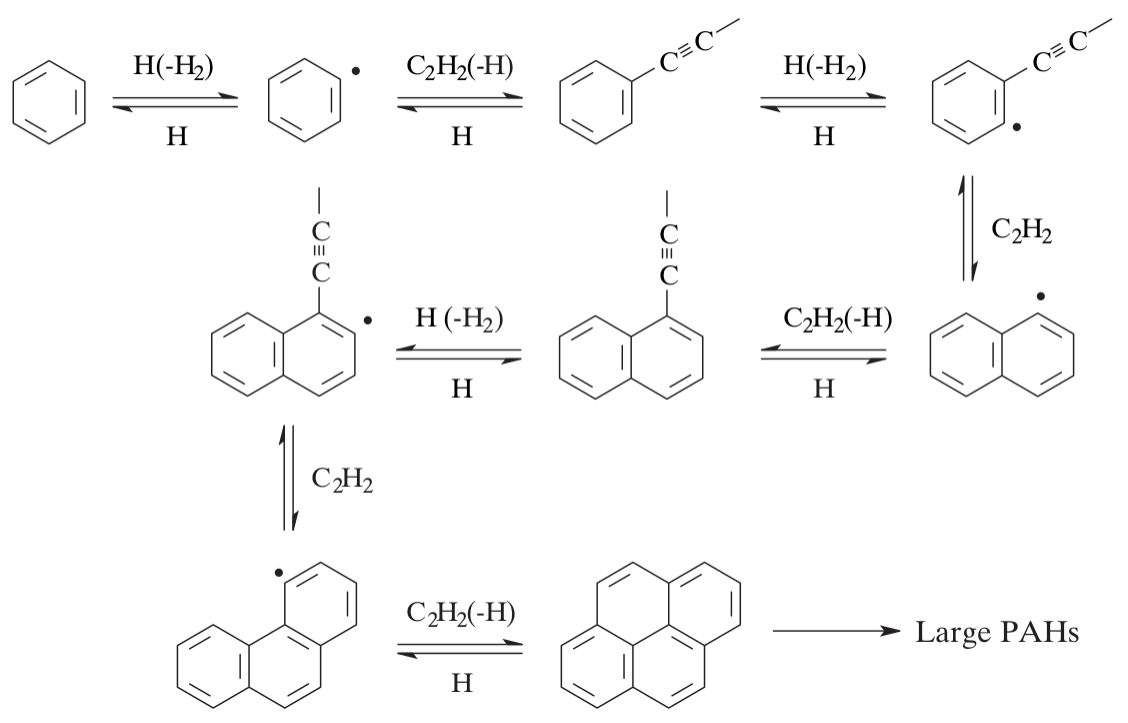

Figura 1.3: Mecanismo HACA de formação de hidrocarbonetos aromáticos de maiores cadeias via adição de etino e dehidrogenação. Adaptado de (10)

A Fig. 1.4 apresenta as etapas de formação de fuligem partindo do seu principal precursor, o acetileno $\left(\mathrm{C}_{2} \mathrm{H}_{2}\right)$. O combustível passa pelo processo de pirólise formando o precursor, $\mathrm{C}_{2} \mathrm{H}_{2}$, que é envolvido em reações químicas para formar hidrocarbonetos aromáticos de cadeias menores, benzeno $\left(\mathrm{C}_{6} \mathrm{H}_{6}\right)$ e fenil $\left(\mathrm{C}_{6} \mathrm{H}_{5}\right)$. A partir dai, as moléculas passam por nucleação que, apesar de ser um processo não tão bem compreendido, é entendido como a formação das primeiras partículas sólidas a partir de espécies gasosas. Formado-se as primeiras partículas (partículas primárias), começa-se então o processo de crescimento e aglomeração, onde os núcleos das partículas, em presença de altas temperaturas (> $1800 \mathrm{~K}$ ), absorvem as espécies gasosas e perdem um hidrôgenio, aumentando sua massa e seu volume, levando assim à formação de estruturas fractais de fuligem (partículas maduras). 


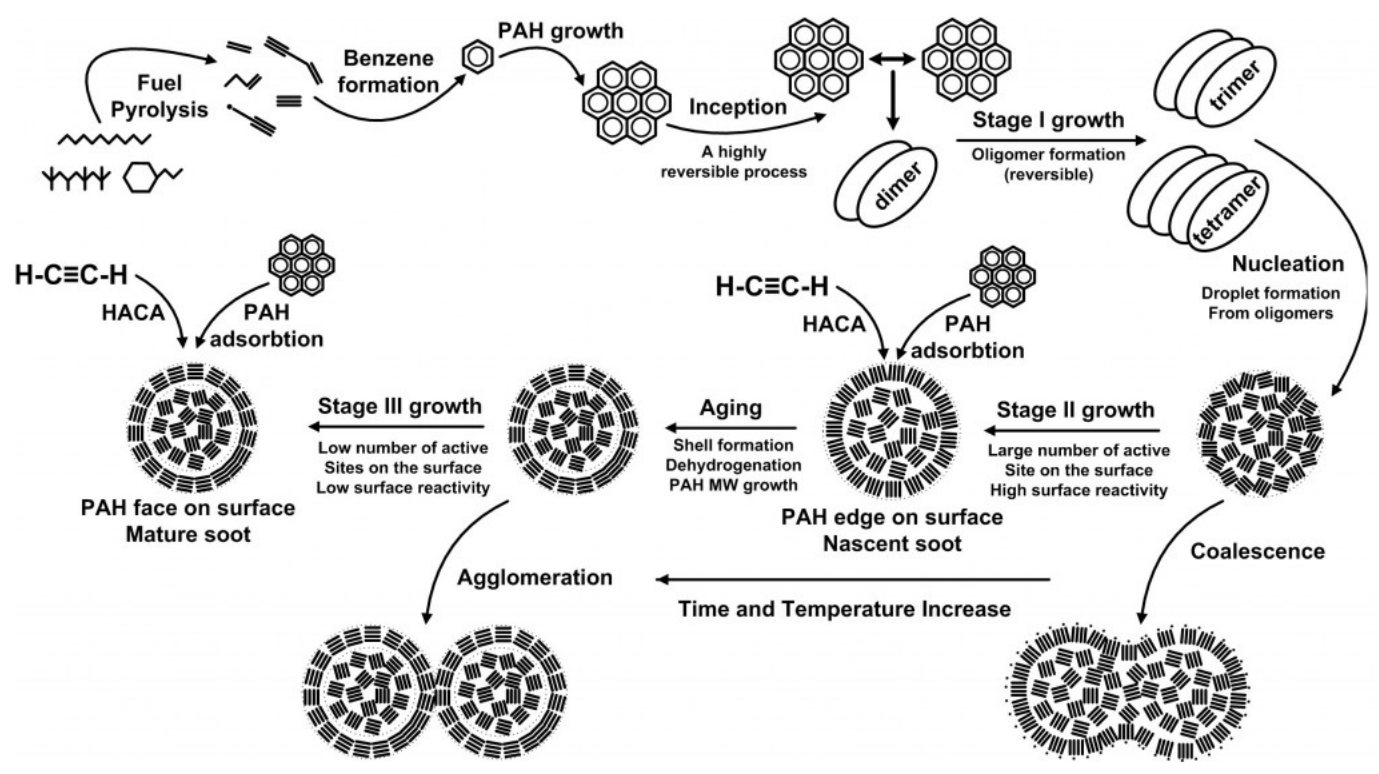

Figura 1.4: Etapas de formação de fuligem. Adaptado de (3).

A interação da turbulência com o processo de formação de fuligem, é um problema aberto. As leis e mecanismos físico-químicos que regem o processo de combustão turbulenta devem ser adequadamente entendidos para o devido desenvolvimento de modelos de combustão que descrevem esta interação. Sendo assim, se faz necessária a realização de experimentos detalhados em condições controladas que possibilitem uma melhor compreensão dos fenômenos físicoquímicos abrangidos na formação de fuligem em escoamentos turbulentos.
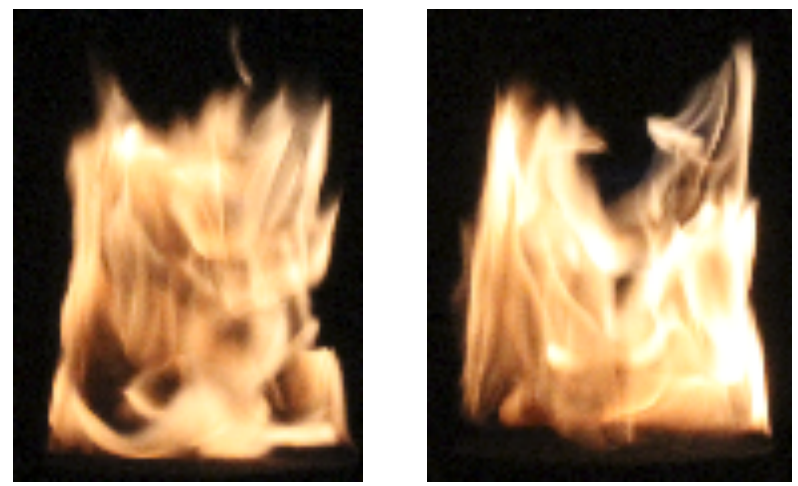

Figura 1.5: Imagens das chamas de etileno/ar estudadas.

Neste estudo, os experimentos são realizados num queimador turbulento não pré-misturado do tipo Bluff-Body. A geometria simples do queimador permite o fácil acesso óptico, e enseja a extração simples das informações de interesse. Por ser capaz de estabilizar chamas em sua zona de recirculação, tal 
como o mostrado na Fig. 1.5 este queimador apresenta grande relevância para aplicações industriais. Sendo assim, possibilita alcançar regimes de combustão que vão desde o regime laminar até o regime de exinção de chama, passando pelo regime de elemento de chama e o de efeitos transientes (11).

\section{1 \\ Objetivos}

O objetivo geral desta dissertação é a caracterização da presença de partículas de fuligem e o estudo da distribuição das mesmas em chamas turbulentas não pré-misturadas de etileno e ar. Os regimes aqui estudados foram escolhidos de forma a promover a formação de fuligem na zona de recirculação de uma chama turbulenta não pré-misturada estabilizada num queimador do tipo bluff-body, que possibilita uma melhor análise do processo de formação de partículas de fuligem em processos de combustão turbulenta. Os objetivos específicos são:

- A compreensão do Estado da Arte da caracterização experimental da formação de fuligem em chamas turbulentas de hidrocarbonetos e ar, e do uso de técnicas de diagnóstico laser.

- O desenvolvimento de um experimento empregando as técnicas de incansdescência induzida por laser e extinção da luz.

- A medição da fração volumétrica e de intermitência de fuligem variandose o tempo de integração do detector e altura acima do queimador.

Vale ressaltar que a contribuição original deste estudo, relacionada ao último objetivo específico, permite que as técnicas ópticas de diagnóstico laser possam ser aplicadas numa melhor caracterização de chamas turbulentas em processos de formação de poluentes.

\section{2}

\section{Organização do Manuscrito}

A presente dissertação está organizada em cinco capítulos. O primeiro capítulo consiste desta introdução.

O segundo capítulo (Estado da Arte) expõe o conteúdo teórico das diversas técnicas experimentais envolvidas no trabalho e descreve algumas técnicas que vêm sendo estudadas.

O terceiro capítulo (Metodologia Experimental) apresenta as etapas experimentais, assim como os equipamentos e técnicas usadas na análise dos casos estudados. Neste capítulo, são expostas as técnicas utilizadas na identificação da distribuição das partículas de fuligem em chamas turbulentas. 
O quarto capítulo (Resultados e Discussões) apresenta e discute os resultados obtidos.

Finalmente, o quinto capítulo (Conclusões e Perspectivas) apresenta as conclusões e propostas para trabalhos futuros. 


\section{Estado da Arte: Medição de Fuligem em Chamas}

Neste capítulo, são discutidos os principais trabalhos no que diz respeito às técnicas ópticas relevantes no contexto desta dissertação, isto é, no estudo da formação de fuligem e de sua caracterização. No caso específico do estudo de chamas laminares, artigos recentes de revisão da literatura podem ser consultados para expandir o conteúdo aqui apresentado (6) (7) (12).

\section{1}

\section{Aplicação de Técnicas Ópticas}

As aplicações de um laser são diretamente associadas às propriedades singulares do feixe de luz gerado por estes dipositivos (9). Como o feixe laser pode ter uma largura de banda espectral afilada e, em muitas vezes, ser sintonizável, o laser se torna uma ferramenta poderosa de análise.

Em diagnóstico de combustão, a utilização de lasers é de grande benefício para o estudo dos processos de interação luz-partícula, para a determinação da temperatura de chama e da presença de componentes químicos, caracterização da distribuição de tamanho de partículas de fuligem, entre outros (9). Neste trabalho é abordada a aplicação de lasers em técnicas de medição que permitem a caracterização de materiais particulados (fuligem) em chamas turbulentas.

Incandescência induzida por laser (LII) é definida por (6) como sendo obtida a partir do aquecimento de partículas utilizando um laser potente, isto é, de alta energia. As partículas interagem com o laser e absorvem luz, aumentando assim a sua temperatura, o que leva a um forte aumento da radiação térmica, segundo a lei de Planck (13):

$$
E_{b \nu}(T, \nu)=\frac{2 \pi h \nu^{3} n^{2}}{c_{0}^{2}\left[e^{h \nu / k T}-1\right]},
$$

onde $h$ é a constante de Planck, $C_{0}$ a velocidade da luz em $[\mathrm{m} / \mathrm{s}], \nu$ a frequência em $[\mathrm{Hz}], n$ o índice de refração do meio, $k$ a constante de Boltzmann em $[\mathrm{J} / \mathrm{K}]$ e $T$ a temperatura em $[\mathrm{K}]$.

A LII é uma poderosa ferramenta de mediçoes in-situ de partículas maduras de fuligem em processos de combustão. Uma das vantagens da técnica, explicitada por (6), é ser particularmente sensível e altamente seletiva para partículas de fuligem, devido à forte absorção das mesmas, que podem ser 
aquecidas a temperaturas de até $4000 \mathrm{~K}$ antes de sublimar. Com isto, a técnica LII fornece informações sobre a distribuição de tamanho de partículas de fuligem.

Medidas de extinção da luz, a qual resulta da combinação de absorção e espalhamento, fornecem o valor absoluto ou médio da fração volumétrica de fuligem, se as propriedades ópticas do meio participante das partículas forem conhecidas. É a técnica mais comumente empregada para medições diretas de concentração de fuligem em chamas e, frequentemente, usada para calibração da técnica LII, possibilitando obter a distribuição da fração volumétrica de fuligem (14). Aplicações de extinção da luz costumam fazer uso de uma abordagem padrão de passagem de um feixe de laser numa linha de visão por uma chama ou amostra ou, mais recentemente, usando um feixe planar (14) (15).

\section{2}

\section{Estudos em Chamas Laminares}

As chamas laminares pré-misturadas têm aplicação em muitos equipamentos e processos residenciais, comerciais e industriais. Exemplos incluem fogões a gás, aparelhos de aquecimento de água e queimadores de Bunsen. Chamas laminares pré-misturadas de gás natural também são frequentemente empregadas na fabricação de produtos de vidro. Como sugerido por estes exemplos, as chamas laminares são, por si só importantes. Talvez mais relevante, entender as chamas laminares é um pré-requisito necessário para o estudo de chamas turbulentas. Em ambos os escoamentos laminar e turbulento, os mesmos processos físicos estão presentes, e muitas teorias de chamas turbulentas são baseadas na existência de uma estrutura de chama laminar subjacente (10) (15).

Um estudo feito por (7) salienta a aplicação de técnicas ópticas no estudo de formação de fuligem em chamas. A distribuição de tamanho de partículas de fuligem, por exemplo, pode ser obtida através da comparação das taxas de resfriamento de partículas modeladas e medidas. Os principais mecanismos de resfriamento são: o resfriamento condutivo e a sublimação condutiva (16) (17). Mecanismos adicionais de transferência de calor são resumidos por (6). Estudos sobre o impacto da aglomeração nas taxas de resfriamento de partículas, propostos inicialmente por (18) e posteriormente refinados por (19) mostram um efeito de blindagem de partículas primárias vizinhas que reduz a eficiência de transferência de calor. As mudanças mais pronunciadas ocorrem a partir de partículas primárias não agregadas, transformando-se em agregados de apenas algumas partículas primárias. 
Diferentes tipos de chamas de difusão laminares foram empregadas na análise de formação de fuligem. Em estudos feitos por (20) foi empregada a técnica de incandescência, LII, no estudo da oxidação de partículas de fuligem em uma chama laminar pré-misturada, usando uma mistura de propano/ar, num queimador do tipo McKenna. Os resultados mostraram que o diâmetro das partículas primárias de fuligem não varia significativamente durante o pulso laser. Pode ser observado, também, que o perfil de temperatura e, consequentemente, o decaimento temporal do sinal de incandescência, são fortemente dependentes da altura acima do queimador, $\mathrm{HAB}$, devido à forte variação de temperatura na chama. Isto resulta num decaimento do valor do sinal LII em função da variação da altura HAB, devido ao decréscimo da concentração local de fuligem presente na chama.

A relação entre fração volumétrica de fuligem, temperatura, altura de chama e fração radiante foi investigada por (21) utilizando a técnica de incandescência em dois comprimentos de onda em uma chama de difusão laminar do tipo "coflow" dopada com $\mathrm{O}_{2}$. Foram empregados os combustíveis etileno, propano e butano. Uma redução na altura de chama foi observada com o aumento do índice de oxigênio (IO), para todas as chamas dos diferentes combustíveis empregados, mantendo-se a vazão de combustível constante. Isto é explicado pela variação estequiométrica prevista pela teoria de Roper (22). O aumento do IO reduz o tempo de residência na chama, aumentando assim a oxidação dos precursores e das partículas de fuligem, causando uma redução na concentração de fuligem local. Um aumento da temperatura é observado com o aumento do IO para os três combustíveis estudados.

A técnica de extinção é comumente utilizada na calibração da técnica de incandescência a fim de quantificar a fração volumétrica de fuligem integral. Em investigações feitas por (23), a técnica de extinção da luz foi combinada com a técnica de incandescência induzida por laser resolvida espacialmente e empregadas numa chama laminar não pré-misturada. A combinação de ambas técnicas, realizadas simultâneamente, permite não só a determinação da fração volumétrica de fuligem madura e da contribuição de precursores de fuligem para medidas de extinção local, como também permite extrair informação da distribuição de tamanho de partículas.

A variação nas curvas de fluência (razão entre a intensidade da energia do laser e a área transversal do plano) em função da riqueza da mistura combustível de chamas laminares pré-misturadas, $\phi$, para diferentes alturas acima de um queimador de chama laminar foi estudada por (24). Para riquezas altas, da ordem de $\phi=2$, as curvas exibem comportamento similar ao sinal LII, com formato de $S$ para baixas fluências, e apresentam um regime de platô (região 
onde a energia do feixe é praticamente constante para qualquer aumento no sinal de incandescência) para altas fluências. Foi mostrado, também, através da técnica de incandescência resolvida no tempo (TiRe-LII), que a formação de fuligem pode ser acompanhada, desde a formação inicial das partículas primárias, até a aglomeração, através dos processos de crescimento superficial e coagulação.

A técnica de incandescência (LII) espacialmente resolvida no tempo foi utilizada por (25) empregando altas energias do laser em estudos de formação de fuligem numa chama de difusão laminar. Os resultados de fração volumétrica de fuligem obtidos via LII foram comparados com os obtidos via extinção da luz para diferentes alturas acima do queimador (HAB). Em particular, é sugerido que o sinal LII pode ser usado como uma medida instantânea, espacialmente resolvida, em diagnósticos de fração volumétrica de fuligem, sem a necessidade de uma calibração convencional através da técnica de extinção da luz.

\section{3}

\section{Estudos em Chamas Turbulentas}

A formação de fuligem em chamas turbulentas depende das condições experimentais, tais como o combustível empregado, a geometria do queimador, a quantidade de oxidante disponível, a vazão de operação, o tempo de residência e, por consequência, das características de mistura na chama (26). As chamas turbulentas estabilizadas em queimadores do tipo bluff-body apresentam escoamentos complexos, envolvendo zonas de recirculação similares às encontradas nos combustores práticos. Neste tipo de queimador, a razão de vazões de ar e combustível pode ser variada e a interação entre o processo químico e a turbulência pode ser estudada em diferentes regimes de queima (26) (27) (28) (29). 


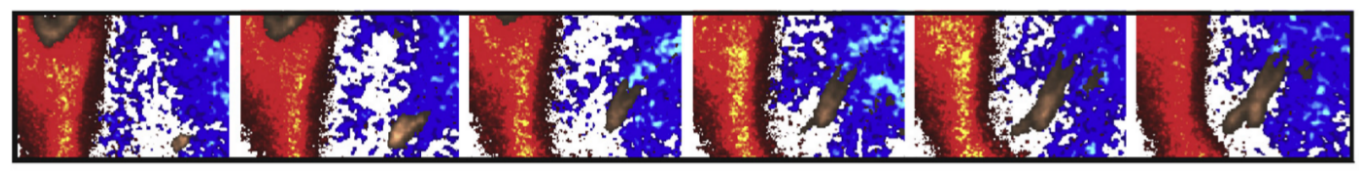

Figura 2.2: Evolução temporal da fuligem que cresce em uma forma ligamentar. Representação de cores: $\mathrm{OH}$ em vermelho, HPA em azul e fuligem em preto, adaptado de (30).

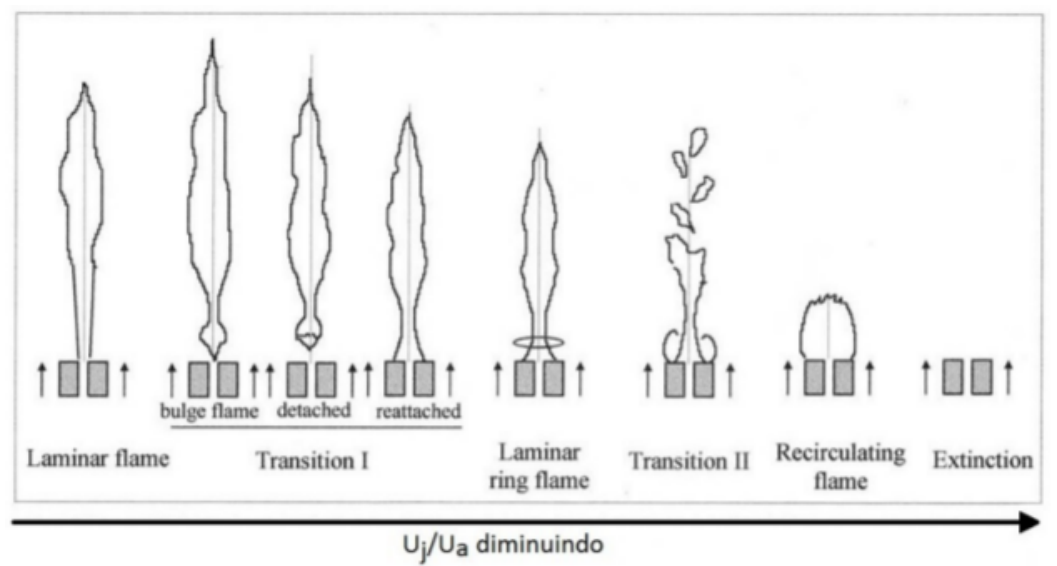

Figura 2.1: Regimes característicos de chamas não pré-misturadas estabilizadas num bluff-body, adaptado de (28).

Numa chama de gás natural, ao incrementar a velocidade de injeção de ar anular $\left(U_{a}\right)$, mantendo fixa a velocidade de combustível $\left(U_{j}\right)$, é possível obter cinco tipos de chamas estabilizadas, mostrados na Fig. 2.1. A visualização direta permite classificar estes regimes em: (i) chama laminar, (ii) transição I, (iii) chama laminar com anel, (iv) transição II, e (v) chama de recirculação, segundo (28). A transição entre estes regimes estabilizados é unicamente atribuída à redução da razão da quantidade de movimento dos escoamentos de combustível e oxidante. O incremento da velocidade do ar anular faz com que o jato de combustível passe de uma chama clássica de difusão para uma chama turbulenta complexa, onde a extensão do jato de combustível se reduz até a chama ficar totalmente encapsulada na região de recirculação, culminando na extinção total da chama (28).

A caracterização de estruturas de fuligem levando em consideração as regiões de formação, crescimento e mistura foi analisada por (30). Uma chama de difusão turbulenta de metano, circundada por um escoamento anular de $\mathrm{O}_{2}$ puro, foi utilizada. Os autores empregaram a técnica de fluoresência induzida por laser planar (PLIF) no estudo dos campos de $\mathrm{OH}$ - fuligem, hidrocarbonetos policíclicos aromáticos (HPA) e fuligem. Os resultados mostram que as 

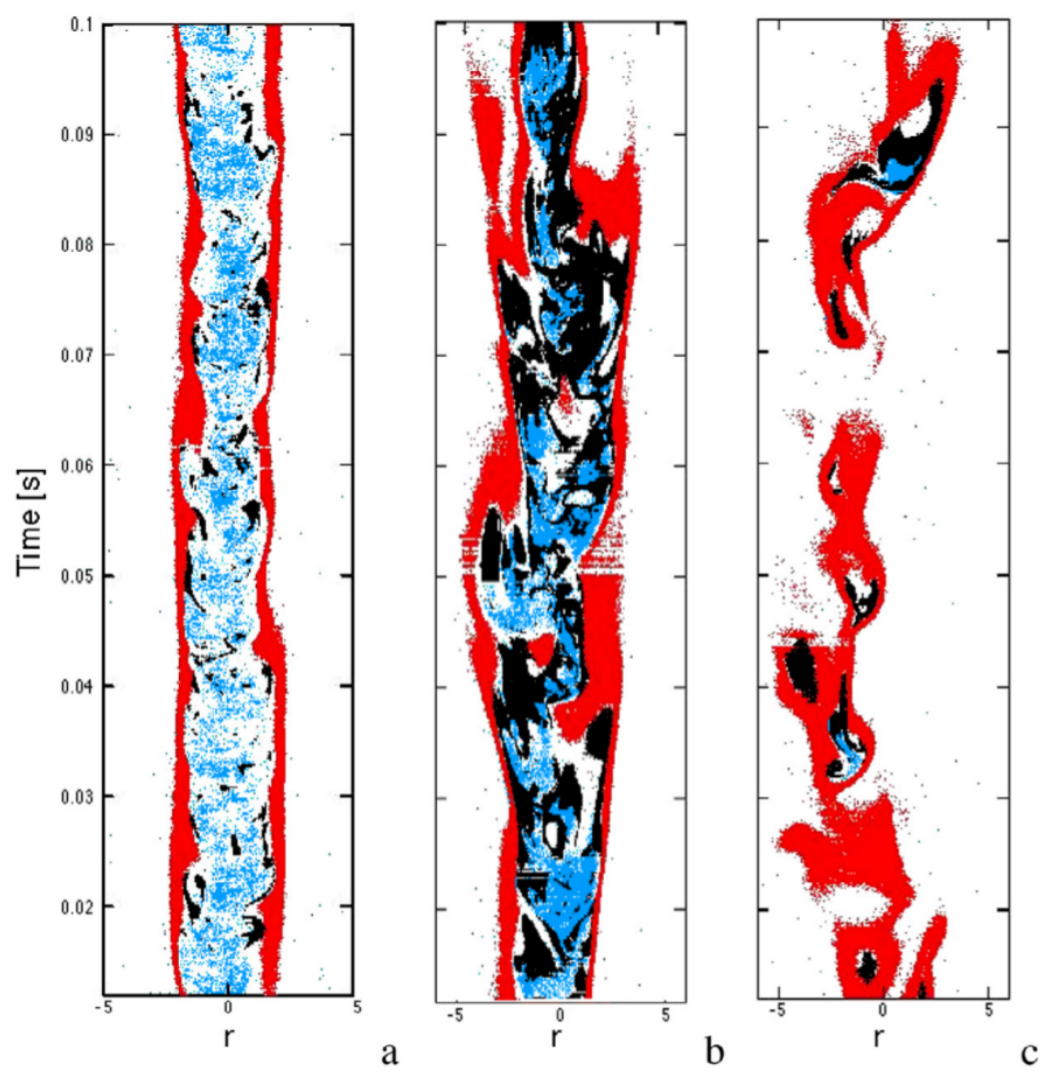

Figura 2.3: Evolução temporal da taxa de ocupação da fuligem na linha central do plano laser em função da posição radial em três posições de medição: (a) formação de fuligem $(h=35 d)$, (b) dominada pela mistura $(h=80 d)$ e $(\mathrm{c})$ regiões de oxidação da fuligem $(h=120 d)$. Representação de cores: $\mathrm{OH}$ em vermelho, HPA em azul e fuligem em preto, adaptado de (30).

estruturas de fuligem são altamente intermitentes e sua localização radial difere das de OH. A Fig. 2.2 mostra que uma pequena mancha de fuligem é formada, inicialmente, no meio da chama e progressivamente se move radialmente da região de HPA para a frente de chama formando ligamentos de fuligem, que resultam da interação com a turbulência. Foi verificado, também, que a taxa de ocupação de fuligem na chama passa por um aumento drástico na região dominada pela mistura, como pode ser observado na Fig. 2.3 (b). A média de conjunto da fração volumétrica de fuligem aumenta na região dominada pela mistura, o que é um indicativo de que a fuligem é largamente distribuida nesta região. 


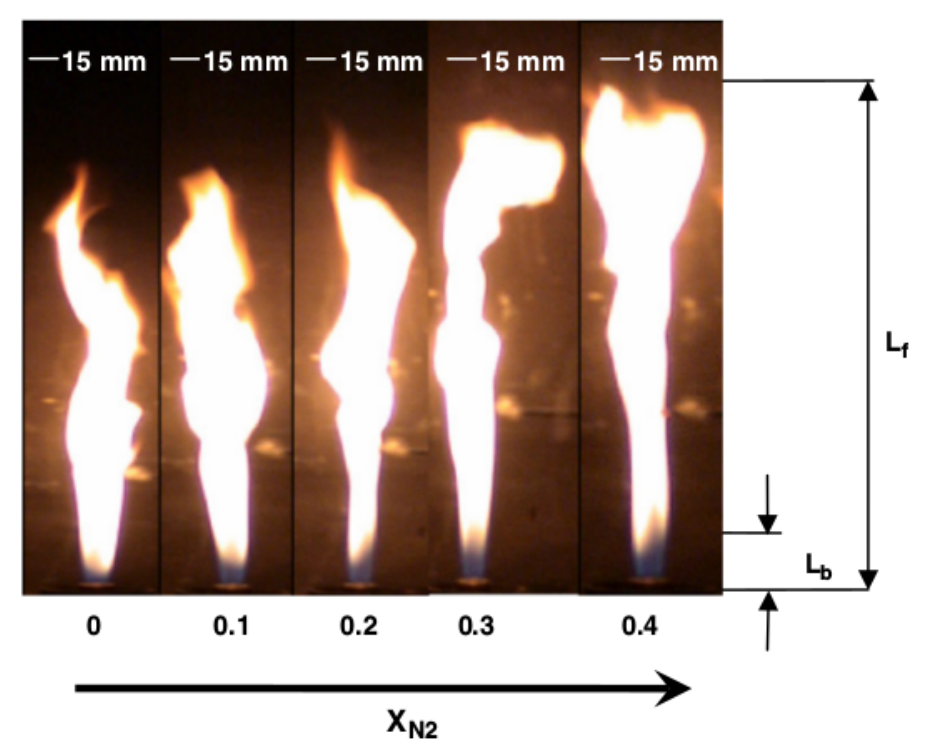

Figura 2.4: Imagens instantâneas de uma chama de GLP com adição de $\mathrm{N}_{2}$ na corrente de combustível, adaptado de (31).

Experimentos numa chama tipo difusão jato de GLP estabilizada num queimador do tipo bluff-body foram desenvolvidos por (31) a fim de analisar o efeito da adição de um inerte, $\mathrm{N}_{2}$, na estrutura da chama. Também foi avaliada a influência da geometria do queimador nas características da chama. Os resultados mostram que o comprimento de chama aumenta gradualmente com a adição do inerte à corrente de combustível, como pode ser observado na Fig. 2.4. A estrutura da chama é divida em duas regiões diferentes, (i) comprimento de chama livre de fuligem ( $L_{b}$ na Fig. 2.4); e (ii) comprimento de chama luminosa que provém da formação de partículas de fuligem, $L_{f}$.

No que diz respeito à formação de fuligem, (31) reporta que uma adição de $\mathrm{N}_{2}$ na corrente de combustível provoca uma redução na concentração de fuligem aumentando a fração de comprimento livre de fuligem em até $200 \%$. Isto é atribuido à diminuição da concentração do combustível e da temperatura de chama quando $\mathrm{N}_{2}$ é adicionado.

A formação de fuligem numa chama não pré-misturada turbulenta foi estudada por (32) utilizando a técnica de LII para medir a fração volumétrica de fuligem num queimador bluff-body. Foi encontrado que, próximo à superfície do bluff-body, o tempo de residência é longo. A presença de fuligem na zona de recirculação, caracterizada por estruturas toroidais entre o jato anular de oxidante e o jato combustível, é um indicativo de que a fração de mistura é maior do que a estequiométrica. É possível, também, encontrar maiores valores de fração volumétrica de fuligem na região externa da zona de recirculação, 
devido ao tempo de residência mais longo. Um aumento na intermitência das estruturas de fuligem também é observado (32).

\section{Probability}

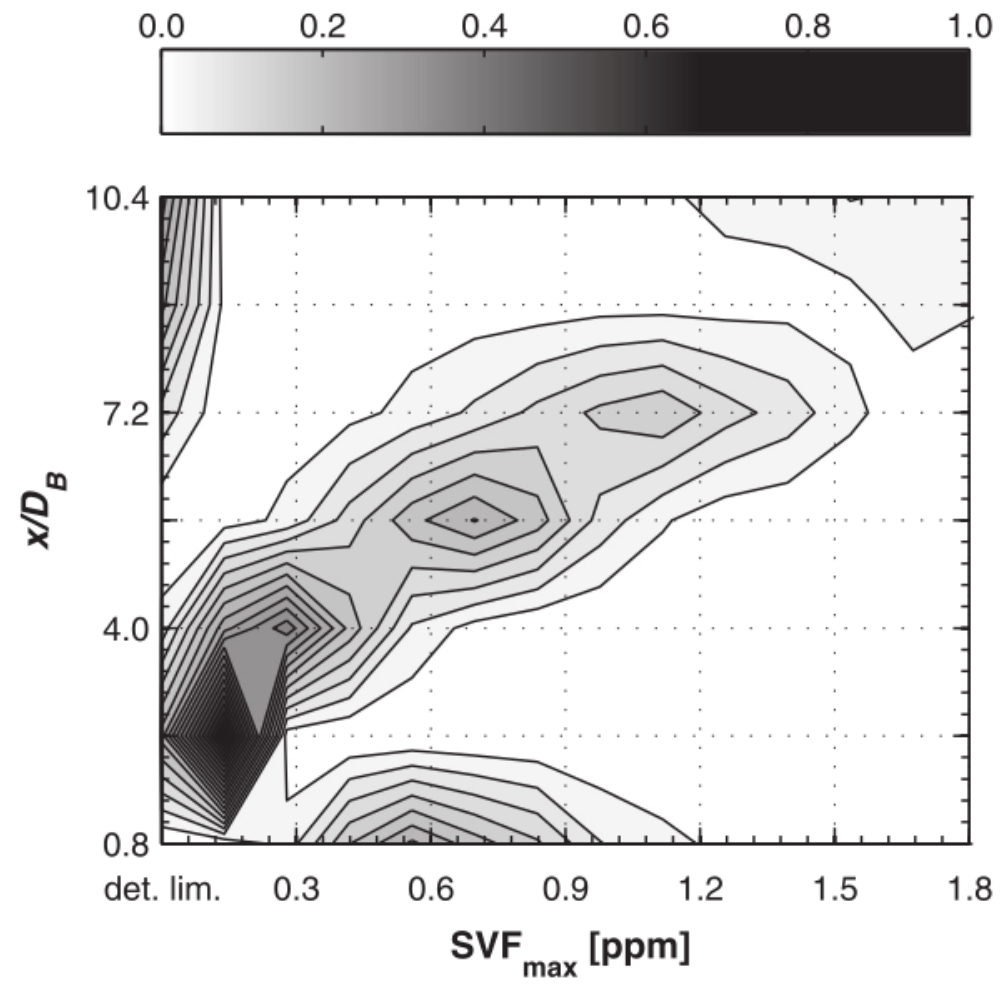

Figura 2.5: PDF do extremo instantâneo da fração volumétrica de fuligem obtido de medidas experimentais ao longo de uma chama turbulenta. Adaptado de (32).

Os resultados de fração volumétrica de fuligem integrados radialmente apontam onde é mais provável de se encontrar fuligem na região da chama (32). Uma função densidade probabilidade (PDF) foi medida e permite apreciar a distribuição de fração volumétrica de fuligem instantânea na chama como mostra a Fig. 2.5. A PDF também permite caracterizar a intermitência da fuligem, que representa a probabilidade de não se achar fuligem acima do limite de detecção.

A formação de fuligem em chamas turbulentas é altamente localizada em regiões isoladas, e a fração volumétrica de fuligem local varia através da chama a qualquer instante de tempo. O processo de formação de fuligem em chamas turbulentas não pré-misturadas foi estudado por (33) empregando técnicas ópticas, como incandescência e fluorescência induzidas por laser (LII e LIF). Estes autores buscaram determinar a relação espacial entre o processo de formação de fuligem e o campo de $\mathrm{OH}$ e, também, como essa relação é 


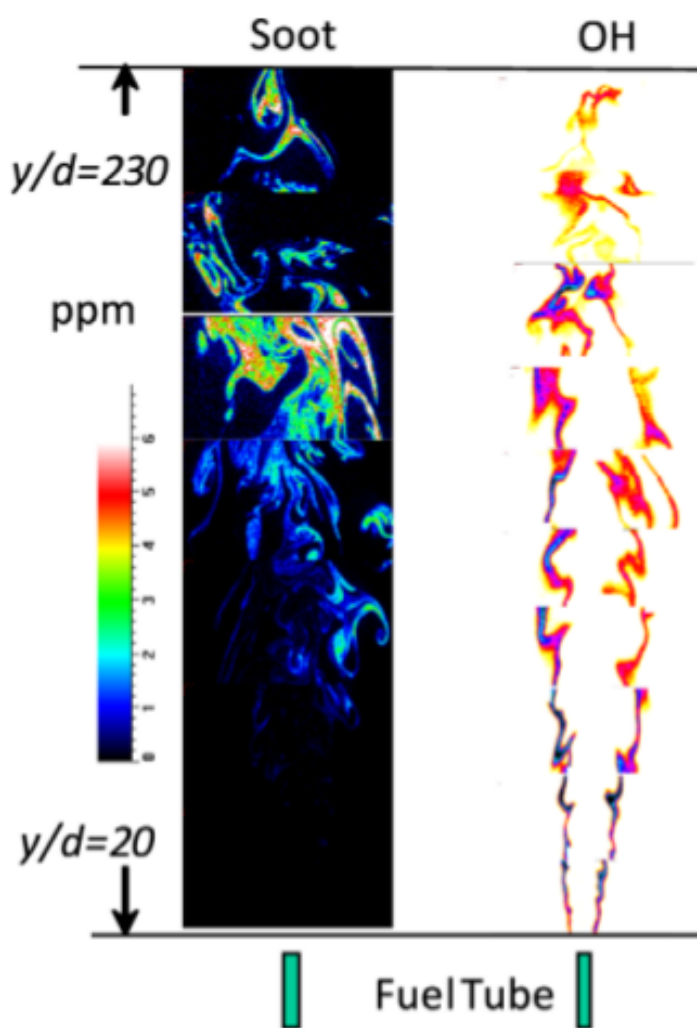

Figura 2.6: Estruturas globais de fuligem e radicais $\mathrm{OH}$ em uma chama de difusão turbulenta $(\mathrm{Re}=12.000)$. Cada seção da imagem foi obtida em um tempo diferente e reunida para criar uma representação composta da chama. Adaptado de (33).

afetada pela intensidade turbulenta inicial do jato. Os resultados mostraram que a fuligem é altamente intermitente e espacialmente isolada, como pode ser observado na Fig. 2.6. Observa-se que a formação de fuligem em chamas turbulentas não ocorre como um processo espacial continuo, tal como acontece em chamas laminares. 


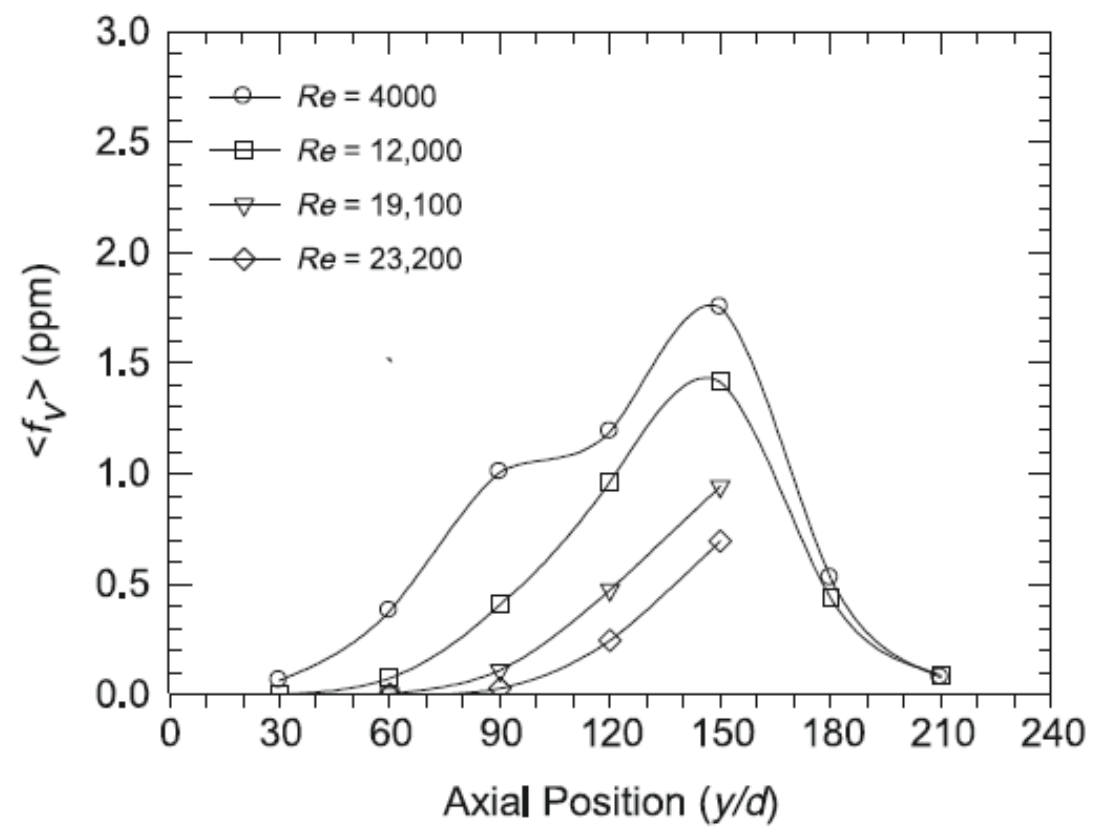

Figura 2.7: Perfis axiais das frações volumétrica de fuligem média no eixo de saída do jato, para chamas com vários números de Reynolds. As flutuações de concentração de fuligem variam aproximadamente de 100\% em torno do eixo do jato e atingem até $800 \%$ perto do limite da chama (não mostrado na figura). Adaptado de (33).

O perfil axial da fração volumétrica de fuligem, mostrado na Fig. 2.7, apresenta a variação de $f_{v}$ para diferentes valores do número de Reynolds. A formação de fuligem se dá até um valor máximo de altura adimensional na chama, $y / d \approx 150$, após esse valor a região de oxidação é observada para todos os valores de Reynolds apresentados. É possível constatar, também, que a concentração de fuligem diminui com o aumento da velocidade do jato, ou seja, o aumento do número de Reynolds. Para todos os casos apresentados na Fig. 2.7 a máxima $\left\langle f_{v}\right\rangle$ é inferior a $2 \mathrm{ppm}$.

As técnicas de incandescência (LII) e velocimetria de imagem de partículas (PIV) foram utilizadas por (34) na investigação da fração volumétrica de fuligem e campos de velocidade dentro da região de formação de fuligem em uma chama turbulenta não pré-misturada, a fim de compreender como a turbulência afeta a formação das partículas de fuligem e seu transporte. Estes autores reportam estruturas de fuligem mais alongadas e contínuas, em regiões de baixa taxa de deformação, e estruturas mais irregulares ou intermitentes, a taxas de deformação mais elevadas. Essa mudança na estrutura é acarretada, provavelmente, por efeitos de taxa finita da reação e interação com a turbu- 
lência, uma vez que o maior caso de taxa de deformação também possui um alto número de Reynolds (34).

Afim de fornecer novas perspectivas na evolução de fuligem, (35) reporta estudos de fração volumétrica de fuligem e temperatura feitos numa chama jato turbulenta. As medidas simultâneas de $f_{v}$ e de temperatura foram realizadas utilizando as técnicas de LII e Fluorescência Atômica de duas linhas num regime de excitação não linear (NTLAF). Os resultados das PDFs conjuntas de fração volumétrica de fuligem e temperatura mostram que fuligem é fortemente correlacionada com o campo de temperatura condicional.

A sensibilidade relativamente fraca do PDF com a posição radial, apresentada na Fig. 2.8, demonstra que a PDF é mais fortemente controlada pela localização instantânea local da mistura em relação à zona de reação, do que pela dependência absoluta da posição radial. Em outras palavras, as condições locais são determinadas pelas flutuações em grande escala no envelope da chama, que controla as condições instantâneas radialmente (35). Portanto, a PDF é relativamente insensível à localização radial. 

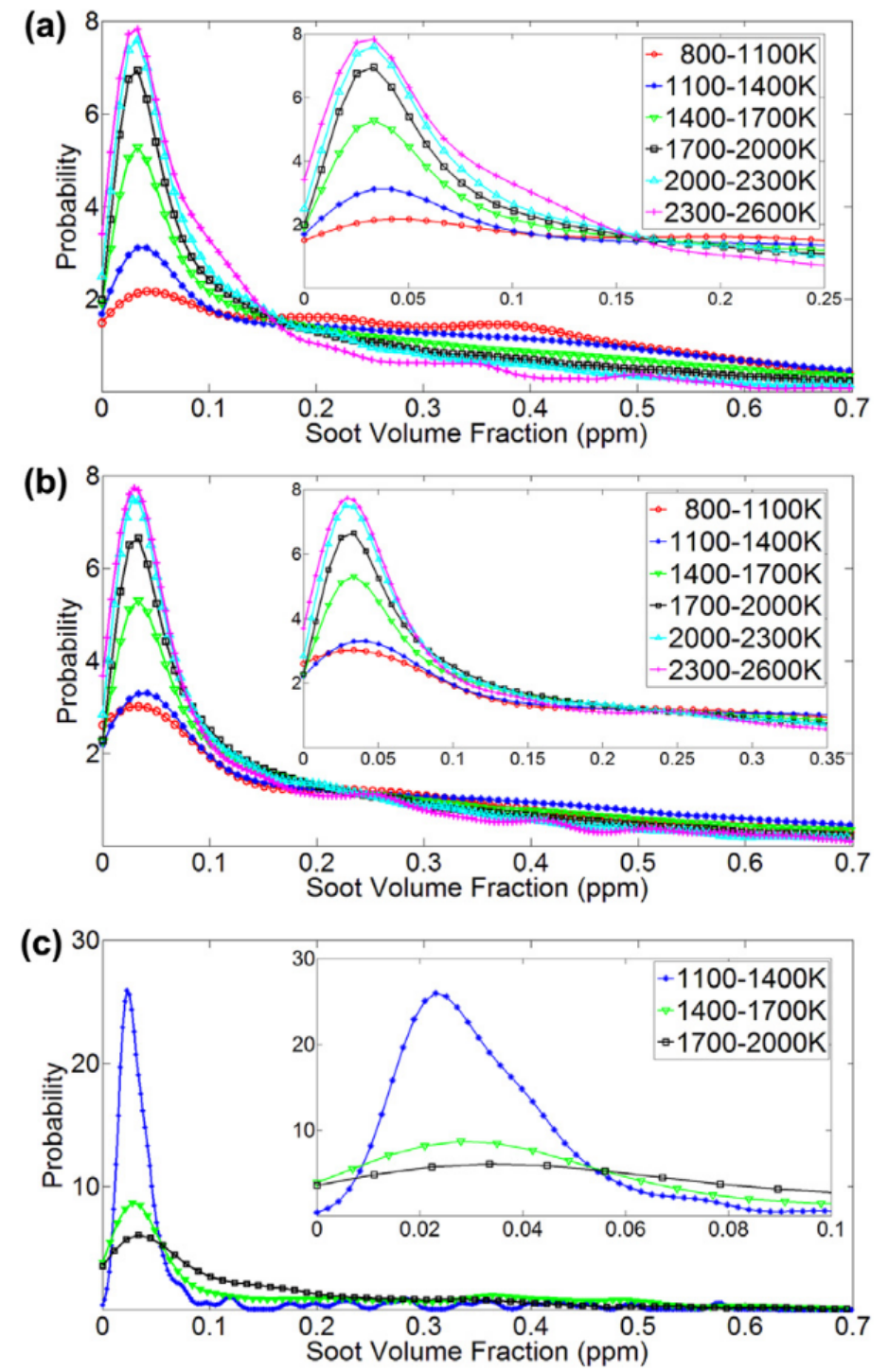

Figura 2.8: PDFs conjuntas da fração volumétrica de fuligem colocadas em faixas de temperatura condicionais de $300 \mathrm{~K}, 100$ diâmetros a jusante do tubo de fornecimento de combustível. (a) $0<r / d<1$, (b) $4<r / d<5$ e (c) $10<r / d<11$. Adaptado de (35).

\section{4}

\section{Sumário do Estado da Arte}

A revisão de trabalhos da literatura mostra que os conhecimentos previamente obtidos em estudos de formação de fuligem em chamas laminares são de grande utilidade na caracterização de fuligem em chamas turbulentas. Técnicas ópticas, tais como LII, LIF, PLIF, entre outras, vêm sendo aplicadas na determinação da fração volumétrica de fuligem, interação turbulência-fuligem, estrutura de chama, etc. Todavia, a influência que a turbulência exerce sobre 
Tabela 2.1: Características das técnicas ópticas de diagnóstico laser empregadas neste estudo.

\begin{tabular}{|c|c|}
\hline Diagnóstico & Características \\
\hline Extinção laser & $\begin{array}{l}\text { Medida pontual, mas integral. Va- } \\
\text { lores integrais da fração volumé- } \\
\text { trica de fuligem. Laser e um ou dois } \\
\text { fotodetectores são necessários. Es- } \\
\text { palhamento negligenciado, e assu- } \\
\text { mir hipóteses de valores de vários } \\
\text { parâmetros como } E(m) \text {. }\end{array}$ \\
\hline $\begin{array}{l}\text { Incandescência in- } \\
\text { duzida por laser } \\
\text { (LII) }\end{array}$ & $\begin{array}{l}\text { Medida bidimensional, onde um la- } \\
\text { ser e uma câmara intensificada são } \\
\text { os principais componentes. Tem- } \\
\text { pos de aquisição da ordem de de- } \\
\text { zenas de nano segundos. Incandes- } \\
\text { cência induzida da fuligem pelo } \\
\text { rápido aquecimento das partículas } \\
\text { até valores próximos da sublima- } \\
\text { ção. } S_{L I I} \text { é proporcional à fração } \\
\text { volumétrica de fuligem } f_{v} \text {. Tempo } \\
\text { de vida, } \tau_{F}>100 \text { ns. Faixa de de- } \\
\text { tecção da fuligem: UV-Visível-IR. }\end{array}$ \\
\hline $\begin{array}{l}\text { Fluorescência in- } \\
\text { duzida por plano } \\
\text { laser (PLIF) }\end{array}$ & $\begin{array}{l}\text { Emissão induzida de determinadas } \\
\text { espécies devido a irradiação laser. } \\
S_{L I F} \text { é seletiva e proporcional a } \\
\text { concentração de PAHs, mas depen- } \\
\text { dente da temperatura. Tempo de } \\
\text { vida: } \tau_{F}<50 \text { ns. Faixa de detec- } \\
\text { ção dos PAH: UV-Visível. }\end{array}$ \\
\hline
\end{tabular}

a formação das partículas de fuligem ainda é um problema a ser totalmente compreendido. A falta de modelos numéricos validados em chamas turbulentas também se apresenta como um desafio científico. Sendo assim, o presente estudo busca caracterizar a presença de fuligem e sua estrutura em chamas turbulentas através da detecção do sinal de incandescência induzida por laser, que é de grande interesse industrial no âmbito de aumento de eficiência energética dos processos de combustão e redução de emissão deste tipo de particulados. A Tabela 2.1 apresenta o sumário das principais características das técnicas de diagnóstico laser empregadas na caracterização de partículas de fuligem deste estudo. 


\section{Metodologia Experimental}

Neste capítulo, a instalação experimental do queimador é descrita. Além disso, são detalhados as técnicas e os equipamentos de medição da fração volumétrica de fuligem média por extinção da luz (LE) e da distribuição de fuligem utilizando a técnica de incandescência induzida por laser (LII).

\section{1}

\section{Queimador: Bluff-Body}

O queimador do tipo bluff-body utilizado no presente estudo foi desenvolvido em (29). Este queimador gera um escoamento turbulento contendo um jato central concêntrico a uma saída de ar anular, separados por uma região

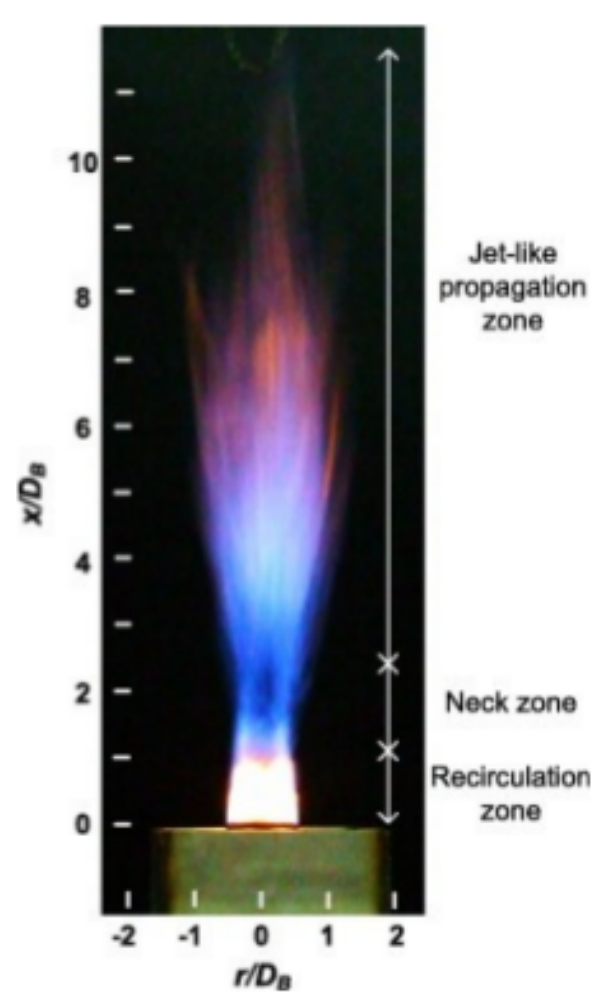

Figura 3.1: Chama turbulenta do tipo bluff-body apresentando as três regiões: (i) Zona de recirculação, (ii) região de gargalo e (iii) região de propagação, respectivamente, adaptado de (32). 
de esteira produzida pelo corpo do bluff-body, de um diâmetro de $60 \mathrm{~mm}, d_{b b}$. Este é circundado por um tubo concêntrico de $200 \mathrm{~mm}$ de diâmetro, $d_{c o}$, que fornece o escoamento de oxidante (ar) tal como mostrado na Fig. 3.2. O alinhamento vertical do corpo central é cuidadosamente ajustado na base, onde está localizada uma grade geradora de turbulência com orifícios de diâmetro de $12 \mathrm{~mm}$ (não mostrados), para garantir um escoamento uniforme e nível de turbulência de aproximadamente $20 \%$. No presente estudo, a fim de garantir um escoamento plenamente desenvolvido, o diâmetro do tubo de fornecimento de combustível $\left(d_{j}\right)$ é de $4,3 \mathrm{~mm}$, e seu comprimento é de $150 \mathrm{~cm}$.

Uma chama turbulenta de etileno estabilizada num queimador do tipo bluff-body pode ser dividida em três regiões, como mostrada na Fig. 3.1 (32). A região de recirculação ou vórtice localizada acima da saída do bluff-body, seguida da região de gargalo tipicamente em cor azul, e finalmente a região de propagação de jato. Na região de recirculação, existem dois turbilhões, um vórtice, exterior próximo ao cofluxo de ar e um vórtice interior entre o vórtice exterior e o jato (26). 

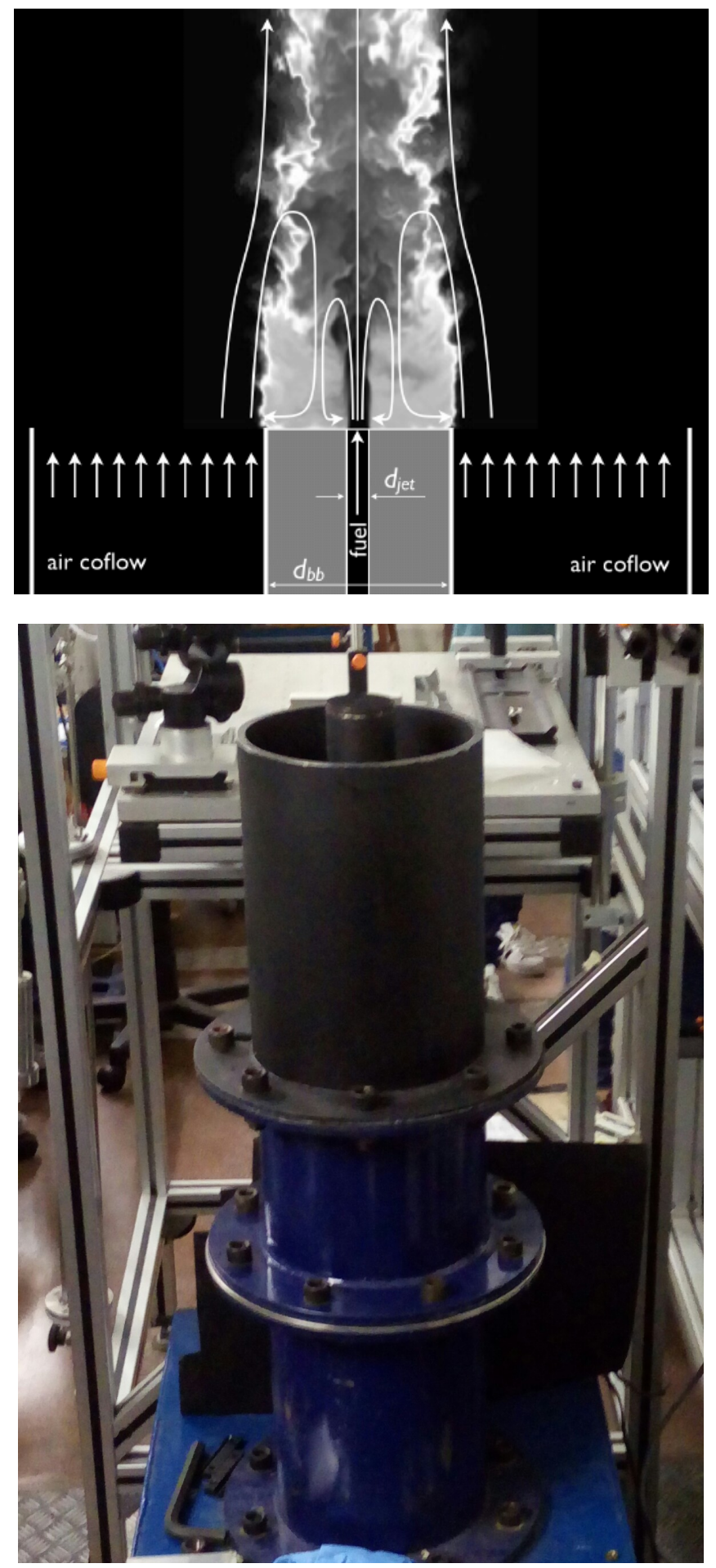

Figura 3.2: Representação esquemática, adaptado de (36) e vista do queimador utilizado.

O queimador opera com um escoamento de ar anular que é alimentado por um ventilador centrífugo, DELTRA VC 400, que leva a uma velocidade máxima do ar de $u_{0}=11,8 \mathrm{~m} / \mathrm{s}$ e, portanto, a um número de Reynolds com 
base no diâmetro do corpo central de $R e_{b b}=45.400$.

A vazão de combustível é medida por um medidor de vazão, modelo ELFLOW F-201AC Bronkhorst, calibrado para vazão nominal de $0,5 \mathrm{~nm}^{3} / \mathrm{h}$ de metano $\left(\mathrm{CH}_{4}\right)$. Dois regimes de chama são especificamente escolhidos, em $30 \%$ e $40 \%$ da vazão nominal, respectivamente, de forma a produzirem uma chama fuliginosa completamente contida na esteira, possibilitando, assim, uma melhor detecção do sinal óptico da técnica de incandescência e forte interação entre turbulência e formação de fuligem.

Como o medidor de vazão de combustível é originalmente calibrado para o metano, uma conversão se faz necessária quando da utilização do combustível etileno (eteno). Usando o software de conversão disponibilizado pela Bronkhorst (37), é possível determinar a vazão de etileno como mostrado na Fig 3.3. A conversão é feita através de um fator de conversão. Este, por sua vez, é o fator de divisão que é usado para calcular a vazão de massa normal de um determinado fluido de referência, $\mathrm{F}_{2}$, que deve ser aplicado a um medidor de vazão de massa para obter o mesmo sinal de saída quando aplicado ao fluido de operação final para o medidor (37).

\begin{tabular}{|c|c|c|c|c|c|c|}
\hline & \multicolumn{3}{|l|}{ Fluid from } & \multicolumn{3}{|l|}{ Fluid to } \\
\hline Fluid: & \multicolumn{3}{|c|}{ CH4 ("Methane") } & \multicolumn{3}{|c|}{ C2H4 ("Ethylene") } \\
\hline Phase: & \multicolumn{3}{|c|}{ Gas } & \multicolumn{3}{|c|}{ Gas } \\
\hline \multirow[t]{2}{*}{ Flow: } & 0.5 & $\mathrm{~m} 3 \mathrm{n} / \mathrm{h}$ & $\mathbf{v}$ & 6.524 & I/min & $\mathbf{v}$ \\
\hline & \multicolumn{3}{|c|}{$0.00{ }^{\circ} \mathrm{C}$ and $1013.25 \mathrm{hPa}(\mathrm{a})$} & \multicolumn{3}{|c|}{$0.00^{\circ} \mathrm{C}$ and $1013.25 \mathrm{hPa}(\mathrm{a})$} \\
\hline Pressure: & 2 & bar (a) & $\boldsymbol{v}$ & 2 & bar (a) & $\checkmark$ \\
\hline Temperature: & 20 & ${ }^{\circ} \mathrm{C}$ & $\checkmark$ & 20 & ${ }^{\circ} \mathrm{C}$ & $\checkmark$ \\
\hline Density $(n)(c)$ : & 0.7174 & $\mathrm{~kg} / \mathrm{m}^{3}$ & & 1.261 & $\mathrm{~kg} / \mathrm{m}^{3}$ & \\
\hline Heat capacity (cal): & 2381 & $\mathrm{~J} / \mathrm{kg} \cdot \mathrm{K}$ & & 1739 & $\mathrm{~J} / \mathrm{kg} \cdot \mathrm{K}$ & \\
\hline Viscosity: & $1.097 \mathrm{E}-05$ & Pa.s & & 1.013E-05 & Pa.s & \\
\hline Thermal cond. (cal): & 0.04027 & $\mathrm{~W} / \mathrm{m} \cdot \mathrm{K}$ & & 0.02674 & $\mathrm{~W} / \mathrm{m} \cdot \mathrm{K}$ & \\
\hline Instrument model ${ }^{1)}$ : & $F-201 A C$ & $\checkmark$ & & & & \\
\hline \multicolumn{7}{|c|}{ Calculate } \\
\hline
\end{tabular}

\begin{tabular}{|lccc|}
\hline & CH4 $\left[\mathbf{m}^{3} \mathbf{n} / \mathbf{h}\right]$ & C2H4 [//min] & Conversion factor \\
\hline 30 & 0.1500 & 1.942 & 1.287 \\
$25 \%$ & 0.1250 & 1.619 & 1.287 \\
$50 \%$ & 0.2500 & 3.236 & 1.288 \\
$75 \%$ & 0.3750 & 4.864 & 1.285 \\
$100 \%$ & 0.5000 & 6.524 & 1.277 \\
\hline
\end{tabular}

Background information for use by factory only: Conversion type: EL-FLOW

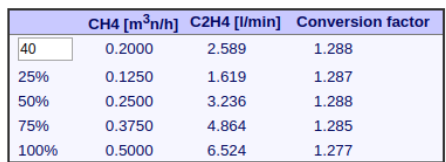

Background information for use by factory only: Conversion type: EL-FLOW

Figura 3.3: Ilustração do uso do programa de conversão de vazão mássica (37).

Em princípio, o fator de conversão entre dois fluidos é um fator de escoamento multiplicador, cujo valor depende do princípio de medição do escoamento. Na Bronkhorst, o fator de conversão aplica-se apenas aos medidores de vazão de massa usando unidades de vazão volumétrica referenciadas às condições normais de $0^{\circ} \mathrm{C}$ e $1013,25 \mathrm{hPa}$. Para um medidor de vazão de massa 
térmica, o fator de conversão é proporcional ao calor específico $\left(\mathrm{C}_{p}\right)$, e a densidade normal dos fluidos $\left(D_{n}\right)$ para os quais o fator de vazão é calculado e, portanto, relacionado a unidades de vazão volumétrica referenciadas apenas às condições normais (37). O fator de conversão é dado por:

$$
C F_{v}=\frac{\left(C_{p, 1} \times D_{n, 1}\right)}{\left(C_{p, 2} \times D_{n, 2}\right)}
$$

onde $\mathrm{C}_{p}$ é o calor específico em $\mathrm{J} / \mathrm{kg} . \mathrm{K}$ a pressão constante; $\mathrm{D}_{n}$ é a densidade normal em $\mathrm{kg} / \mathrm{m}^{3}$, a $0^{\circ} \mathrm{C}$ e $1013,25 \mathrm{hPa}$; e os indíces (1 e 2) se aplicam ao fluido de operação e o fluido de calibração, respectivamente. Como a vazão mássica para um medidor térmico é diretamente proporcional a $\left(D_{n} \times C_{p}\right)$, a fórmula para a conversão de vazão é:

$$
F_{2}=\frac{F_{1}}{C F_{v}},
$$

na qual $F_{1}$ e $F_{2}$ são as vazões do medidor usando o fluido 1 e o fluido 2, respectivamente, em unidades de vazão volumétrica normal.

\section{2}

\section{Extinção da Luz (LE)}

\subsection{1}

\section{Metodologia de Medição}

O coeficiente de extinção para uma nuvem de partículas esféricas é previsto pela teoria de espalhamento da luz, e relaciona o número, tamanho, e as propriedades das partículas como(13):

$$
k_{\lambda}=\frac{\pi}{4} C_{n} \int_{0}^{\infty} E_{e x} N\left(d_{p}\right) d_{p}^{2} \mathrm{~d}\left(d_{p}\right),
$$

onde $k_{\lambda}\left(\mathrm{cm}^{-1}\right)$ é a extinção do meio absorvente, $C_{n}$ é o número de partículas por unidade de volume, $d_{p}$ é o diâmetro das partículas primárias, $N\left(d_{p}\right)$ a função distribuição de probabilidade do diâmetro de partículas $\int N\left(d_{p}\right) \mathrm{d}\left(d_{p}\right)=1$ e $E_{\text {ex }}$ é a eficiência de extinção dada por:

$$
E_{e x}=E_{a b s}+E_{\text {esp }}=4 a\left[-\operatorname{Im}\left(\frac{m^{2}-1}{m^{2}+1}\right)\right]+\frac{8}{3} a^{4} \operatorname{Re}\left(\frac{m^{2}-1}{m^{2}+1}\right),
$$

onde $a=\pi d_{p} / \lambda$, e $m$ é o índice complexo de refração da fuligem. Considerando a teoria de Rayleigh para esferas isotrópicas com diâmetro muito menor do que o comprimento de onda do feixe. Pode se observar que, quando $a<<1$ e $a|m-1|<<1$, a $E_{e s p}(a)<<E_{a b s}(a)$. Neste estudo é considerado que $E_{\text {ext }} \approx E_{\text {abs. }}$. Substituindo este resultado na Eq. 3-3 e introduzindo a definição clássica de fração volumétrica de fuligem: 


$$
f_{v}=\frac{\pi}{6} C_{n} \int_{0}^{\infty} N\left(d_{p}\right) d_{p}^{3} \mathrm{~d}\left(d_{p}\right)
$$

Logo, o coeficiente de extinção local, $k_{\lambda}$, pode ser expresso como:

$$
k_{a b s}=k_{\lambda}=6 \pi E(m) \frac{f_{v}}{\lambda}=K_{\lambda} \frac{f_{v}}{\lambda},
$$

onde $K_{\lambda}$ é o coeficiente adimensional de extinção dado por $K_{\lambda}=6 \pi E(m)$, e $E(m)=0,245$ é a função de absorção em função do índice complexo de refração e é dada por:

$$
E(m)=-\operatorname{Im} \frac{m^{2}-1}{m^{2}+2}=\frac{6 n k}{\left(n^{2}-k^{2}+2\right)^{2}+4 n^{2} k^{2}},
$$

onde $m=n-i k$ é o índice complexo de refração de fuligem, $n=1,1717 \mathrm{e}$ $k=0,6$ são a parte real e imaginária, respectivamente, do índice de refração, $m$, dados pelos polinômios (38):

$$
\begin{aligned}
& n=1,811+0,1263 \ln \lambda+0,0270 \ln ^{2} \lambda+0,0417 \ln ^{3} \lambda, \\
& k=0,5821+0,1213 \ln \lambda+0,2309 \ln ^{2} \lambda+0,0100 \ln ^{3} \lambda,
\end{aligned}
$$

onde o comprimento de onda empregado, $\lambda(\mu \mathrm{m})$, deve estar na faixa de $0,4 \mu \mathrm{m} \leq \lambda \leq 30 \mu \mathrm{m}$.

Uma revisão da técnica de extinção da luz e sua relação com a fração volumétrica de fuligem é dada por (14). A lei de Beer-Lambert refere-se às propriedades ópticas do meio atenuante e às intensidades do feixe colimado antes, $I_{\lambda}(0)$, e depois, $I_{\lambda}(L)$, deste meio, resultando em:

$$
\frac{I_{\lambda}(L)}{I_{\lambda}(0)}=\tau=\exp \left(-\int_{0}^{L} k_{\lambda} \mathrm{d} l\right)=\exp \left(-\frac{\int_{0}^{L} K_{\lambda} f_{v} \mathrm{~d} l}{\lambda}\right)
$$

onde $\tau$ representa a transmitância do feixe laser no meio participante, $L$ o caminho óptico ao longo da chama (60 mm neste trabalho) e $\lambda$ é o comprimento de onda utilizado $(532 \mathrm{~nm})$. Utililizando a hipótese simplificadora de que o coeficiente adimensional de extinção $K_{\lambda}$ é constante ao longo do caminho óptico, $L$, a técnica de extinção permite calcular um valor médio, $\bar{f}_{v}$, a partir do valor integrado da fração volumétrica de fuligem, $\bar{f}_{v} L=F_{v}=\int_{0}^{L} f_{v} \mathrm{~d} l$ como (13):

$$
\bar{f}_{v}=-\frac{\lambda}{K_{\lambda} L} \ln (\tau)
$$

A utilização da técnica de extinção para a análise da combustão turbulenta requer uma atenção especial, pois além da integração espacial, Eq. 3-8, também é efetuada uma integração temporal, durante a qual a chama flutua. Com isto, a intensidade luminosa medida é função do tempo, $I_{\lambda}(L, t)$. Para levar em conta esta dupla integração, são definidas as seguintes intensidades: 


$$
\begin{aligned}
I_{\lambda}\left(L, i_{t}\right) & =\frac{1}{i_{t}} \int_{0}^{i_{t}} I_{\lambda}(L, t) \mathrm{d} t \\
I_{\lambda}\left(0, i_{t}\right) & =\frac{1}{i_{t}} \int_{0}^{i_{t}} I_{\lambda}(0, t) \mathrm{d} t
\end{aligned}
$$

onde $i_{t}$ é o tempo de integração do detector. No caso de chamas turbulentas, é então medida uma transmitância média:

$$
\bar{\tau}=\frac{I_{\lambda}\left(L, i_{t}\right)}{I_{\lambda}\left(0, i_{t}\right)}=\frac{1}{i_{t}} \int_{0}^{i_{t}} \exp \left(-\int_{0}^{L} k_{\lambda} \mathrm{d} l\right) d_{t}
$$

No presente estudo, será admitido que $\bar{f}_{v}\left(L, i_{t}\right)$ é uma quantidade estocástica; devido às flutuações turbulentas da chama, que influenciam $k_{\lambda}$. Como será visto mais adiante, a comparação entre o valor de $i_{t}$ e o das escalas de tempo do movimento turbulento determina o significado de $\bar{f}_{v}\left(L, i_{t}\right)$, calculado com as Eq. 3-9 e 3-10.

\subsection{2}

\section{Montagem Experimental}

O sistema de extinção da luz aqui utilizado, mostrado na Fig. 3.4, consiste de um laser CW contínuo de diodo (DPSSL-0,5W-LaVision), com comprimento de onda visível de $532 \mathrm{~nm}$, com uma potência nominal de $0,5 \mathrm{~W}$, que gera um feixe laser de diâmetro de $330 \mu \mathrm{m}$, usado como fonte de luz. Dois fotodetectores (V9LaVision, com tempo de integração de $i_{t}=1,5 \mathrm{~ms}$ ) medem simultaneamente a intensidade luminosa do feixe laser atenuada pela absorção das partículas de fuligem antes, $I_{\lambda}(0, t)$, e após, $I_{\lambda}(L, t)$, a passagem do feixe pela chama. Durante os experimentos a emissão natural da chama foi, também, fotografada com uma câmera (Canon Rebel T3E) com um tempo de exposição de 1/200 s.

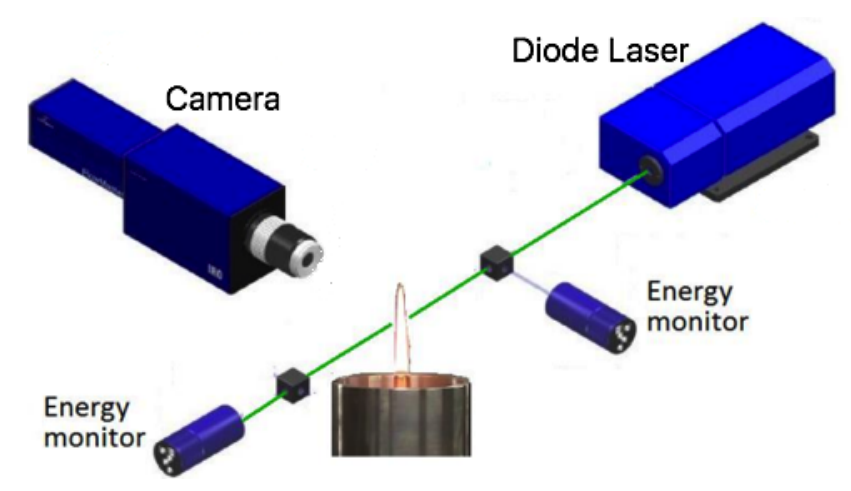

Figura 3.4: Aparato experimental extinção da luz 
Os sinais medidos pelos fotodetectores são convertidos em unidades arbitrárias. Estes sinais são diferentes, mesmo na ausência de atenuação pela chama, devido às diferentes sensibilidades dos detectores e ao ruído eletrônico. Portanto, sua calibração se faz necessária. Primeiramente, com o laser desligado, é feita a leitura dos fotodetectores para que as mesmas sejam corrigidas para zero, offset correction. Depois, uma segunda leitura é feita com o laser ligado sem a presença da chama, o que caracteriza uma transmitância total, ou seja, $\tau=1$, e as diferentes sensibilidades dos fotodetectores são corrigidas. Um conjunto de 300 amostras são tomadas e um fator de correção é calculado e utilizado para igualar as leituras dos dois detectores. A análise feita é a média de conjunto das transmitâncias, $\langle\tau\rangle$, calculadas para cada par de sinais obtidos, no conjunto de $\mathrm{N}=4000$ sinais medidos, dado por:

$$
\langle\tau\rangle=\frac{1}{N} \sum \frac{I_{\lambda}\left(L, i_{t}\right)}{I_{\lambda}\left(0, i_{t}\right)}
$$

o que permite determinar a média de conjunto da fração volumétrica de fuligem,

$$
\left\langle\bar{f}_{v}\right\rangle=-\frac{\lambda \ln (\langle\tau\rangle)}{6 \pi E(m)\langle L\rangle}
$$

onde $\langle L\rangle$ é a média de conjunto do caminho óptico, que, por hipótese, é $\langle L\rangle=d_{b b}=60 \mathrm{~mm}$.

\section{3}

\section{Incandescência Induzida por Laser (LII)}

O objetivo da técnica LII é medir a ditribuição de fuligem e a fração volumétrica de fuligem, $f_{v}(r, z)$, onde $r$ é a coordenada radial e $z$ a axial, que tem origem no centro do tubo combustível e na superfície do queimador.

\subsection{1}

\section{Metodologia de Medição}

A aplicação da técnica de incandescência, LII, envolve o uso de uma fonte de luz de alta energia, na maioria dos casos uma fonte laser, para promover, de forma tão uniforme quanto possível, o aquecimento das partículas. Nesta técnica a distribuição espacial da energia do laser durante o pulso deve ser a mais uniforme possível. A energia do feixe laser por unidade de área (seção transversal) do mesmo é definida como sendo a fluência $\left[\mathrm{J} / \mathrm{m}^{2}\right]$. A forma (distribuição de energia) do feixe laser possui um grande impacto sobre o sinal de incandescência. Feixes com perfis de energia com forma Gaussiana (Gaussian sheet) geram uma região conhecida como platô, pois a emissão do sinal permanece aproximadamente constante com o incremento da 


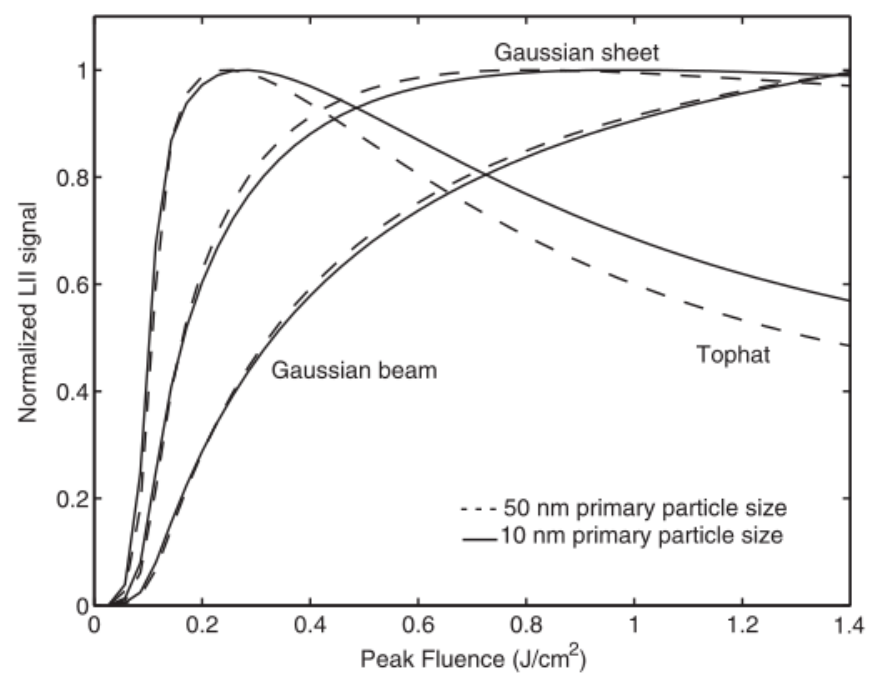

Figura 3.5: Sinal LII pulsado em função de diferentes perfis de feixe laser. Curvas de fluência com 18 ns de gate, iniciando 20 ns após o início do pulso de laser, adaptado de (6).

energia do laser, como pode ser visto na Fig. 3.5. Nesta figura, é mostrado o sinal LII normalizado em função da fluência do laser para diferentes perfis de feixe laser e tamanhos distintos de partículas primárias distintas. Essa constância se deve à simultânea perda de massa das partículas de fuligem ao atingirem o ponto de sublimação e à novas partículas de fuligem que emitem o sinal LII $\left(S_{L I I}\right)$. Já para feixes com perfil de cartola, top-hat, Fig. 3.5, a região de platô não é observada e uma calibração se faz necessária em valores de fluência onde se tem o máximo sinal LII $\left(S_{L I I}\right)$. Assim, a interação luzpartícula faz com que a energia do laser seja um parâmetro extremamente importante no estudo da temperatura de partículas, distribuição de tamanho e concentração de particulas de fuligem, entre outros. Uma análise do efeito da fluência do laser na temperatura das partículas pode ser encontrado em (6).

É necessário um conhecimento prévio sobre a fluência do sistema laser, antes de aplicar técnicas ópticas, para se obter resultados adequados em diagnóstico de fuligem. Operar o sistema a fluências muito altas pode causar sublimação das partículas de fuligem, causando um decaimento no sinal LII devido à perda de massa das partículas. Já a fluências baixas, a temperatura das partículas aumenta durante a maior parte do pulso laser, até o equilibrio entre os mecanismos de aquecimento por absorção e resfriamento ser alcançado (6).

O sinal de incandescência, $\mathrm{S}_{L I I}$, é o resultado da emissão da radiação de uma distribuição de partículas aquecidas de fuligem capturadas por um fotodetector. O sinal é obtido como resposta de um pulso de laser idealizado, 
com base nas leis de radiação do corpo negro e no balanço de energia da partícula de fuligem. Considera-se que as partículas de fuligem atingem uma temperatura próxima ao ponto de sublimação e têm dimensões menores do que o comprimento de onda de detecção $\left(d_{p}<\lambda\right)$.

$$
S_{L I I}^{\lambda}=C_{c a l} C_{n} \int_{0}^{\infty} N\left(d_{p}\right) d_{p}^{x} \mathrm{~d}\left(d_{p}\right),
$$

onde $C_{\text {cal }}$ é uma constante de calibração, $x=3+0,154 / \lambda[1 / \mu \mathrm{m}]$ é o fator de dependência de $\mathrm{S}_{L I I}$ [u.a] com o $d_{p}[\mu \mathrm{m}], C_{n}$ é o número de partículas por unidade de volume, $N\left(d_{p}\right)$ a função distribuição de probabilidade do diâmetro de partículas e $d_{p}$ o diâmetro das partículas primárias. Classicamente, a fração volumétrica de fuligem, $f_{v}$, é definida pela Eq. 3-5, e permite afirmar que o sinal $S_{L I I}$ é proporcional a fração volumétrica da fuligem pela relação

$$
S_{L I I}^{\lambda}=C_{c a l} f_{v}
$$

Para comprimentos de onda de detecção empregados no presente estudo, isto é, $0,340 \leq \lambda \leq 0,45 \mu \mathrm{m}, x=3,28$ a 3,45 , respectivamente. No entanto, incertezas na análise termodinâmica, física e óptica, fazem com que a aproximação para o fator de dependência do sinal incandescência, $x$, seja um pouco grosseira. Portanto, a aproximação de (39) para o fator de dependência do sinal de incandescência é empregada aqui e a técnica de extinção a laser apresentada na seção 3.2 é utilizada para a comparação dos valores absolutos de $f_{v}(40)$, pois uma calibração utilizando a mesma necessitaria de hipóteses fortes, e conhecimentos de paramêtros como, por exemplo, valores instantâneos do caminho óptico e a variação da função complexa do índice de refração $(E(m))$.

\subsection{2}

\section{Montagem Experimental}

O sistema referente a técnica de incandescência induzida por laser (LII) é apresentado na Fig. 3.6. Este consiste de um laser de Nd:YAG (modelo brilliant B, Quantel), que gera um feixe pulsado $(10 \mathrm{~Hz})$ de alta energia (0,90 J) no comprimento de onda fundamental $1064 \mathrm{~nm}$. No presente estudo, o comprimento de onda do feixe é de $266 \mathrm{~nm}$ (90 mJ) empregando, para este fim, dobradores de frequência de quarto $(4 \omega)$ e segundo $(2 \omega)$ harmônico. A utilização de um comprimento de onda de excitação no UV tem por finalidade permitir a detecção simultânea de fuligem e HPA (41).

Um detetor de energia (LaVision - modelo V9) monitora a intensidade de cada disparo do laser durante o ensaio, e sua medida é usada para rejeitar imagens com valores fora de um desvio padrão em torno da média. Um filtro 


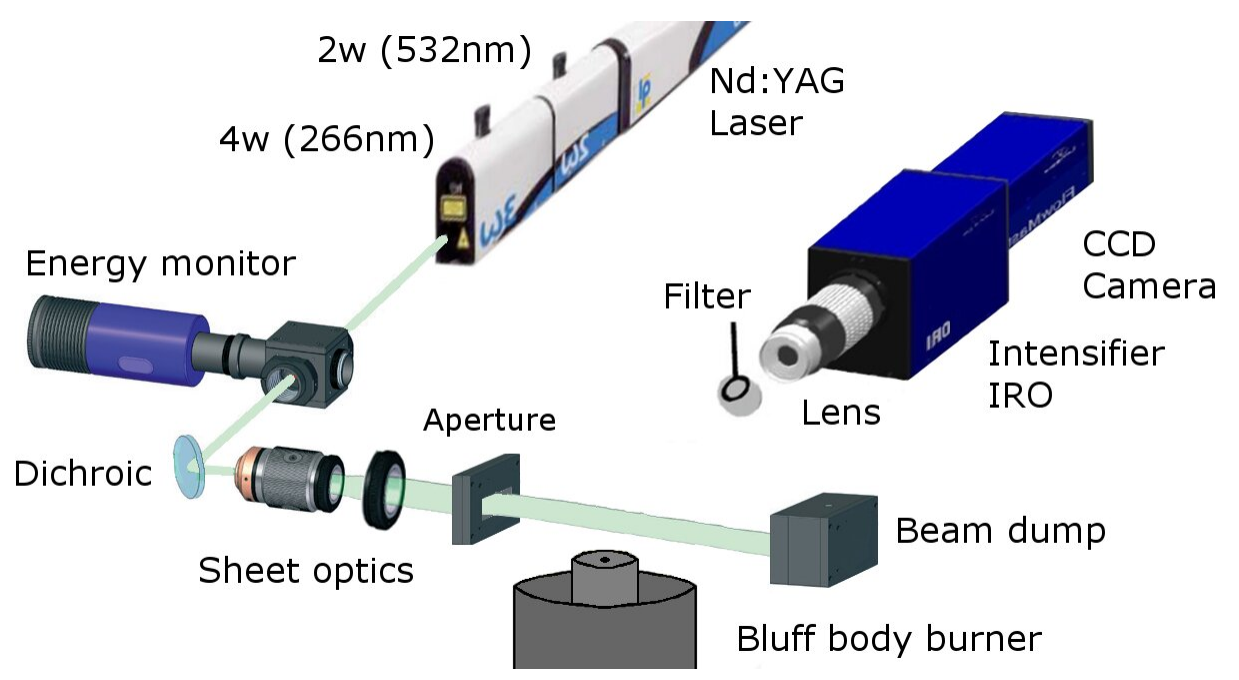

Figura 3.6: Aparato experimental da técnica de incandescência induzida por laser, LII, disponível no Laboratório de Combustão e Turbulência da PUC-Rio.

dicroico (CVI Laser Optics - F10-532-0-4-50.0M) é utilizado para filtrar a componente residual de $532 \mathrm{~nm}$ gerada no segundo harmônico $(2 \omega)$. Um plano laser de $0,45 \times 35 \mathrm{~mm}^{2}$, verticalmente deslocado de $10 \mathrm{~mm}$ acima da base do queimador, e que passa pelo plano de simetria do mesmo, é gerado usando dois pares de lentes. As duas primeiras são lentes esféricas, que convergem o feixe para a espessura desejada, enquanto o segundo par de lentes cilindrícas, $f=-50 \mathrm{~mm}$ e $f=150 \mathrm{~mm}$ expande o feixe verticalmente. Por fim, o feixe laser passa, então, por uma abertura mecânica controlada manualmente a fim de controlar a altura do plano. A luz resultante do processo de incandescência da fuligem passa por uma lente $f / 2,8$ - $100 \mathrm{~mm}$ (LaVision - lente UV reforçada). São acopladas a esta lente dois filtros, alternadamente, passa banda centrados em 340 nm (modelo Edmund Optics - CWL - 84108) e 400 nm (modelo Edmund Optics - CWL - 86664), ambos com $10 \mathrm{~nm}$ de largura de banda e 90\% de transmissividade. Esta montagem filtro + objetiva é utilizada numa câmera CCD (Charged Coupled Device - LaVision, Image Intense). Entretanto, a intensidade do sinal de incandescência das partículas de fuligem não é suficiente para sensibilizar os sensores CCD de câmeras comuns. Logo, é necessário o uso de um intensificador de imagens. A câmera Intensificadora ICCD (Lavision IRO) é composta por uma câmera CCD, um dispositivo eletro-óptico, uma placa de fósforo e um fotocátodo, como mostra a Fig 3.7 (42). Os fótons oriundos do processo de incandescência são focalizados na janela de entrada do intensificador de imagem, onde os fótons incidentes na tela frontal do ICCD são convertidos em elétrons, pelo foto-cátodo, através do efeito fotoelétrico. Em seguida, esta corrente elétrica dentro do cátodo é amplificada pela diferença de potencial e, finalmente, convertida na forma de luz ao atingir uma superfície 


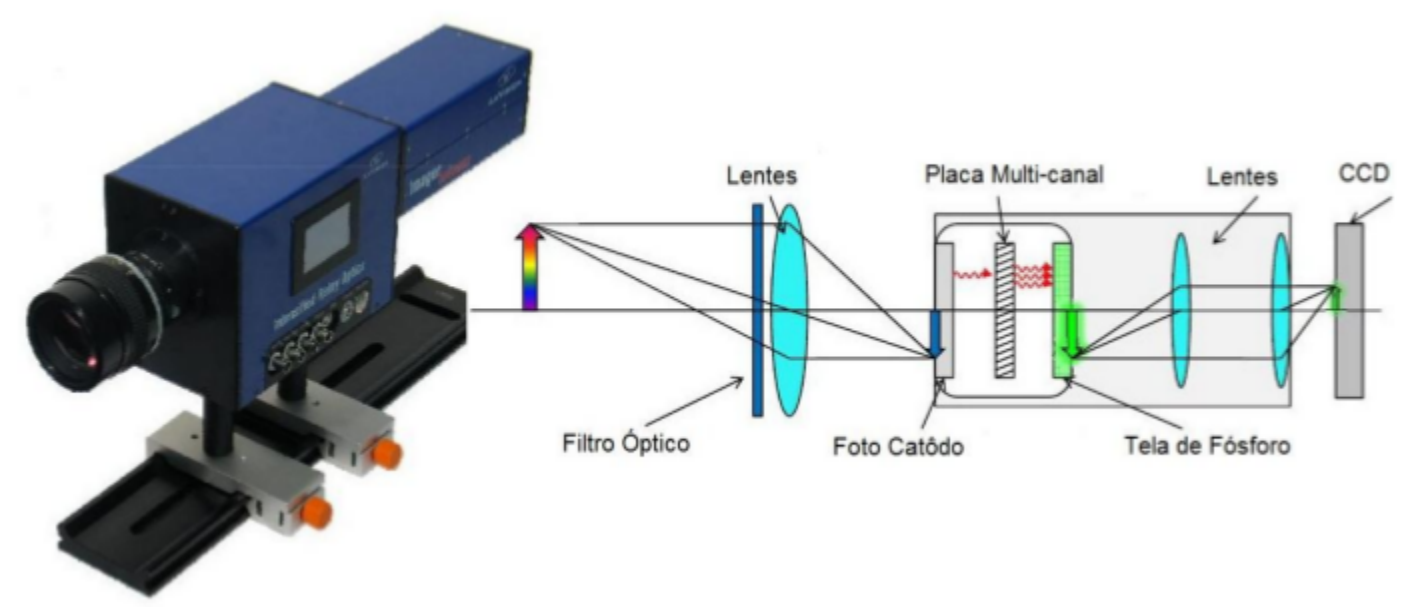

Figura 3.7: Imagem esquemática da configuração do Intensificador de imagem. Adaptado de (42).

de fósforo, criando um sinal luminoso na saída do intensificador de imagem. Este sinal ocorre sempre na faixa de comprimentos de onda na região da cor verde e, então, a única variável é a intensidade desta luminosidade na saída do intensificador, a qual produz a imagem digital em níveis de cinza. A imagem que sai da janela do intensificador é focalizada no CCD, por meio de um conjunto de lentes. A exposição efetiva da câmera é obtida pela integração dos intervalos de tempo da emissão por parte do fósforo, que permite que o tempo de captura da imagem seja modulado através do intensificador, reduzindo o tempo de exposição até valores da ordem de 10 ns.

Devido a sua natureza de vida curta, os sinais de incandescência são, geralmente, pouco intensos e emitidos em bandas espectrais largas. A luz oriunda da chama, $S_{\Delta t}$, é capturada num lapso de tempo, $\Delta t$. O amplificador aqui empregado possui a finalidade de incrementar a razão sinal/ruído formando um conjunto câmera - intensificador, ICCD.

O sinal de fluorescência dos HPA, cujo tempo de vida é de poucas dezenas de nano segundos (43), diminui rapidamente, quando comparado com o sinal da incandescência da fuligem, como pode ser observado na Fig. 3.8, que apresenta a evolução temporal dos sinais de incandescência e fluorescência após o pulso laser e detectados na faixa do UV-vísivel. A figura indica que a vida do sinal de fuligem é da ordem de centenas dos nano segundos. Desta forma, uma detecção espectral empregando janelas temporais atrasadas (delay) em relação ao pulso laser permitiria discriminar o sinal de incandescência do sinal combinado de HPA + fuligem (44). Portanto, empregando um atraso de t>50 ns na detecção, apenas o sinal de incandescência (LII) é observado (45). 

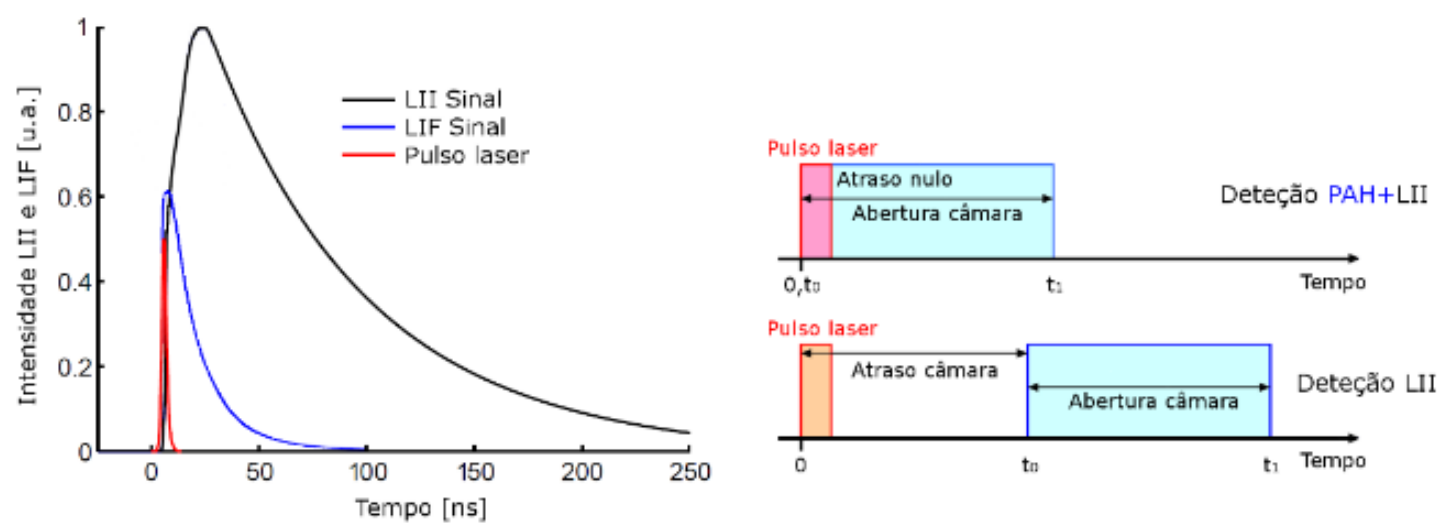

Figura 3.8: Esquema da evolução temporal da incandescência e fluorescência detectadas na faixa UV-Vísivel e janelas temporais de detecção das câmeras, adaptado de (46).

Esta particularidade torna possível uma diferenciação entre os sinais de LIF e de LII empregando-se diferentes atrasos do início $\left(t_{0}\right)$ da janela temporal de detecção $\left(t_{1}, t_{2} ..\right)$ com relação ao pulso laser $(0)$, tomado como origem desta escala temporal. Na Fig. 3.8 se pode observar os dois tipos de abordagens utilizados na detecção: (a) abertura imediata (prompt), onde o início da janela de detecção $\left(t_{0}\right)$ é quase simultâneo com o pulso laser $\left(t_{0} \approx 0\right)$ e $(\mathrm{b})$ abertura com atraso (delay), onde a detecção se inicia um lapso de tempo após o pulso laser $\left(t_{0}>0\right)$.

\subsection{3}

\section{Calibração LII Por LE}

No arranjo experimental empregado, o plano laser usado para excitar LII atravessa a chama no seu plano de simetria e o feixe laser de extinção atravessa a chama horizontalmente numa altura $z_{0}$ da superfície do bluff-body. A técnica de extinção de luz permite determinar, indiretamente, o valor integrado médio da fração volumétrica de fuligem ao longo de um caminho óptico, $L$, numa determinada altura $z$ a partir da Eq. $3-9, F_{v}(z)=L(z) \cdot \bar{f}_{v}\left(z_{0}\right)$.

A técnica de incandescência mede a distribuição bidimensional, o qual é proporcional à fração volumétrica de fuligem, $f_{v}(r, z)$. Se o feixe de extinção passa pelo o mesmo plano laser de incandescência, estas duas medidas podem ser relacionadas. No presente estudo, esta calibração não será efetuada de forma sistemática, pois, requer hipóteses fortes. 


\section{4}

\section{Escalas Características do Movimento Turbulento}

A natureza do escoamento turbulento é irregular com rápidas flutuações na velocidade, densidade, temperatura e composição. Essa natureza inconstante faz com que o escoamento turbulento resulte num aumento do transporte de quantidade de movimento, massa e energia. Entre as características mais importantes dos escoamentos turbulentos, destaca-se a multiplicidade das escalas que a caracterizam. As maiores estruturas (baixas frequências) são controladas pela geometria que as geram, e as menores estruturas (altas frequências) são controladas pela viscosidade do fluido (47).

De acordo com (48), as menores escalas de movimento turbulento, ditas de Kolmogorov, fazem com que os movimentos de tamanhos característicos menores que $\ell_{\eta}$ definido na Eq. 3-15, sejam dissipados por efeitos viscosos e não podem se desenvolver. As menores escalas são dadas por:

- Comprimento $\left(\ell_{\eta}\right)$

$$
\ell_{\eta}=\left(\nu^{3} / \epsilon\right)^{1 / 4}
$$

- Tempo característico $\left(t_{\eta}\right)$

$$
t_{\eta}=(\nu / \epsilon)^{1 / 2}
$$

- Velocidade $\left(u_{\eta}\right)$

$$
u_{\eta}=(\nu \epsilon)^{1 / 4}
$$

onde $\nu$ é a viscosidade cinemática $[\nu=\nu(T)]\left[\mathrm{m}^{2} / \mathrm{s}\right]$, e $\epsilon$ é a taxa de dissipação viscosa $\left[\mathrm{m}^{2} / \mathrm{s}^{3}\right]$.

As razões da menor para a maior escala são prontamente determinadas a partir das definições das escalas de Kolmogorov e da escala $\epsilon \sim u_{0}^{3} / l_{0}$, que resultam em (48):

$$
\begin{aligned}
& \ell_{\eta} / l_{0} \sim R e_{T}^{-3 / 4}, \\
& u_{\eta} / u_{0} \sim R e_{T}^{-1 / 4}, \\
& t_{\eta} / t_{0} \sim R e_{T}^{-1 / 2},
\end{aligned}
$$

onde $\operatorname{Re}_{T}$ é o Reynolds da turbulência dado por:

$$
R e_{T}=\frac{l_{0} u^{\prime}}{\nu}
$$

Por simplicidade, e de acordo com as imagens das chamas estudadas (ver Fig. 1.5), será admitido que $\ell_{0}=D / 4$ é o comprimento da escala integral da turbulência e $u^{\prime}=\sqrt{\frac{2}{3} k}$ é a intensidade turbulenta, sendo $k$ a energia cinética do movimento turbulento. A fim de se estimar a ordem de grandeza das escalas 


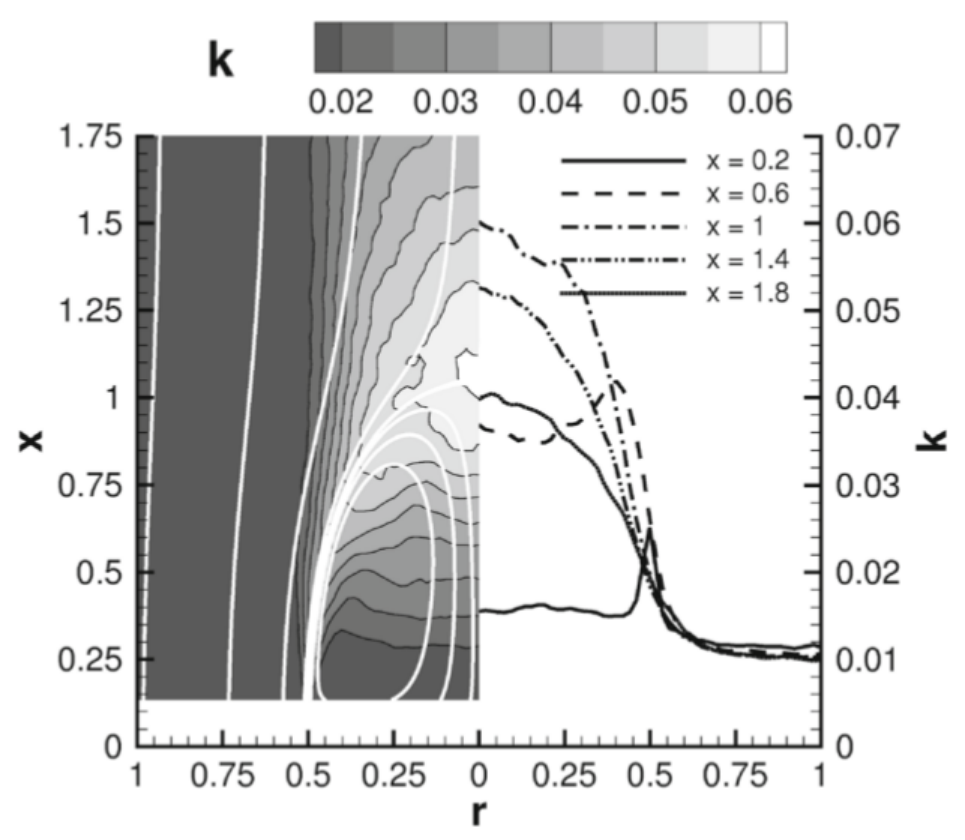

Figura 3.9: Perfis e campos da energia cinética turbulenta adimensional, $k$. Linhas de corrente em branco, $\mathrm{Re}=45.400$. Adaptado de (49).

características do movimento turbulento, será admitido que $k=0,04 u_{0}^{2}$, estimativa obtida a partir de (49), como pode ser observado na Fig. 3.9, que mostra os perfis para diferentes posições axiais e campo da energia cinética turbulenta adimensional na esteira isotérmica do queimador bluff-body.

\section{5}

\section{Sumário das Incertezas Experimentais}

O estudo aqui desenvolvido utilizou as mesmas técnicas e procedimentos de medição na caracterização de estruturas de fuligem que trabalhos anteriores realizados no Laboratório de Combustão e Turbulência da PUC-Rio (LCTPUC-Rio). Portanto, foram considerados os mesmos valores de incertezas associadas à medição (41). A metodologia utilizada para o cálculo das incertezas são baseadas supondo que um resultado $R$ é função de $N$ variáveis independentes $R=\left(x_{1}, x_{2}, x_{3}, \ldots, x_{n}\right)$ Uma possível maneira de se estimar a incerteza final no resultado $R$, pode ser obtida através da chamada combinação da pior situação. Assim,

$$
\delta R=\left|\frac{\delta R}{\delta x_{1}} \delta x_{1}\right|+\left|\frac{\delta R}{\delta x_{2}} \delta x_{2}\right|+\left|\frac{\delta R}{\delta x_{3}} \delta x_{3}\right|+\ldots+\left|\frac{\delta R}{\delta x_{n}} \delta x_{n}\right|,
$$

onde $\delta R$ é a incerteza no resultado $\mathrm{R}$, e $\delta x_{i}$ é a incerteza em cada variável $x_{i}$. As derivadas parciais $\frac{\delta R}{\delta x_{i}}$ são chamadas de coeficientes de sensibilidade e medem o quão sensível o resultado $R$ é a cada variável $x_{i}$. É pouco provável que 
as incertezas individuais se combinem da pior maneira possível como propõe a Eq. 3-22. As previsões obtidas com esta expressão são normalmente exageradas quando comparadas com experimentos reais. Uma outra forma de calcular a propagação de incertezas experimentais foi proposta por (50), que fornece boa previsão das incertezas e é dada por:

$$
\delta R^{2}=\left(\frac{\delta R}{\delta x_{1}} \delta x_{1}\right)^{2}+\left(\frac{\delta R}{\delta x_{2}} \delta x_{2}\right)^{2}+\left(\frac{\delta R}{\delta x_{3}} \delta x_{3}\right)^{2}+\ldots+\left(\frac{\delta R}{\delta x_{n}} \delta x_{n}\right)^{2} .
$$

Nesta expressão, os níveis de probabilidade das medidas individuais são preservados na grandeza $R$. Isto é, se $\delta x_{i}$ é conhecido dentro de $\pm 2 \sigma$, $\delta R$ será obtido também dentro de $\pm 2 \sigma$. Esta expressão apresenta resultados satisfatórios e é amplamente utilizada.

Os resultados das incertezas associadas ao estudo experimental deste trabalho e apresentadas na Tabela 3.1, são reportadas no trabalho de (41) desenvolvido no LCT-PUC-Rio. O alto valor de incerteza de medição está associado, principalmente, à função de absorção em função do índice de refração, $E(m)$, que é uma propriedade óptica das partículas de fuligem e depende do tamanho, temperatura e forma da partícula, os quais são altamente variável no tempo e espaço.

Tabela 3.1: Incertezas associadas a erros experimentais. Adaptado de (41).

\begin{tabular}{|c|c|}
\hline$x_{i}$ & $\delta x_{i} / x_{i}(\%)$ \\
\hline$\lambda$ & $\approx 0$ \\
\hline$E(m)$ & 16,3 \\
\hline$\tau$ & 1,4 \\
\hline$L$ & 0,7 \\
\hline Total & 18,4 \\
\hline
\end{tabular}

\section{6}

\section{Sumário da Metodologia Experimental}

A utilização das técnicas ópticas de incandescência induzida por laser e extinção da luz empregadas numa chama turbulenta num queimador do tipo bluff-body permite caracterizar a fração volumétrica de fuligem integrada e determinar a distribuição espacial de fuligem e HPA, sendo esse via PLIF, ver (41). O regime de turbulência aqui utilizado é aquele que possibilita a formação de fuligem e HPA dentro da zona de esteira. Isto é alcançado através da escolha de um Reynolds do jato combustível laminar e um número de 
Reynolds do escoamento de ar turbulento. E provoca, assim, uma interação turbulência-fuligem suficiente para que seja observada a influência dos movimentos turbulentos nas estruturas de fuligem. O próximo capítulo apresenta uma análise dessa interação, a nível de distribuição de fuligem na chama. 


\section{Resultados e Discussão}

Neste capítulo, são apresentados e discutidos os resultados da aplicação das técnicas experimentais descritas no capítulo 3. Apresenta-se, primeiramente, a fração volumétrica de fuligem medida em três alturas distintas acima do queimador (HAB) com o intuito de estudar a distribuição das partículas de fuligem ao longo da chama. Em seguida, a estrutura instantânea e intermitente das estruturas de fuligem é caracterizada em dois diferentes comprimentos de onda de detecção, 340 e $400 \mathrm{~nm}$. Por fim, a estrutura média da chama fuliginosa de etileno/ar e a probabilidade da presença de fuligem em toda região da chama são discutidas.

\section{1 \\ Considerações Gerais Sobre as Chamas Estudadas}

A Tabela 4.1 apresenta os dois casos estudados neste trabalho. A vazão de ar foi mantida fixa e variou-se a vazão de etileno em 1,97 L/min e 2,64 L/min, respectivamente. O etileno empregado nos experimentos foi fornecido pela White Martins, com 99,5 Mol/Mol de pureza. O número de Reynolds do jato de combustível correspondente, $\mathrm{Re}_{j}$ (baseado no diâmetro do jato) é laminar em ambos os casos. No entanto, após a interação com a zona de esteira, condições turbulentas são alcançadas, e espera-se que o estado turbulento da zona de recirculação seja controlado pela corrente de ar. 

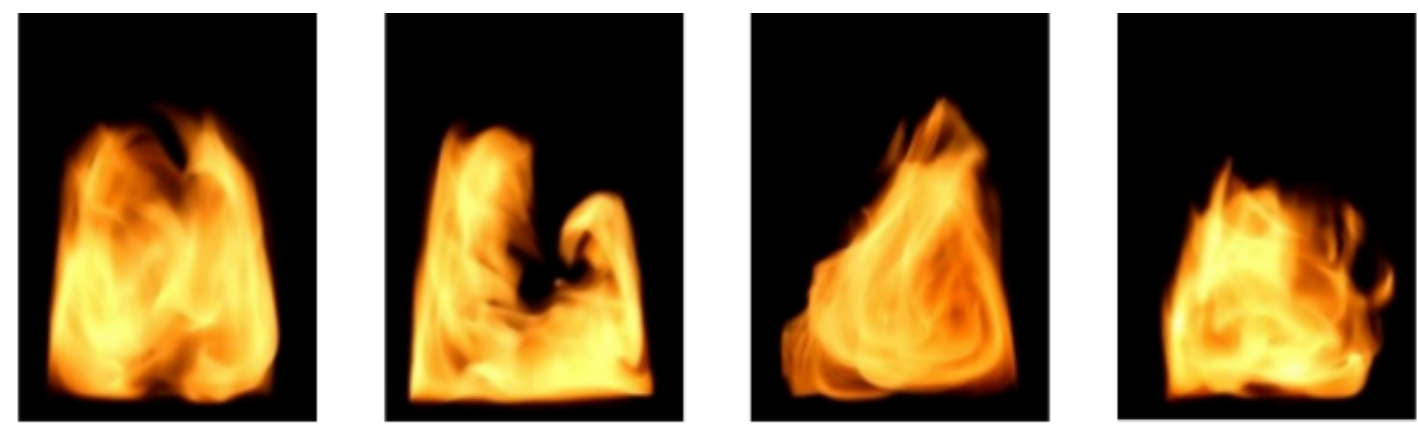

(a) Chamas turbulentas estabilizadas para o Caso A.
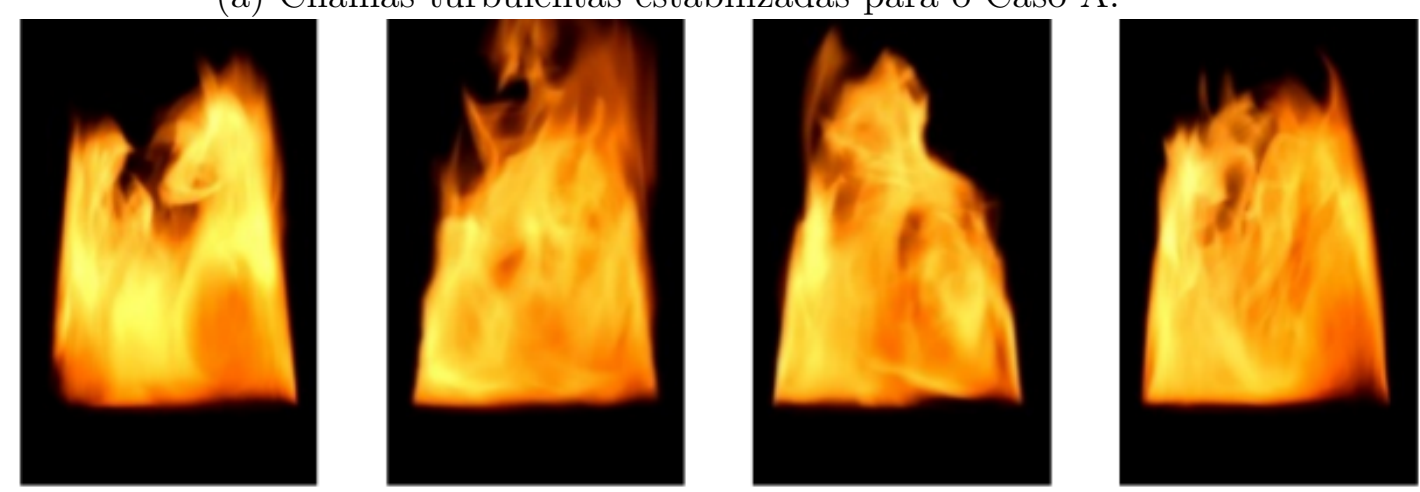

(b) Chamas turbulentas estabilizadas para o Caso B.

Figura 4.1: Fotografias das chamas de etileno/ar estudadas no queimador do tipo bluff-body.

A velocidade do ar de co-fluxo usada é de $11,8 \mathrm{~m} / \mathrm{s}$ a 1 bar, resultando em um número de Reynolds de 45.400 (baseado no diâmetro do bluff-body). Nestas condições, a máxima fração volumétrica de fuligem medida é de 1,1 ppm. Estas condições de operação foram escolhidas a fim de se obter a máxima produção de fuligem na região de esteira. Imagens da chama turbulenta de etileno/ar podem ser observadas na Fig. 4.1, onde a luminosidade da chama dá a falsa impressão que há partículas de fuligem presentes em quase toda a região da chama, o que será examinado na seção 4.3. Nota-se também, que a região fuliginosa é completamente confinada nas imediações da superfície do queimador. Isto garante que a produção de fuligem ocorra em presença de intensa agitação turbulenta e num local de grande tempo de residência da mistura reativa.

A tabela 4.2 mostra os valores calculados das escalas características que serão utilizados para auxiliar a interpretação dos resultados obtidos. Cabe enfatizar que estas escalas foram calculadas admitindo-se que a turbulência na esteira do bluff-body é controlada pelo escoamento de ar. 
Tabela 4.1: Condições de operação para os casos estudados.

\begin{tabular}{|c|c|c|c|c|}
\hline Caso & $\mathrm{Q}_{j}(\mathrm{~L} / \min )$ & $\mathrm{U}_{j}(\mathrm{~m} / \mathrm{s})$ & $\mathrm{Re}_{j}$ & $\mathrm{U}_{j} / \mathrm{U}_{a r}$ \\
\hline $\mathrm{A}$ & 1,97 & 9,04 & 1.070 & 0,77 \\
\hline $\mathrm{B}$ & 2,64 & 12,11 & 1.440 & 1,03 \\
\hline
\end{tabular}

Tabela 4.2: Escalas características da turbulência utilizadas.

\begin{tabular}{c|c|c|c} 
& $u(\mathrm{~m} / \mathrm{s})$ & $\ell(\mathrm{mm})$ & $t(\mathrm{~ms})$ \\
\hline integral & 11,8 & 15 & 1,27 \\
\hline Kolmogorov & 1,76 & $4,8 \times 10^{-2}$ & $27,2 \times 10^{-3}$
\end{tabular}

\section{2}

\section{Fração Volumétrica de Fuligem Integrada}

A técnica de extinção foi aplicada no caminho óptico, $L=60 \mathrm{~mm}$, que atravessa o eixo de simetria da chama em três alturas diferentes num passo de $10 \mathrm{~mm}$. Estas alturas foram escolhidas por serem aquelas por onde passa o plano laser da técnica LII. O comprimento de onda de detecção empregado foi $\lambda=532 \mathrm{~nm}$, com um tempo de integração de $i_{t}=1,5 \mathrm{~ms}$, escolhido aqui por fornecer um melhor sinal de extinção das partículas de fuligem entre os tempos de integração estudados. O valor da função de absorção usada aqui $[E(m)=0,245]$ foi calculado de acordo com a Eq. 3-7 na seção 3.2.1 baseado no comprimento de onda utilizado e assumido a hipótese de que o parâmetro é constante ao longo de todo o caminho óptico para todos os instantes. Os resultados de fração volumétrica de fuligem, calculados utilizando a Eq. 3-9, em função do tempo de integração do sistema e da altura acima do queimador são apresentados nas Tabelas 4.3 e 4.4, respectivamente. A primeira destas tabelas mostra que a escolha do tempo de integração do detetor, $i_{t}$ (ver seção 3.2.2), influi quantitativamente sobre o resultado medido de $\bar{f}_{v}$. A tabela 4.4 mostra que o valor de $\bar{f}_{v}$ decai monotonicamente com $H A B$, indicando que a fuligem é produzida na vizinhança da superfície do queimador, e oxidada mais acima. 
Tabela 4.4: Fração volumétrica de fuligem obtida para chama de etileno/ar em alturas HAB distintas, $i_{t}=1,5 \mathrm{~m} / \mathrm{s}$, Caso A.

\begin{tabular}{c|c|c|c}
$H A B(\mathrm{~mm}):$ & 27 & 37 & 47 \\
\hline$f_{v}(\mathrm{ppm}):$ & 1,08 & 0,732 & 0,467
\end{tabular}

Tabela 4.3: Fração volumétrica de fuligem obtida para chama de etileno/ar para diferentes tempos de integração, $H A B=27 \mathrm{~mm}$, Caso A.

\begin{tabular}{c|c|c|c|c}
$i_{t}(\mathrm{~ms}):$ & 0,450 & 0,750 & 1,0 & 1,50 \\
\hline $\bar{f}_{v}(\mathrm{ppm}):$ & 0,930 & 0,940 & 0,846 & 1,08 \\
\hline $1-\langle\tau\rangle$ & 0,384 & 0,387 & 0,356 & 0,430 \\
\hline Desvio Padrão & 0,118 & 0,128 & 0,127 & 0,142
\end{tabular}
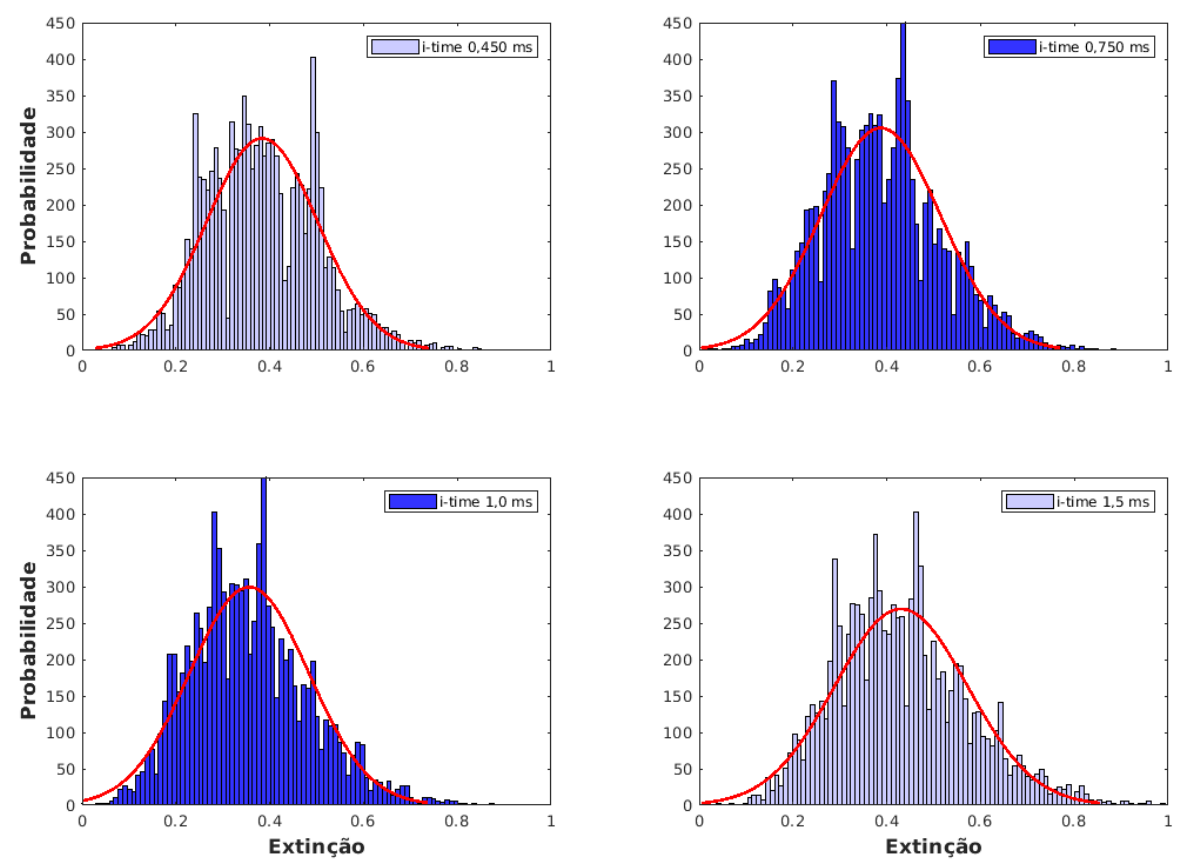

Figura 4.2: Histogramas do sinal de extinção da fuligem superpostos por uma distribuição Normal para diferentes tempos de integração, Caso A.

A Fig. 4.2 apresenta o histograma dos resultados de extinção $[1-\langle\tau\rangle]$ para diferentes tempos de integração empregados no monitor de energia. Nesta figura, os histogramas são comparados com a distribuição normal 
correspondente. Na Fig. 4.3, são comparadas as PDFs de extinção para os diferentes tempos de integração usados. A análise destas figuras confirma que o valor de extinção depende pouco do tempo de integração do sistema de deteção. Isto indica que o sistema foi bem calibrado. Os resultados obtidos para extinção apresentam uma dispersão significativa.

Cabe ressaltar que a obtenção de um valor instantâneo da fração volumétrica de fuligem a partir destes dados de extinção do laser exigiria o conhecimento do caminho óptico instantâneo, $L(t)$, que não está disponível, ou então uma forte hipótese envolvendo a homogeneidade do meio ao longo do trajeto do laser.

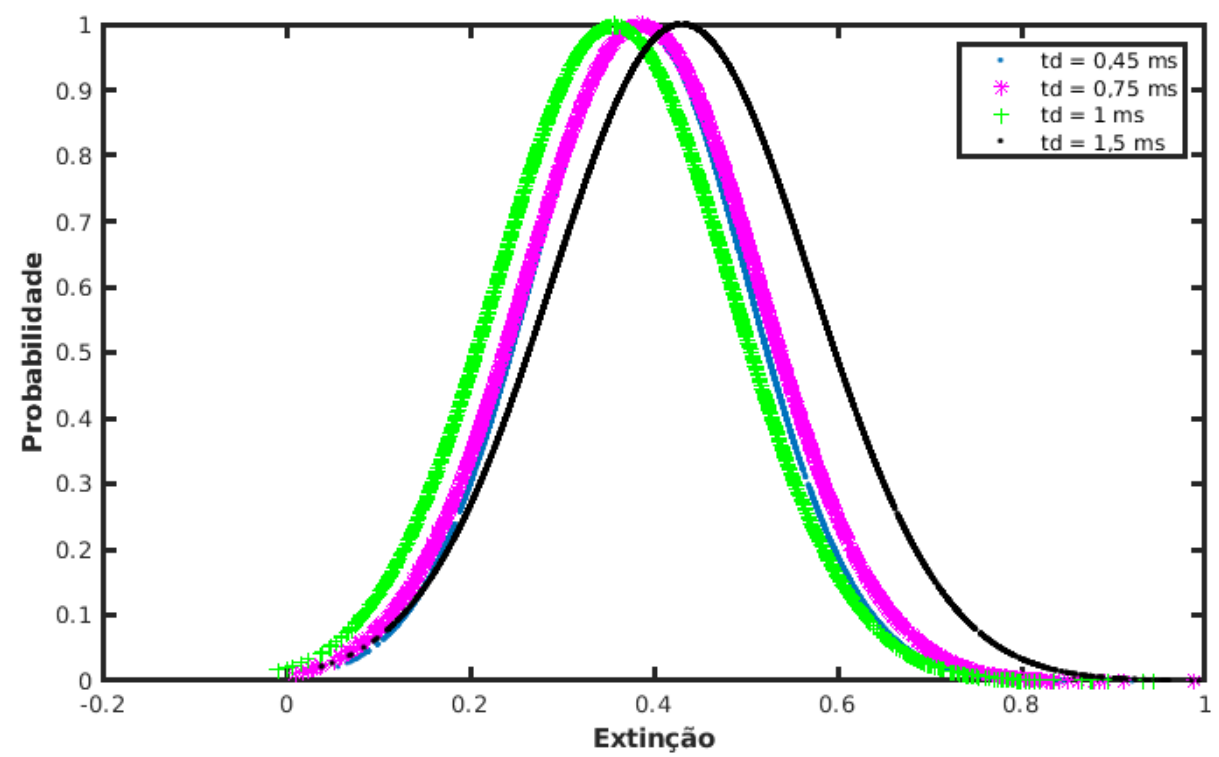

Figura 4.3: Função densidade probabilidade do sinal de extinção para diferentes tempos de integração, $i_{t}$, Caso A.

Como pode ser visto nas Figs. 4.4, 4.5 e 4.6 os histogramas correspondentes da extinção da chama para diferentes valores de HAB mostram um comportamento de distribuição monomial com o maior valor da fração volumétrica de fuligem encontrada na parte mais baixa da chama. Esta figura apresenta a distribuição de probabilidade da fração volumétrica integral de fuligem para diferentes alturas, HAB, ao longo da chama. A natureza turbulenta da chama é, novamente, ressaltada pela distribuição da extinção. Para $\mathrm{HAB}=37$ e 47 mm (ver Figs. 4.5 e 4.6) uma probabilidade não negligenciável de extinção zero é observada. Pelo contrário, na altura de medição mais baixa, $\mathrm{HAB}=27 \mathrm{~mm}$ (ver Fig.4.4), a extinção quase completa com probabilidade significativa é encontrada. O comportamento observado nestas figuras pode 


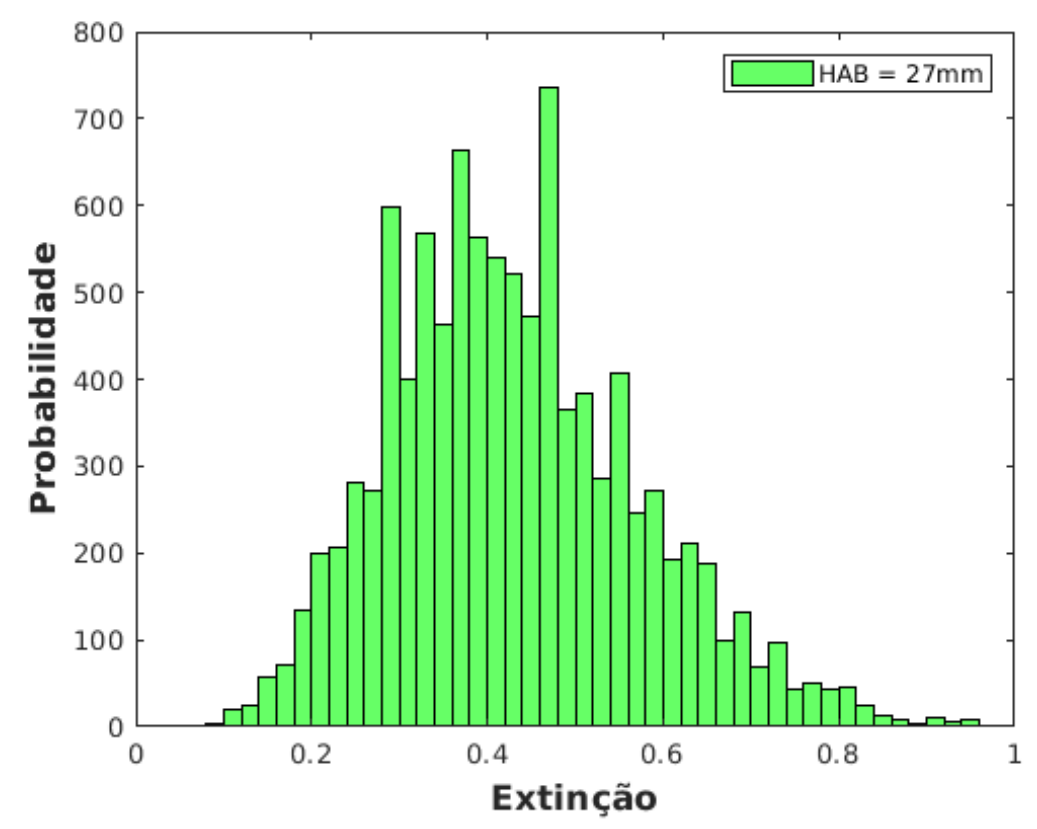

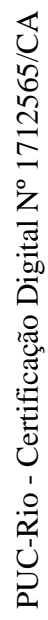

Figura 4.4: Histograma de extinção da fuligem para a chama de etileno/ar na altura acima do queimador (HAB) de $27 \mathrm{~mm}$, Caso A.

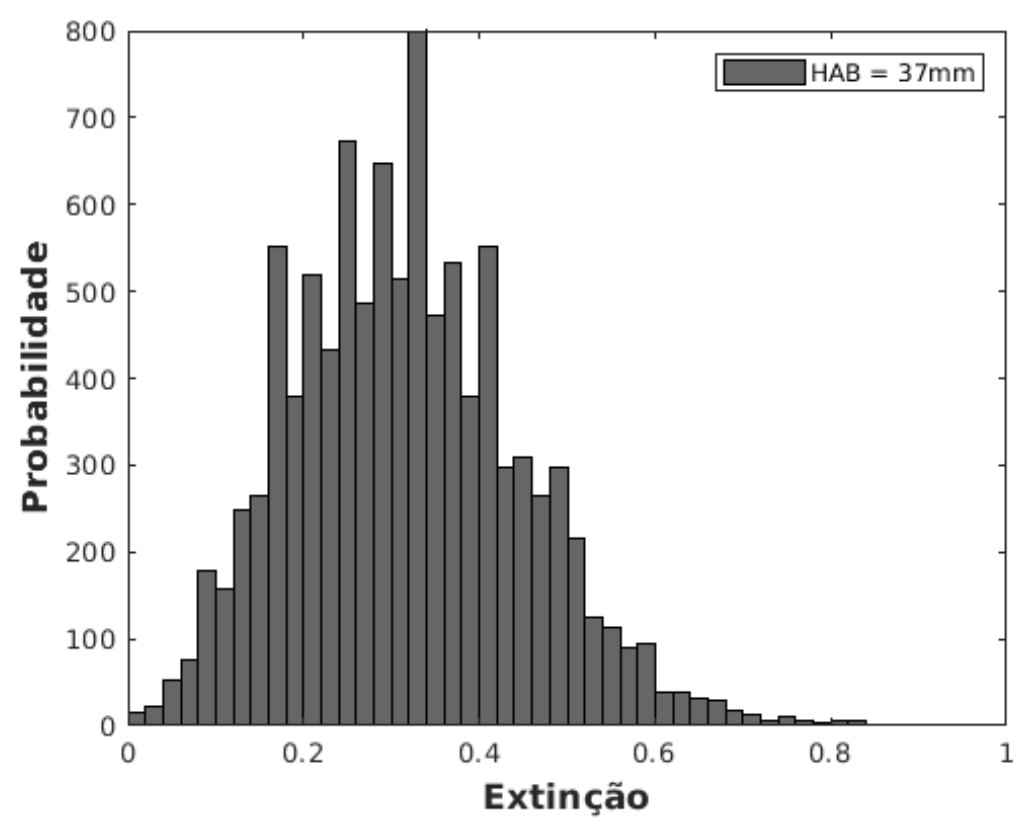

Figura 4.5: Histograma de extinção da fuligem para a chama de etileno/ar na altura acima do queimador (HAB) de $37 \mathrm{~mm}$, Caso A. 


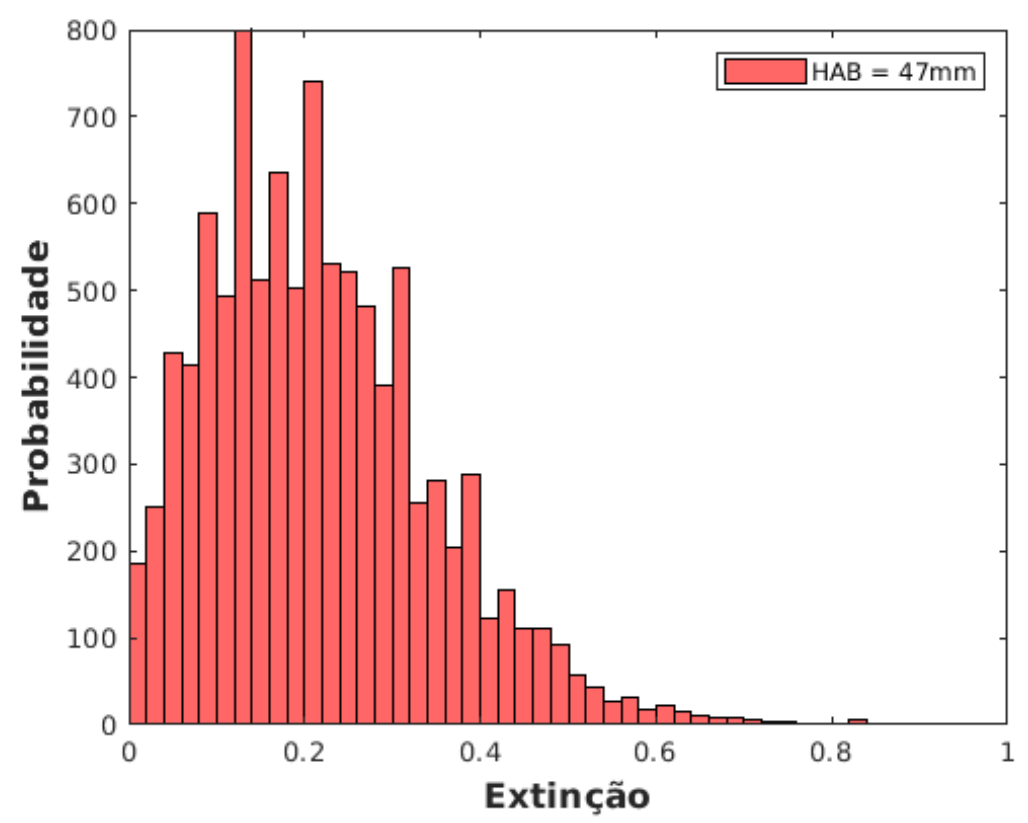

Figura 4.6: Histograma de extinção da fuligem para a chama de etileno/ar na altura acima do queimador (HAB) de $47 \mathrm{~mm}$, Caso A.

ser explicado tanto pelo alto carregamento de fuligem pela chama quanto por uma mudança frequente da espessura do caminho óptico instantâneo, $L(t)$, responsável pela atenuação do laser. Por esta razão, optou-se por analisar, a seguir, apenas o comportamento estocástico da extinção, $\tau$ [ver Eq. 3-11].

O comportamento estocástico de $\tau$ e, logo, de $\bar{f}_{v}$ pode ser compreendido considerando-se os valores de tempos de deteção e de escalas turbulentas. De fato, os resultados apresentados foram obtidos com um tempo de deteção de $i_{t}=1,5 \mathrm{~ms}$ o qual é da mesma ordem de grandeza do valor estimado para o tempo de escala integral da turbulência (ver Tabela 4.2), $t_{0}=1,27 \mathrm{~ms}$. Portanto, os histogramas das Figs. 4.4, 4.5 e 4.6, indicam valores de $\bar{f}_{v}$ que possuem escalas de tempo comparáveis aos maiores movimentos de turbulência. Assim, deve ser ressaltado que as pequenas escalas de flutuação turbulenta não são resolvidas no tempo. Além disto, a distribuição normal de $\bar{f}_{v}$ pode ser explicada considerando o teorema central limite, que diz que uma variável aleatória composta por um conjunto de variáveis aleatórias tem distribuição normal (51). Assim, o feixe de laser pode ser entendido como um processo que realiza a amostragem de $f_{v}(r, z)$ ao longo de uma altura. 


\section{3}

\section{Caracterização da Distribuição de Energia do Laser}

Como já mencionado no capítulo anterior, a forma do feixe laser exerce um grande impacto no sinal de incandescência (52). Portanto, é indispensável caracterizar a distribuição de energia empregada para se obter incandescência da fuligem em cada um dos casos estudados. A Fig. 4.7 apresenta os perfis transversais tipícos de lasers do tipo top-hat, gaussiano e irregular. Os perfis dos feixes utilizados neste estudo são mostrados na Fig. 4.8. Estas imagens são obtidas empregando-se a técnica de espalhamento Rayleigh, que se baseia no espalhamento elástico das partículas e é utilizada para avaliar a distribuição de intensidade de luz laser de excitação no plano formado na seção de medidas. Para construção desta figura, são utilizados a média de 4000 imagens. Os detalhes desta técnica podem ser encontrados nos trabalhos de (41) (42). Como pode ser observado nesta figura, os feixes apresentam um perfil irregular de energia ao longo de toda a região de interesse para ambos os casos estudados. Esta irregularidade é intrínseca do equipamento laser e se constitui num empecilho para comparação dos resultados de incandescência a diferentes alturas. Assim, para fim de análise detalhada são empregados três alturas baseadas nos picos de máxima energia nos perfis, isto é, as posições $z$ onde o máximo sinal de espalhamento Rayleigh foi observado. Vale ressaltar que as medidas (caso A e caso B) foram realizadas em dias diferentes, o que pode explicar as diferenças entre as medidas de Rayleigh apresentadas. Enfim, a medição precisa da distribuição de energia do laser requer um equipamento que não está disponível no laboratório (beam profiler). Assim, apenas esta caracterização qualitativa é possível.

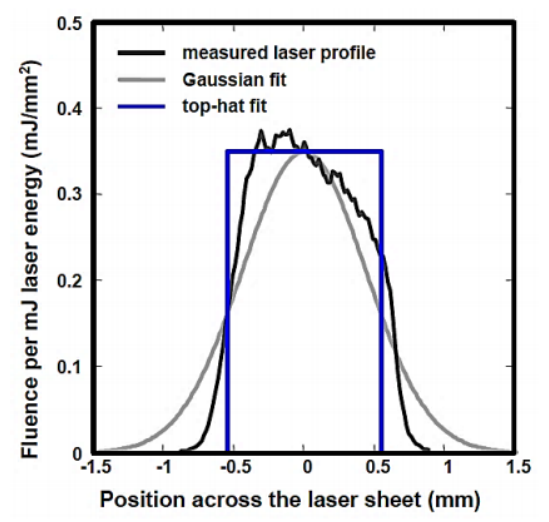

Figura 4.7: Perfil transversal do laser para diferentes tipos de feixe, adaptado de (53). 

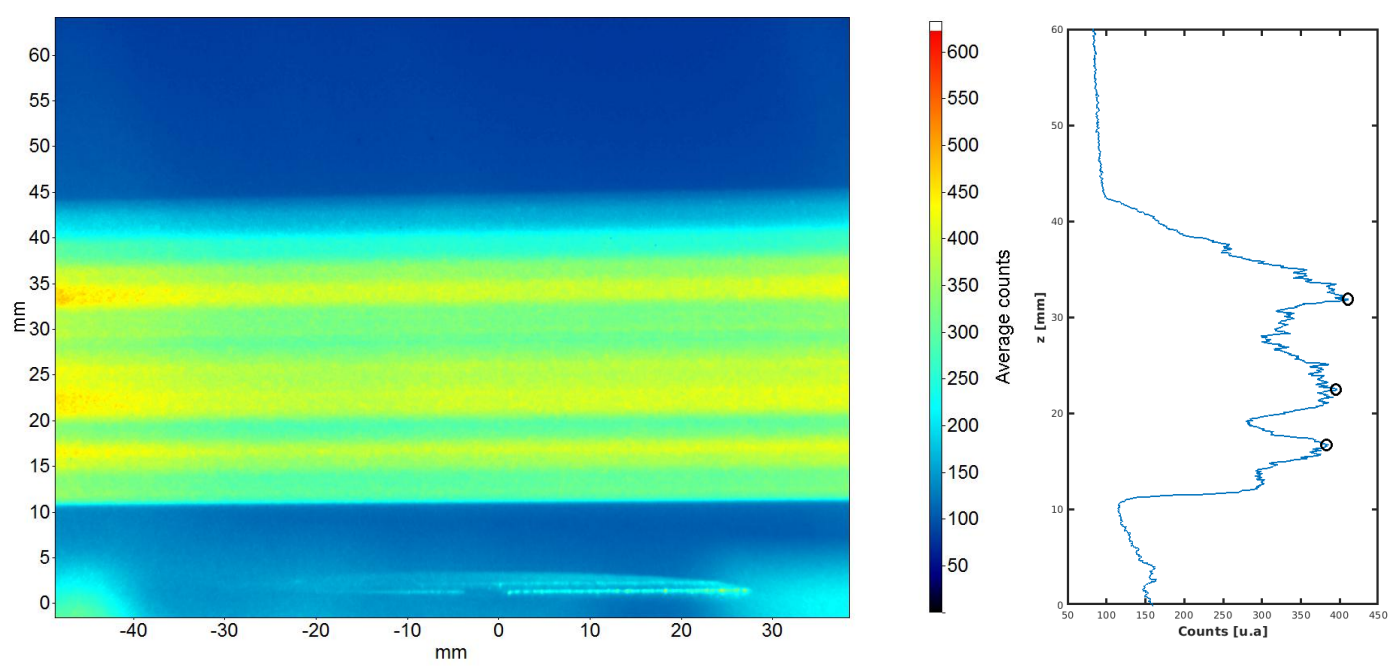

a) Perfis do feixe laser para o Caso A.
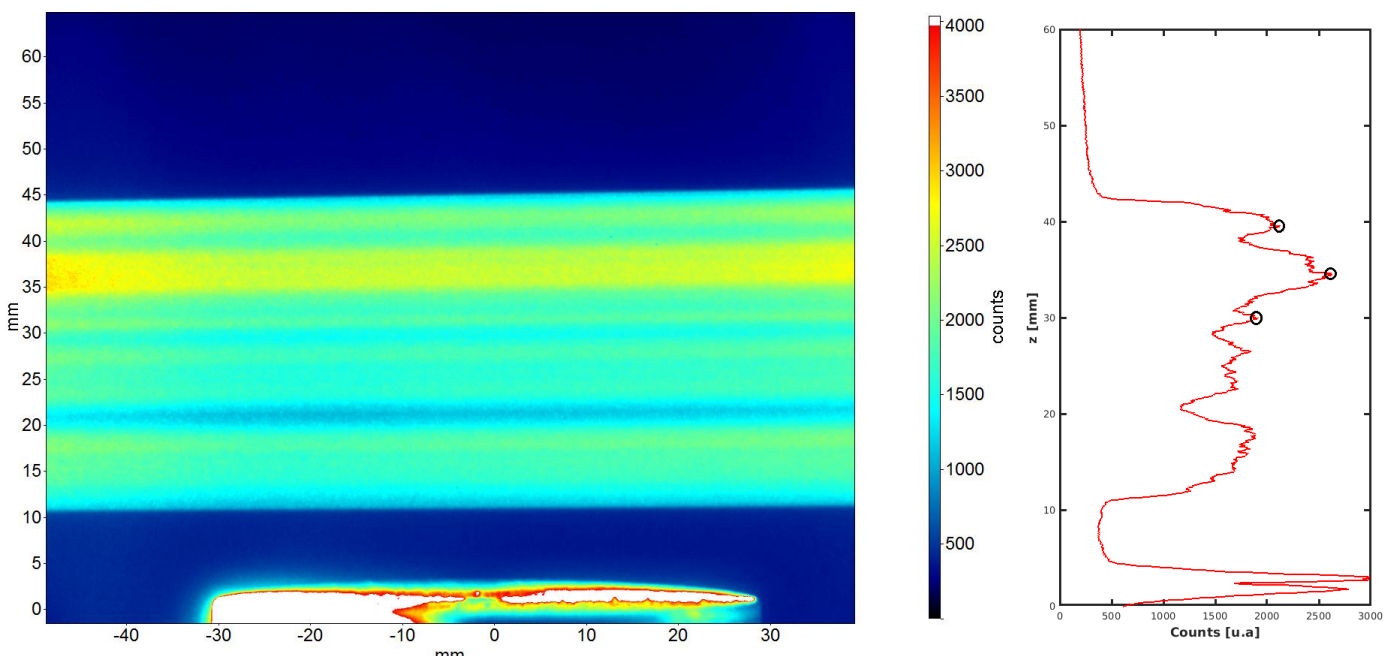

b) Perfis do feixe laser para o Caso B.

Figura 4.8: Perfis do feixe laser utilizados no estudo, medidos utilizando-se espalhamento Rayleigh. Imagem planar (esquerda) e corte vertical (direita).

\section{4}

\section{Estrutura Instantânea da Distribuição Espacial de Fuligem e HPA}

Resultados anteriores obtidos no laboratório de Combustão e Turbulência da PUC-Rio (41) reportam que, em chamas laminares de difusão não prémisturadas fuliginosas de etileno, a zona de produção de HPA se encontra próxima à região inicial de pirólise do combustível e a fuligem é formada numa região envolvendo a região de HPA.

Para chamas turbulentas, dada sua natureza aleatória, não se espera 
que exista uma separação espacial estabelecida entre as regiões de HPA e de fuligem, apenas a maior probabilidade de correlação entre estas duas regiões. Por estes motivos, apenas uma análise qualitativa do campo médio do sinal contendo apenas fuligem (delay) e fuligem mais HPA (prompt) é estudada aqui.

Para cada caso descrito na Tabela 4.1, o padrão global das chamas de etileno é mostrado na Fig. 4.1, sob a forma de fotografia direta. Nos dois casos de estudo, as fotografias das chamas turbulentas apresentam formas de estruturas aleatórias, mas completamente encapsuladas dentro da zona de recirculação ou de vórtice, e com altura aproximada de $60 \mathrm{~mm}$. As chamas se mostram de cor amarela e com grande luminosidade, um indicativo da formação de fuligem. Acredita-se que a combustão ocorra numa região rica em combustível (27).

O comportamento instantâneo das estruturas da chama formada na região de recirculação pode ser mais claramente evidenciado pelas imagens instantâneas resultado da técnica de laser planar empregada. Na Fig. 4.9 e Fig. 4.10, são mostrados os campos instantâneos dos dois casos reportados na Tabela 4.1. Devido ao menor tempo de vida da fluorescência ( $<50 \mathrm{~ns}$ ), os campos instantâneos atrasados (delay > $50 \mathrm{~ns}$ ) no comprimento de onda de 400 nm, ver Fig. 4.9 (c), mostram apenas estruturas instantâneas de fuligem. Os campos instantâneos prompt (0 ns) para os dois comprimentos de onda, $400 \mathrm{~nm}$ e $340 \mathrm{~nm}$ da Fig. 4.9 (b) e 4.9 (a), mostram o sinal combinado de fluorescência de HPA e fuligem. No entanto, como é sabido que o sinal de fluorescência se desloca para maiores comprimentos de onda conforme se incrementa o tamanho dos HPA (54), se espera que a comparação entre estes dois sinais prompt (340 e $400 \mathrm{~nm}$ ) indique, qualitativamente, o crescimento dos hidrocarbonetos aromáticos policíclicos. 

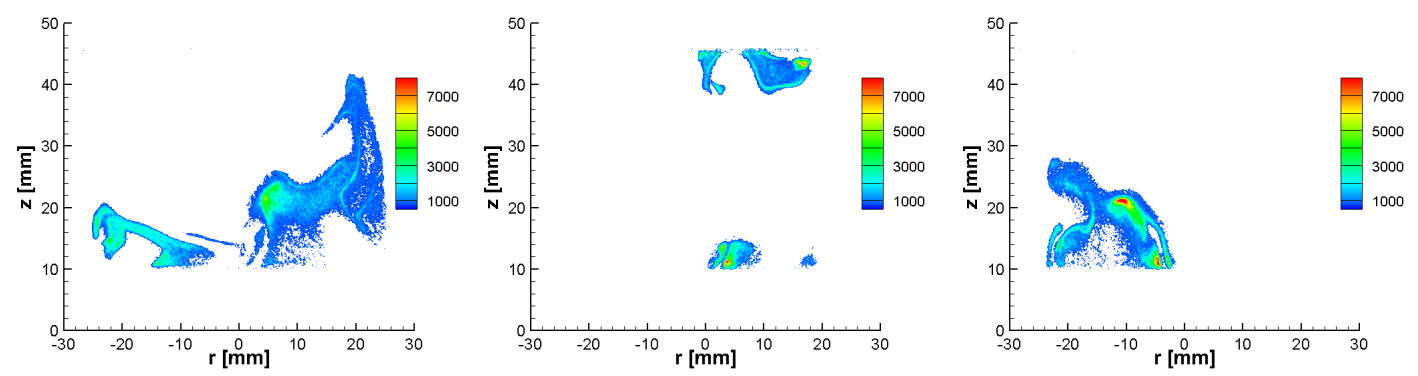

(a) Comprimento de onda de deteção: $340 \mathrm{~nm}$, sinal prompt.
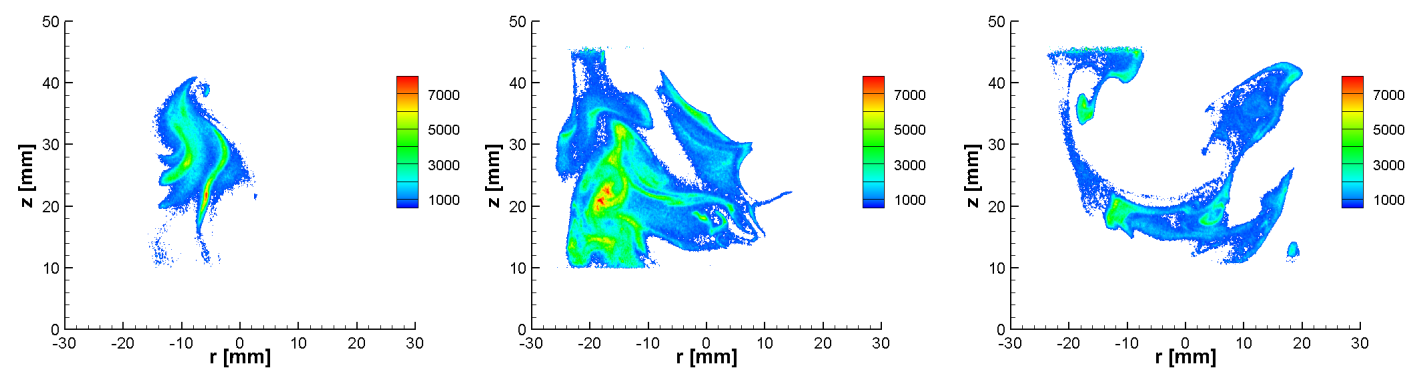

(b) Comprimento de onda de deteção: $400 \mathrm{~nm}$, sinal prompt.
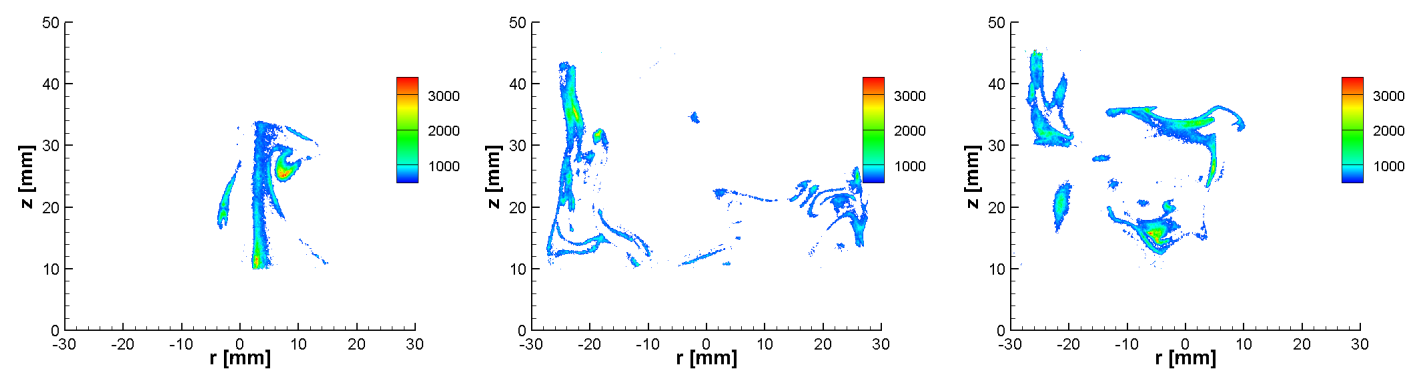

(c) Comprimento de onda de deteção: $400 \mathrm{~nm}$, sinal delay.

Figura 4.9: Estruturas instantâneas de: fuligem + HPA (sinal prompt), e fuligem (sinal delay) para o Caso A.

As estruturas instantâneas típicas do sinal combinado de HPA e fuligem, mostrados na Fig. 4.9 (a) e (b), parecem possuir maior espessura que no caso do sinal delay. As estruturas prompt (340 e $400 \mathrm{~nm}$ ) apresentam uma similitude em ordem de grandeza de suas intensidades. Estruturas finas, esticadas e espacialmente isoladas podem ser encontradas nas imagens da fuligem mostradas para o caso A, na Fig. 4.9 (c). Esta distribuição espacial intermitente na região de recirculação é atribuída à grande intensidade turbulenta nesta região de esteira turbilhonar. Observa-se que, nestas chamas turbulentas, as estruturas de HPA e fuligem estão presentes ao longo de toda a região de recirculação, dificultando a separação e individualização entre esses dois sinais. Cabe enfatizar que as estruturas instantâneas mostradas pelas imagens prompt não podem 
ser atribuídas a uma única espécie química. A dificuldade na análise do sinal prompt poderia ser superada utilizando duas câmaras ICCD sincronizadas com o pulso laser. A primeira destas capturaria o sinal prompt, e a segunda o sinal delay, pelo qual a distribuição de fuligem poderia ser individualizada do sinal conjunto HPA e fuligem com ajuda do sinal atrasado do campo de distribuição de fuligem.

As estruturas instantâneas para o caso B são mostradas na Fig. 4.10. O aumento da vazão de combustível parece incrementar a produção de fuligem na região de recirculação. Um traço do jato central de combustível pode ser observado em quase a totalidade das imagens (Fig.4.1) e para todos os comprimentos de onda aqui mostrados. As estruturas da fuligem parecem ser mais espessas que no caso A, alongadas e curvadas pela turbulência, porém, menos isoladas. As imagens do sinal combinado de HPA e fuligem, mostradas na Fig. 4.10 (a) e (b), também parecem ser mais espessas que os sinais contendo apenas fuligem (Fig. 4.10 (c)), e também ocupam um maior volume do que no caso A. Isto parece indicar uma maior produção de fuligem na região de recirculação, que será discutido na seção 4.4 .

Cabe enfatizar que, no caso A, correspondente à menor vazão de combustível, se observam estruturas filamentares de fuligem, que parecem ser distorcidas e quebradas pela turbulência. Entretanto, não se observam estrutura similares àquelas das chamas laminares de difusão. Em compensação, no caso B, de maior vazão de combustível, há uma reminiscência desta estrutura de chama de difusão nas imagens instantâneas. Esta coexiste com fragmentos de fuligem na região de recirculação. 

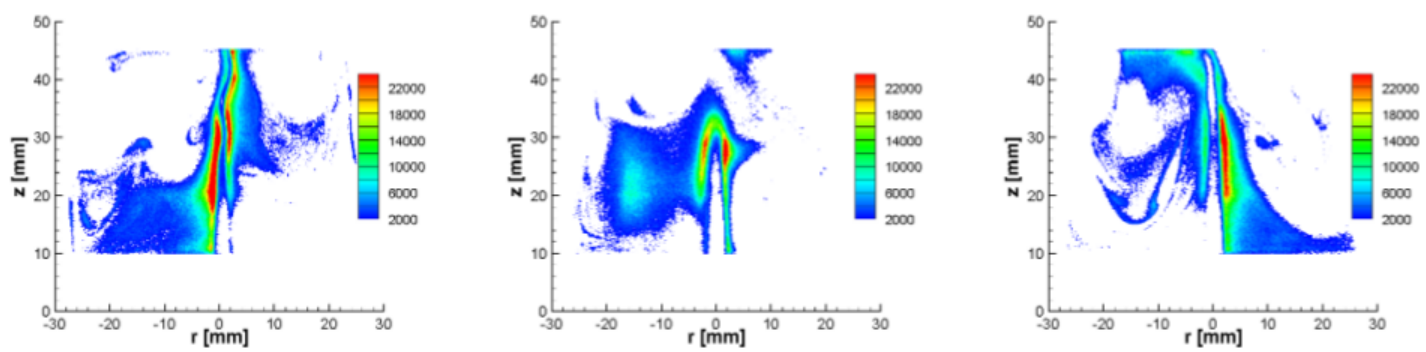

(a) Comprimento de onda de deteção: $340 \mathrm{~nm}$, sinal prompt.
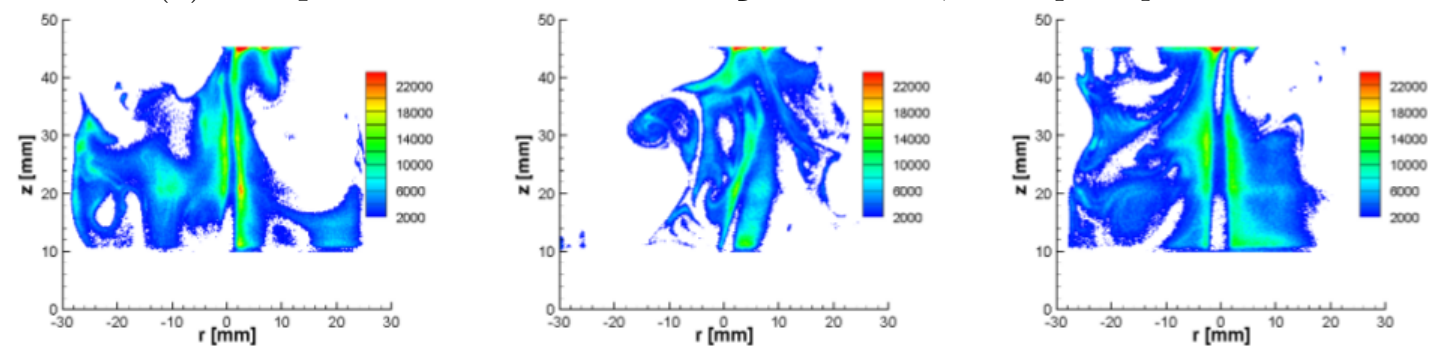

(b) Comprimento de onda de deteção: $400 \mathrm{~nm}$, sinal prompt.
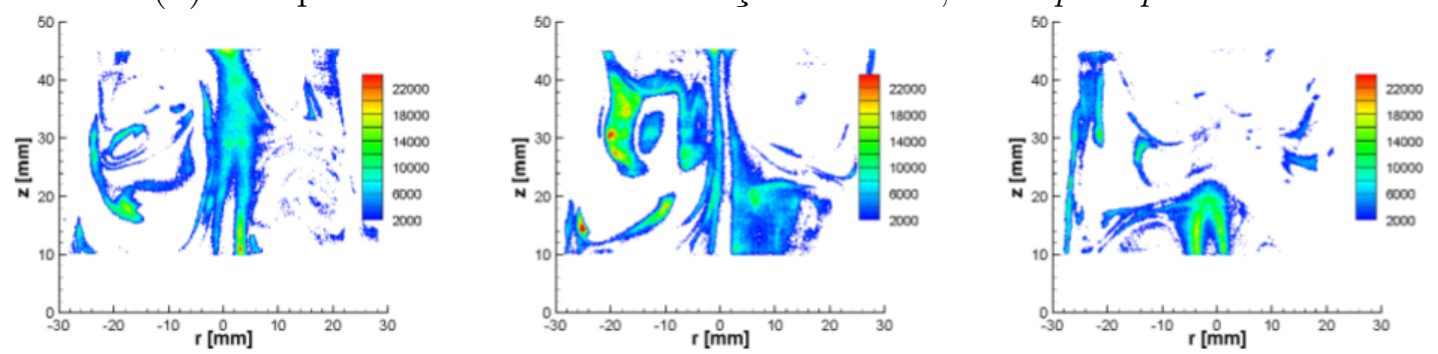

(c) Comprimento de onda de deteção: $400 \mathrm{~nm}$, sinal delay.

Figura 4.10: Estruturas instantâneas de: fuligem + HPA (sinal prompt), e fuligem (sinal delay) para o Caso B.

\section{5 \\ Intermitência}

A fim de expandir a discussão sobre a presença intermitente de fuligem, se define aqui o índice de intermitência, $\Omega(\mathrm{r}, \mathrm{z})$, como a fração de imagens onde foi encontrada algum tipo de sinal, prompt ou delay, indicando desta forma a probabilidade de observar estruturas de fuligem ou HPA. Note que esta definição é diferente da utilizada nos trabalhos de (55), onde $\Omega$ representa a probabilidade de não se observar fuligem. O valor de intermitência é calculado aqui pela média dos campos instantâneos binarizados, empregando um valor limiar acima do ruído de fundo da câmara ICCD.

Os campos de intermitência mostrados na Fig. 4.11, indicam que, para o caso A, existe uma baixa probabilidade de encontrar sinais de HPA e fuligem $(\Omega<0,5)$, quando comparadas com o caso B, Fig. 4.11 (b). Cabe notar que 
nesta figura os resultados mostrados foram "simetrizado" com relação a $r=0$, levando-se em conta apenas a partir da chama mais próxima da fonte laser $(r<0)$. Os resultados com atraso (delay) do caso A, Fig. 4.11 (a), mostram que a distribuição do índice de intermitência para a fuligem é altamente uniforme na região de medição $(\Omega<0,5)$, indicando uma probabilidade relativamente baixa de encontrar fuligem em qualquer ponto e instante. O baixo valor de $\Omega$ justifica a necessidade de se medir 4.000 imagens, de forma a se obter momentos estatísticos significativos da presença de fuligem. No entanto, para os sinais prompt, é possível verificar que a distribuição do índice de intermitência é significativamente diferente para os dois comprimentos de onda utilizados (340 e $400 \mathrm{~nm})$. De fato, para o maior comprimento de onda, $400 \mathrm{~nm}$, uma distribuição quase uniforme, com $\Omega=0,4$, é encontrada na parte inferior da região de medição, já para a deteç̧ão de $340 \mathrm{~nm}$ é observada uma estrutura lobulada.
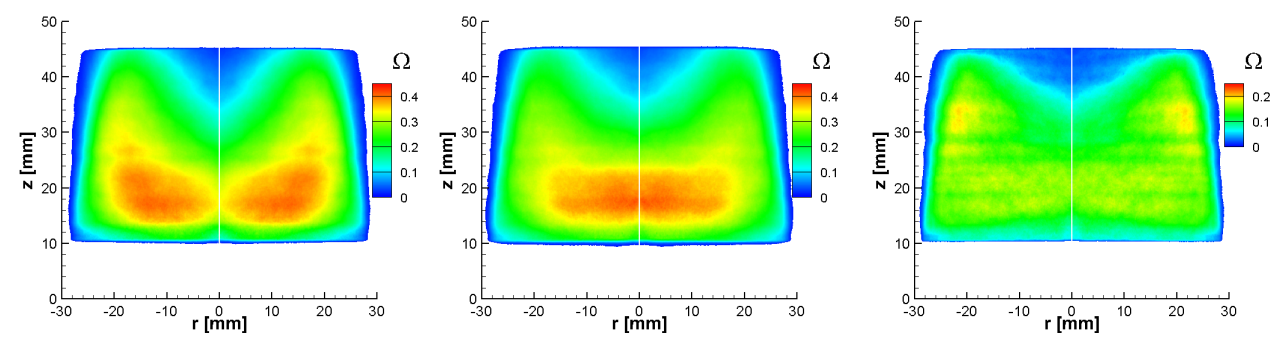

(a) Campo médio de intermitência para o Caso A.
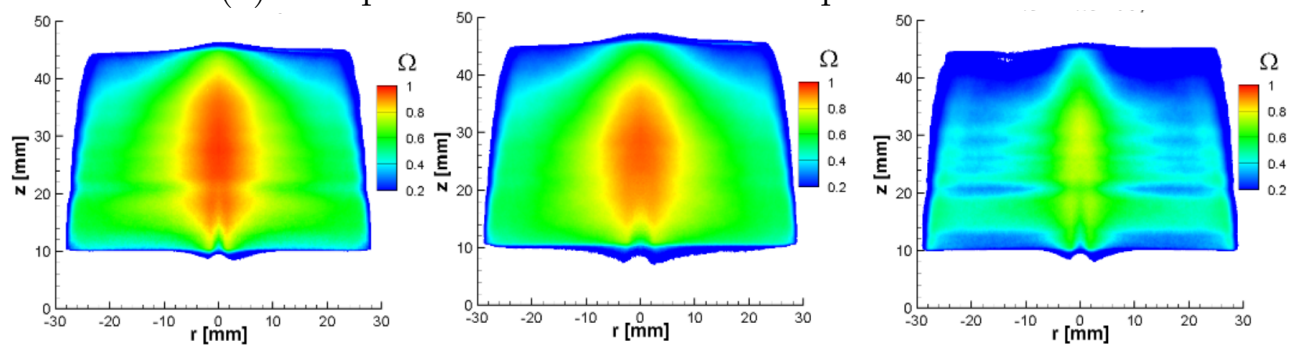

(b) Campo médio de intermitência para o Caso B.

Figura 4.11: Distribuição do indíce de intermitência da fuligem $(\Omega)$ para chamas de etileno/ar estudadas nos comprimentos de deteção de i) esquerda: $340 \mathrm{~nm}$ prompt, ii) centro: $400 \mathrm{~nm}$ prompt e iii) direita: $400 \mathrm{~nm}$ delay.

Como foi observado nas imagens instantâneas do caso B, Fig. 4.11 (b), quase sempre se observam estruturas ao redor do jato central para todos os comprimentos de onda. Consequentemente, o campo de intermitência nesta região mostra uma distribuição com elevado indíce na região do jato $(\Omega \approx 1)$, que decai no sentido radial da borda externa da região de recirculação $(\Omega \approx 0,6)$. No caso da imagem média delay, na qual se observa apenas a intermitência da 
fuligem, o valor de $\Omega$ é de 0,4 na região intermediária entre o jato e a borda da região de recirculação.

\section{6}

\section{Distribuição Espacial Média da Fuligem e de HPA}

Os campos médios das 4000 imagens instantâneas obtidas para cada caso e todos os comprimentos de onda de deteção são mostrados na Fig. 4.12. As faixas de descontinuidade nestes campos médios, $20<\mathrm{z}<30 \mathrm{~mm}$, são atribuídas à distribuição irregular da energia da plano laser (ver seção 4.3). Para ambos casos, comparando os resultados de detecção simultâneos e atrasados no comprimento de onda de $400 \mathrm{~nm}$, pode-se observar uma distribuição espacial bastante similar, mas com diferentes intensidades devido ao decaimento temporal do sinal medido. Cabe enfatizar que se espera que os campos do sinal delay representem apenas a emissão de fuligem, ao passo que o sinal prompt corresponda à combinação de fuligem e fluorescência de HPA. Uma análise destes resultados sugere que, por não se observar regiões onde há apenas fuligem, não é possível individualizar o sinal das espécies de HPA nos campos prompt, a partir do sinal de fuligem, tal como o que foi feito no caso de chamas laminares (41). Ainda assim, esta figura mostra que uma diferença significativa existe entre as duas chamas estudadas (caso A e B) e entre cada um dos sinais medidos. 

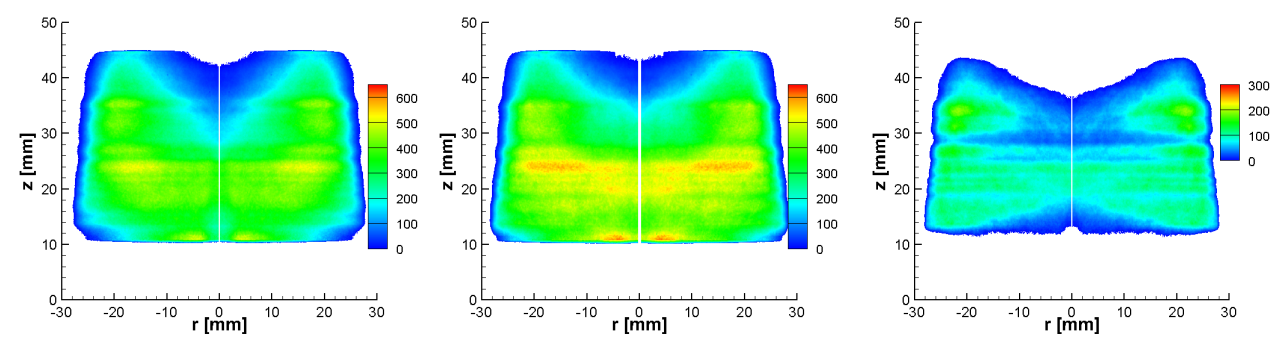

(a) Campo médio dos sinais de LII e HPA para o Caso A.
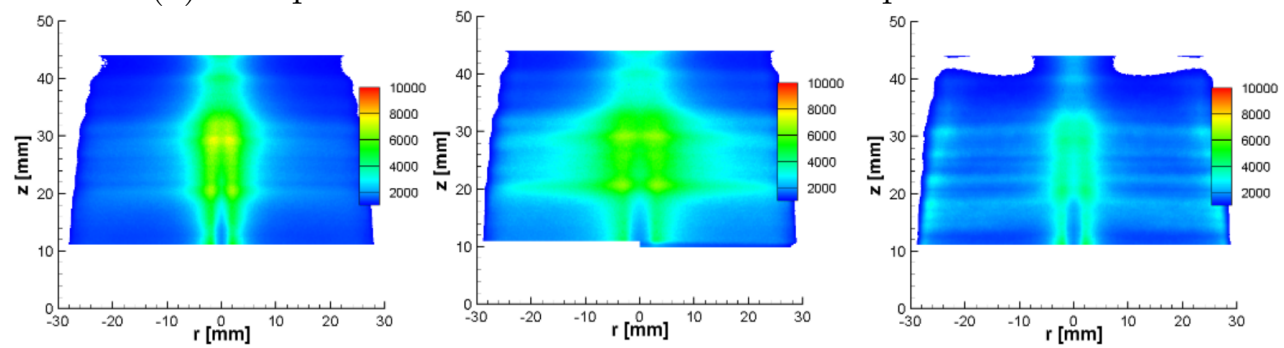

(b) Campo médio dos sinais de LII e HPA para o Caso B.

Figura 4.12: Distribuição do sinal médio das estruturas de fuligem + HPA para as chamas de etileno/ar nos sinais prompt e delay nos comprimentos de deteção i) esquerda: $340 \mathrm{~nm}$, ii) centro: $400 \mathrm{~nm}$ prompt e iii) direita: $400 \mathrm{~nm}$ delay.

A fim de se obter uma descrição mais detalhada da distribuição de fuligem na chama, um corte transversal do sinal em três alturas escolhidas $(z=[16,9$, $23,2,33,5] \mathrm{mm}$ para o caso A e $z=[32,37,42] \mathrm{mm}$ para o caso B) é apresentado nas Figs. 4.134 .14 e 4.15 para os dois casos. Note-se que estas alturas foram escolhidas por corresponderem à um mesmo valor médio de energia do feixe laser, tal como exposto na seção 4.3. Contrariamente aos resultados mostrados nas Figs. 4.11 e 4.12, aqui optou-se por não "simetrizar" os perfis em torno de $r=0$, o que permite apreciar a assimetria dos resultados. Esta assimetria pode ser atribuída à atenuação do feixe laser pelo campo de partículas de fuligem. 

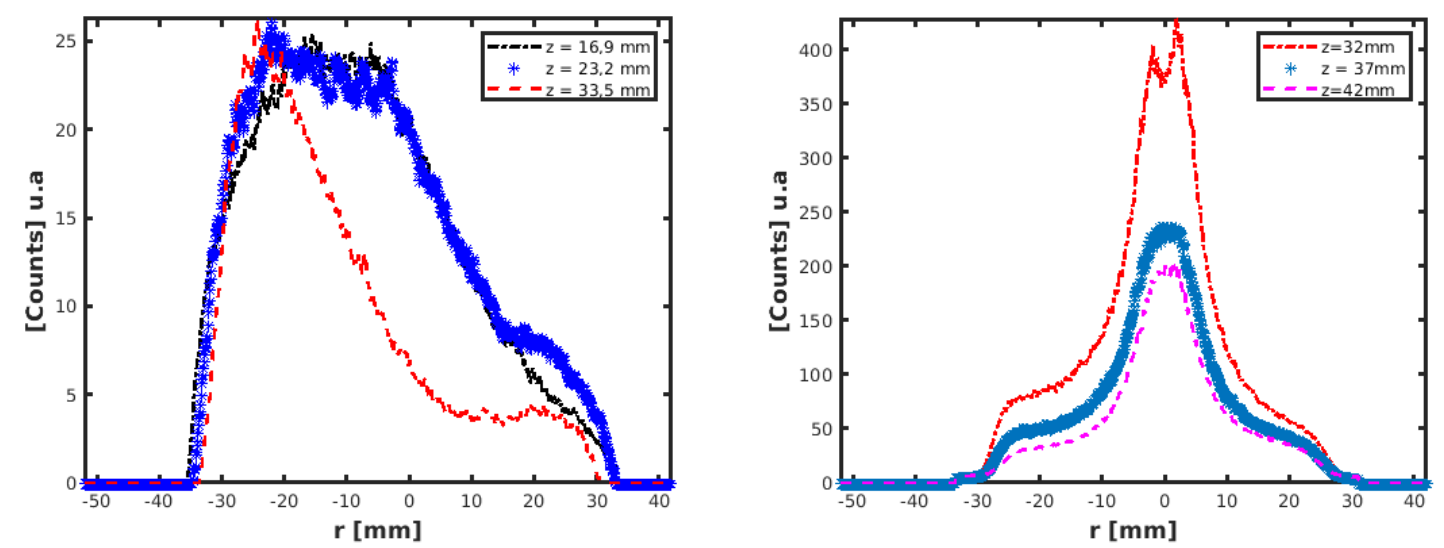

Figura 4.13: Distribuição radial do sinal de fuligem + HPA para as chamas de etileno/ar medidos em $340 \mathrm{~nm}$ prompt para i) esquerda: Caso A e ii) direita: Caso B.
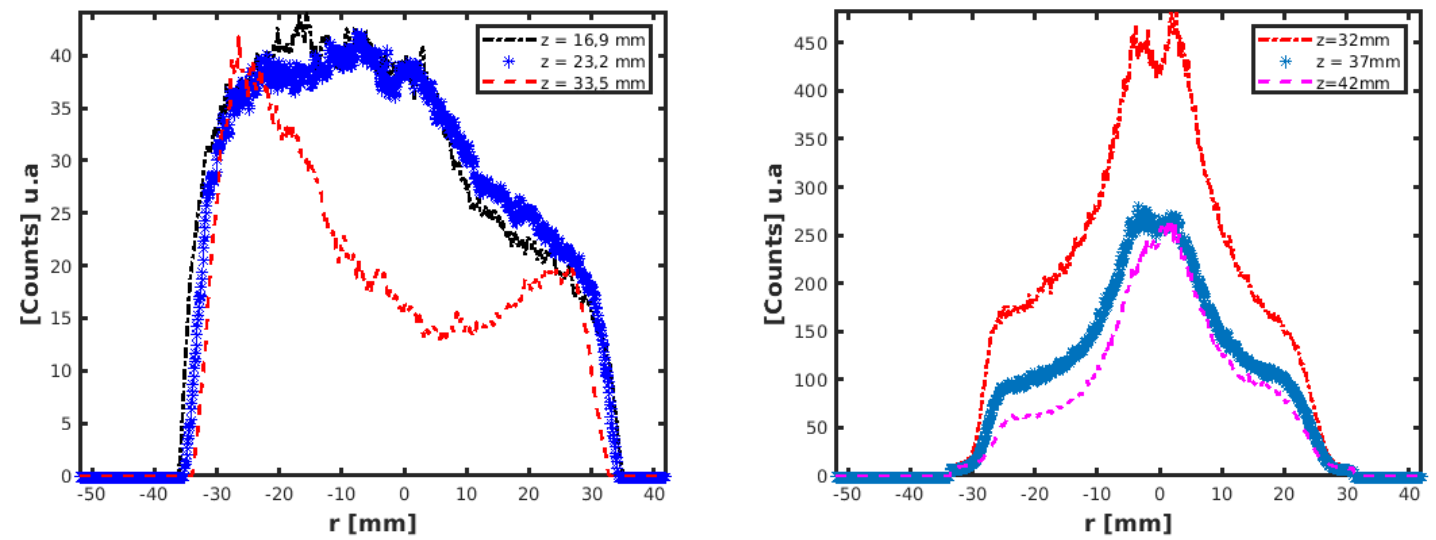

Figura 4.14: Distribuição espacial do sinal de fuligem + HPA para as chamas de etileno/ar nos sinais de $400 \mathrm{~nm}$ prompt para i) esquerda: Caso A e ii) direita: Caso B. 

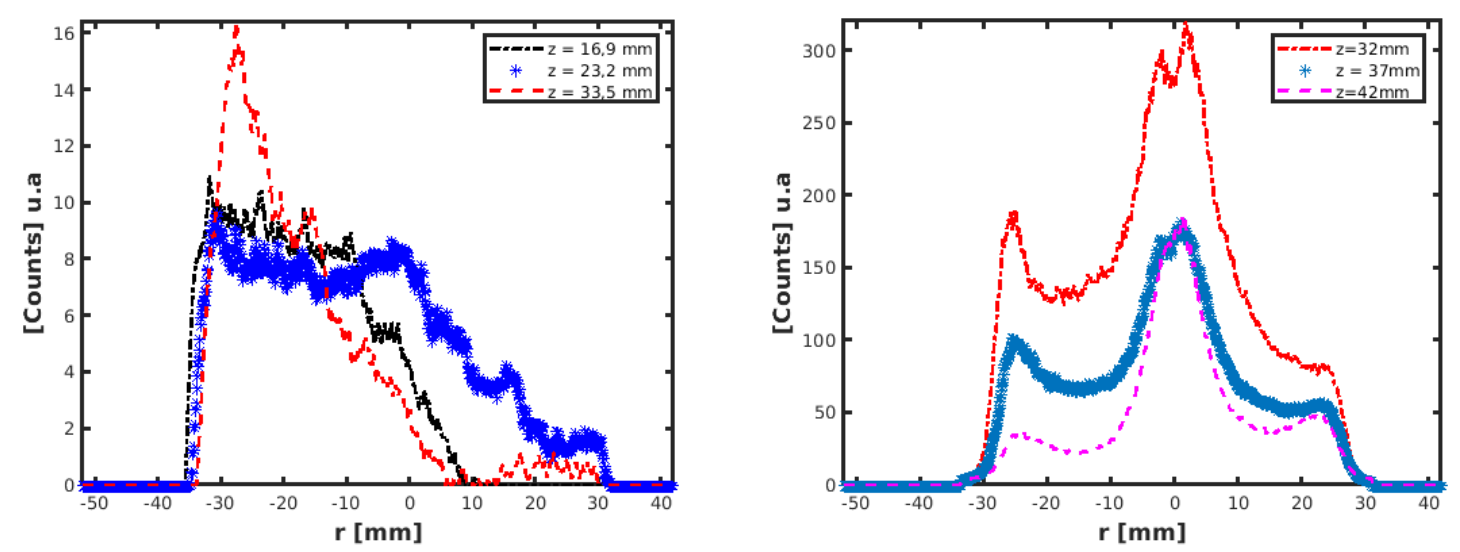

Figura 4.15: Distribuição espacial do sinal de fuligem para as chamas de etileno/ar nos sinais de $400 \mathrm{~nm}$ delay para i) esquerda: Caso A e ii) direita: Caso B.

A Fig. 4.13 apresenta a distribuição espacial do sinal médio LII de fuligem e HPA para o comprimento de onda de deteção de $340 \mathrm{~nm}$ prompt para o caso A (esquerda) e caso B (direita) em três alturas distintas. Os resultados correspondentes às detecções em $400 \mathrm{~nm}$ prompt e delay são mostrados na Fig. 4.14 e 4.15, respectivamente. Uma análise destas figuras corrobora as tendências observadas acima. Além disto, percebe-se que para o Caso A, os sinais prompt em $z=16,9$ e 23,2 mm são praticamente idênticos, o que sugere idêntica distribuição de HPA e fuligem. Uma tendência diferente é observada na altura mais elevada $(z=33,5 \mathrm{~mm})$, que apresenta um decréscimo do sinal entre $r=-30 \mathrm{~mm}$ e $r=0$. Isto pode indicar que a oxidação da fuligem é iniciada na vizinhança de $r=0$ devido ao arraste de ar pela chama, tal como sugerido pela Fig. 3.9.

No tocante ao caso B, uma simetria é observada para todos os comprimentos de onda. Comparando-se os resultados prompt em ambos os comprimentos de onda, também não é possível identificar uma diferença significativa associada à detecção em diferentes $\lambda$. O sinal medido é maior na vizinhança da superfície do bluff-body $(z=32 \mathrm{~mm})$ e nas imediações do jato central, e decresce no sentido da região de recirculação e das maiores alturas. Neste caso, as maiores diferenças são observadas quando da deteção delay (sinal de fuligem), cujos resultados são mostrados na Fig. 4.15. Se por um lado ocorre uma redução do sinal com a altura, o que é semelhante aos observados para os HPA, por outro observa-se um máximo local nas imediações da borda do bluff-body $(|\mathrm{r}| \approx 25 \mathrm{~mm})$. A presença deste máximo local sugere que ocorre uma produção de fuligem na borda da chama, distante do jato central. As razões pelas quais esta produção ocorre não puderam ser identificadas e necessitam de 
uma medida da temperatura de fuligem, por exemplo, empregando a técnica de pirometria de duas cores (41). É possível que fragmentos de hidrocarbonetos não queimados transportados pela turbulência da região do jato de combustível para a borda do queimador provoquem uma liberação de calor localizada quando em contato com o ar do co-fluxo. O aumento de temperatura associado poderia explicar esta maior produção de fuligem.

\section{7}

\section{Função Densidade Probabilidade (PDF) da Distribuição de Fuligem}

Nesta seção são apresentados os resultados da análise estatística da distribuição da fuligem. Para este fim foram utilizadas 4000 amostras obtidas realizando-se a média espacial em janelas de $10 \times 10$ pixels $([2,7 \mathrm{~mm} \times 2,7 \mathrm{~mm}])$ ao longo do raio, $r=[-24,-12,0] \mathrm{mm}$, e na direção axial, $z=[16,28,36] \mathrm{mm}$, tal como o mostrado na Fig. 4.16. Estes pontos, horizontais, foram escolhidos para caracterizar a região intermediária da chama. A partir destas amostras são analisados, a seguir, os histogramas e as função densidade de probabilidade correspondentes.

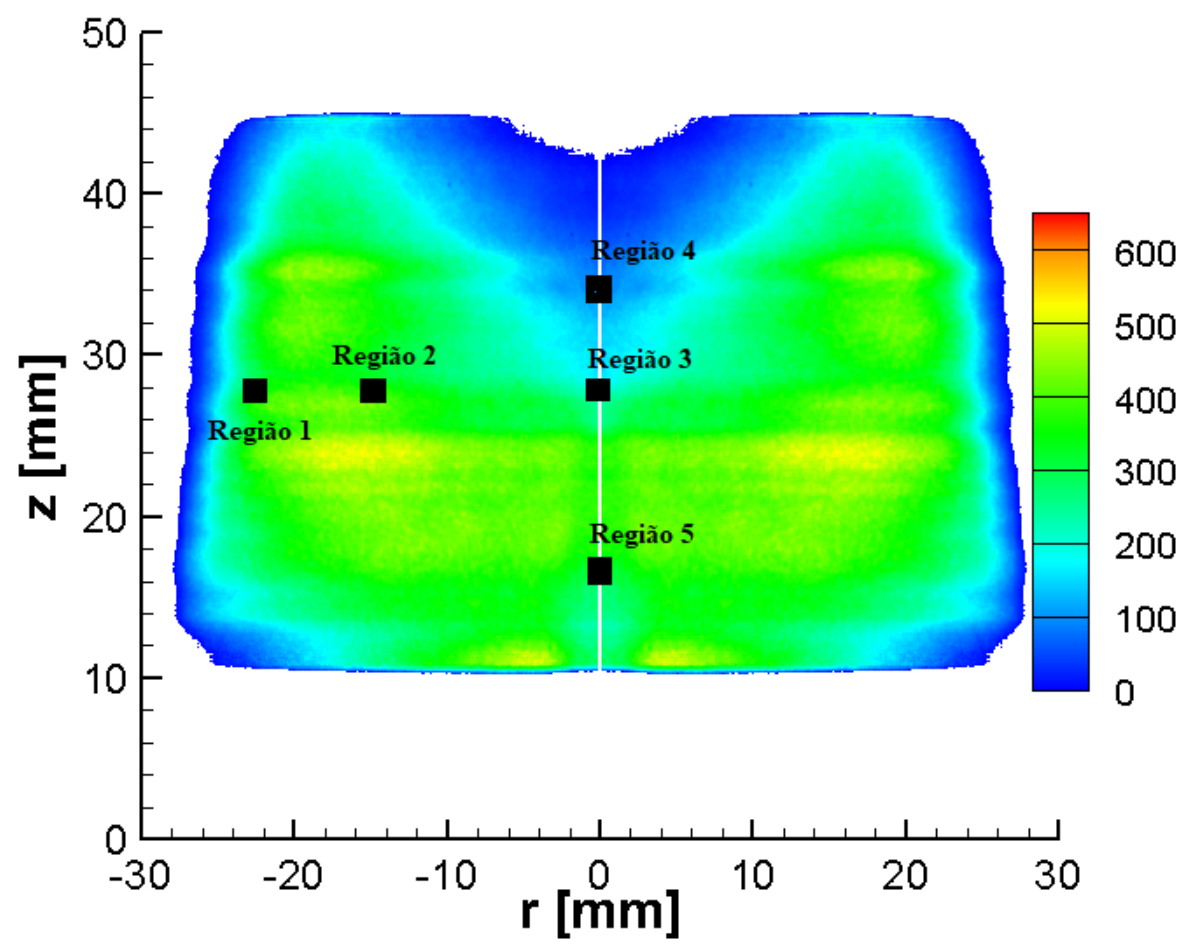

Figura 4.16: Esquema representativo das regiões de análise $(1,2,3,4$ e 5) em janelas $10 \times 10$ pixel nas linhas centrais da chama, $z=[16,28,36] \mathrm{mm}$ e $r=[-24,-12,0] \mathrm{mm}$. 


\subsection{1}

\section{Distribuição de Probabilidade Medida}

A Fig. 4.17 apresenta a dispersão do sinal delay $400 \mathrm{~nm}$, somente para as amostras de sinais de incandescência positivos não nulos, para os casos estudados, na zona de esteira da chama, na altura $z=28 \mathrm{~mm}$. Esta figura indica que, nos regimes escolhidos, a presença de fuligem dentro da zona de recirculação é intermitente, e que há uma grande probabilidade de se ter uma baixa fração volumétrica de fuligem nas diferentes regiões na chama (ver seção 4.4). É possível, também, que observar uma grande quantidade de fuligem é um evento raro. Mais ainda, é possível corroborar os resultados das imagens instantâneas e das imagens médias quanto a presença de fuligem na chama. A Fig.4.17 para o caso B na região $3(\mathrm{r}=0,06 \mathrm{~mm})$ da linha central do jato, apresenta um aumento significativo na dispersão do sinal LII das partículas, onde o número de amostras apresentadas, para valores de $S_{L I I}$ positivos e não nulos, é quase duas vezes maior do que no caso A.
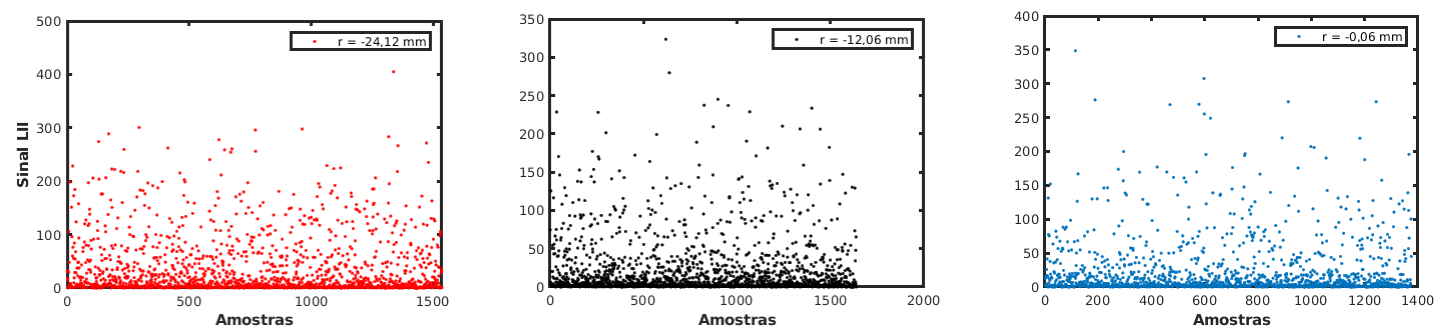

(a) Caso A.
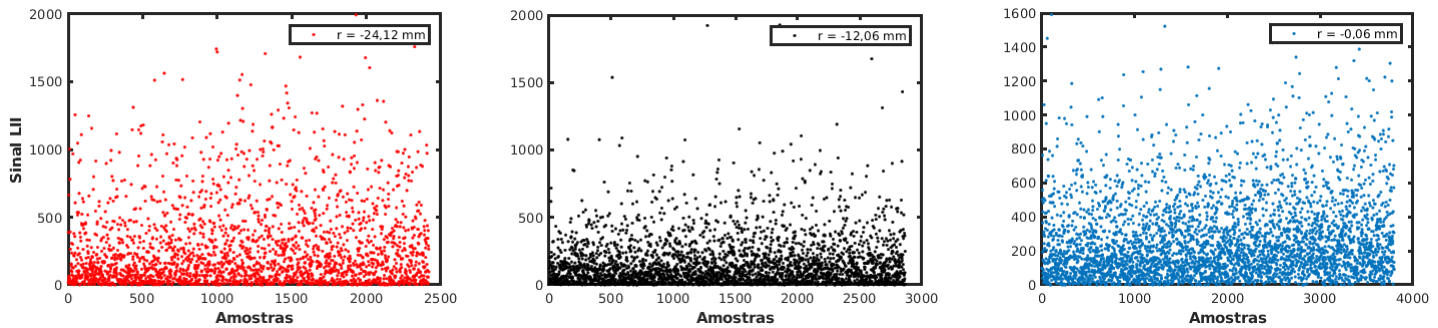

(b) Caso B.

Figura 4.17: Dispersão do sinal medido na zona de esteira para os casos estudados, $400 \mathrm{~nm}$ delay.

A fim de ampliar a análise da intermitência, as Figs. 4.18 e 4.19 apresentam os histogramas da distribuição do sinal LII $400 \mathrm{~nm}$ delay (que mostram somente fuligem, ver seção 4.4) nas regiões de esteira e na linha central do jato combustível, respectivamente, para o caso A. Os histogramas consolidam, assim, os resultados da dispersão apresentada na Fig. 4.17. Estas figuras permitem confirmar que há uma probabilidade muito baixa de se ter altos valores 
de sinal LII, e, também, uma probabilidade alta de se observar baixos valores de sinal de incandescência, $S_{L I I}$, de fuligem, indicando um baixo valor instantâneo de fração volumétrica de fuligem nesta região, de forma consistente nas cinco posições medidas.
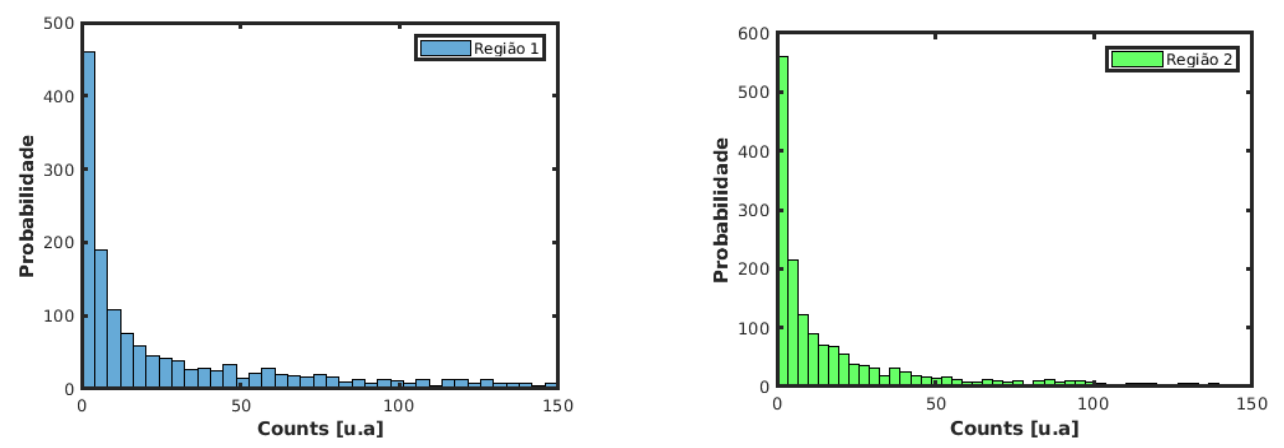

Figura 4.18: Histogramas da distribuição do sinal LII na zona de esteira para o Caso A.
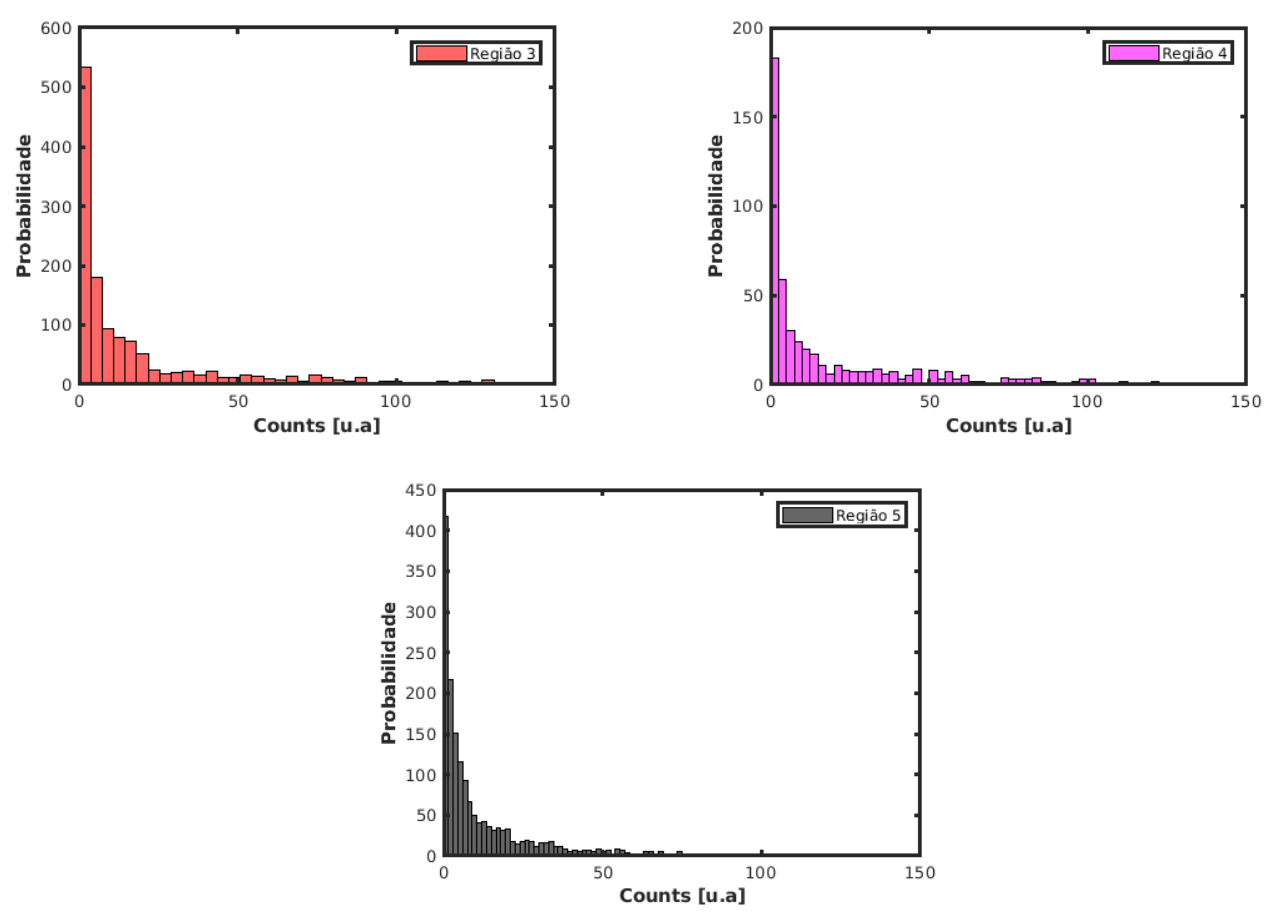

Figura 4.19: Histogramas da distribuição do sinal LII na linha central do jato para o Caso A.

Na Fig. 4.20, são apresentados os histogramas da distribuição do sinal LII $400 \mathrm{~nm}$ delay nas regiões de esteira do caso B. Assim como no caso A, a distribuição apresentada indica que, na zona de esteira, a forma da distribuição 
de probabilidade da presença de fuligem é similar nos dois casos estudados. Isto sugere que os mecanismos físico-químicos que controlam a presença de fuligem são similares.
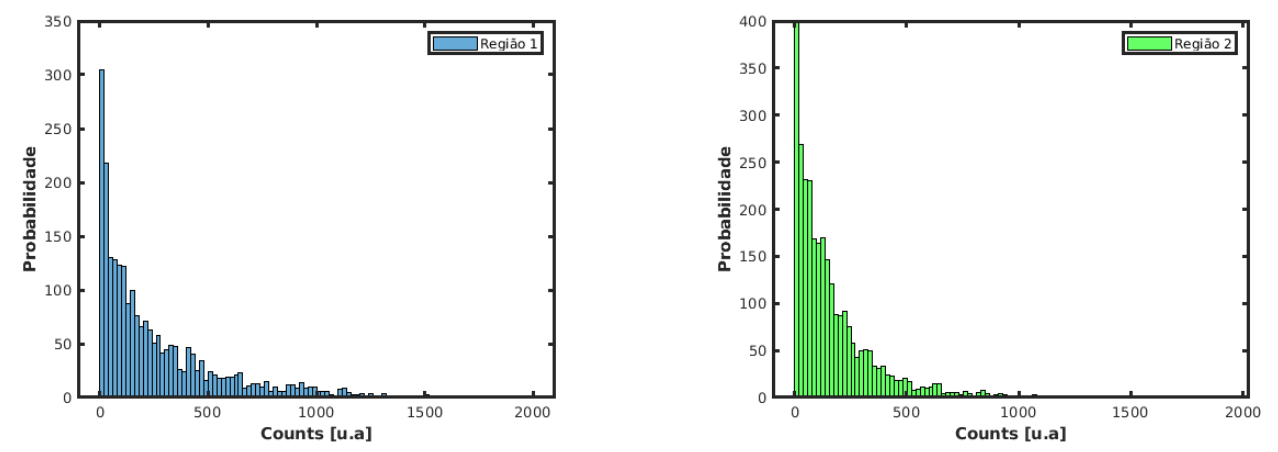

Figura 4.20: Histogramas da distribuição do sinal LII na zona de esteira para o Caso B.

Os histogramas de distribuição do sinal LII para a linha central $(r=0$, jato combustível) do caso B mostrados na Fig. 4.21. O comportamento nesta linha central se distingue dos outros aqui apresentados, pois observa-se que sua distribuição é não monotônica. Isto é consistente com a presença de uma estrutura deterministíca no escoamento, tal como a reminescência de uma chama de difusão (ver seção 4.4). A presença desta estrutura determina, então, a existência de um valor máximo de probabilidade para um número de counts e, logo, um valor de função volumétrica de fuligem maior do que zero. 

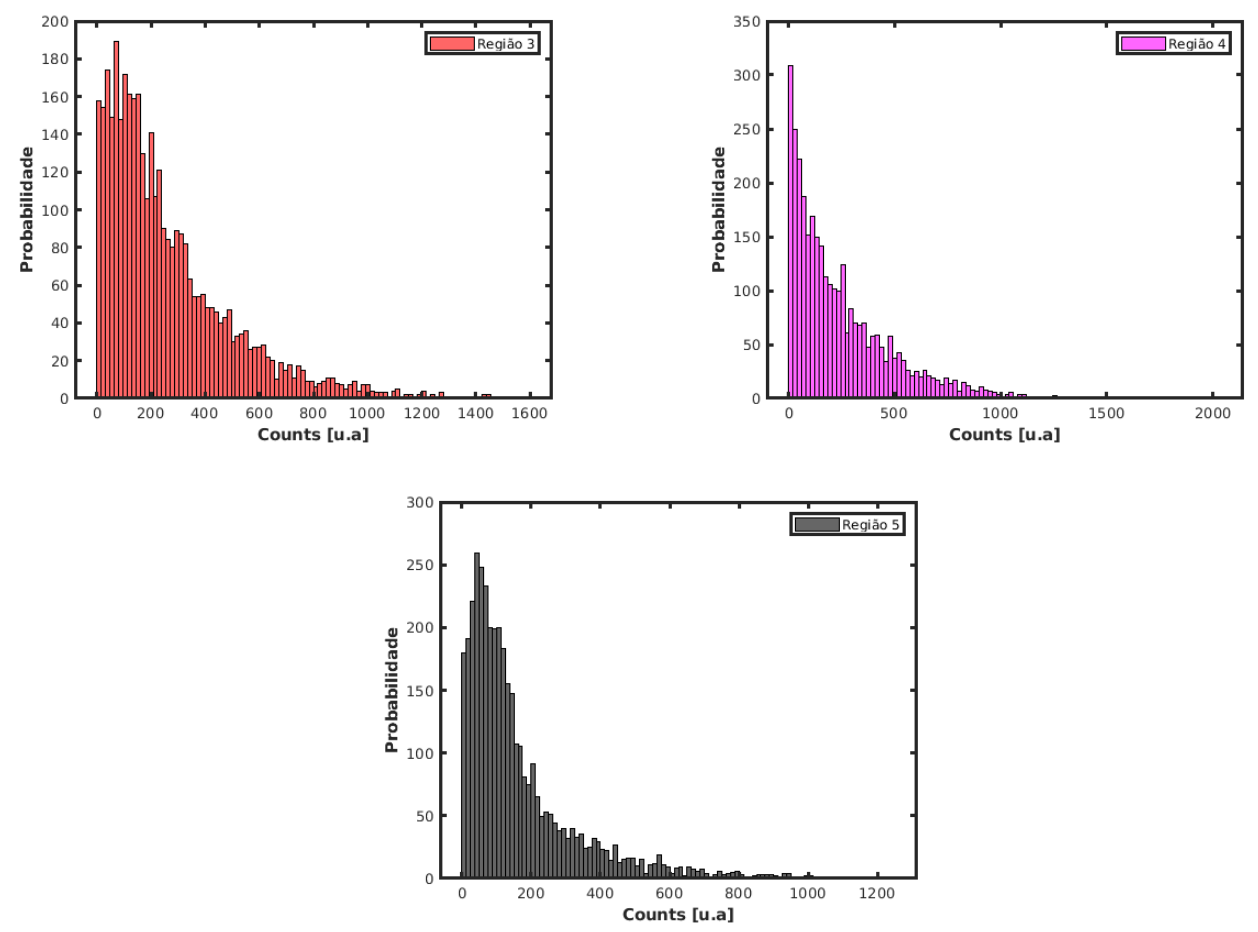

Figura 4.21: Histogramas da distribuição do sinal LII na linha central do jato para o Caso B.

Os histogramas dos casos estudados indicam que pode haver um comportamento subjacente dos dados medidos. Em todas as regiões no caso A e na região de vórtice, no caso $\mathrm{B}$, estes histogramas apresentam um comportamento fortemente decrescente. A compreensão desta estrutura estocástica da distribuição de fuligem requer uma análise mais aprofundada, o que é feito a seguir.

\subsection{2}

\section{Análise Paramétrica da PDF}

A análise dos histogramas na seção anterior sugere que a distribuição dos dados medidos pode ser representada por uma distribuição de probabilidade paramétrica. Buscou-se aproximar esta distribuição medida por diferentes PDFs (gaussiana, exponencial, weibull, etc.), e a forma Lognormal é a que melhor descreve as observações. Os resultados destas aproximações mal sucedidas não são mostrados aqui por serem demasiadamente discrepantes.

A fim de ilustrar este comportamento, a Fig. 4.22 apresenta os quantis dos dois casos estudados na zona de esteira. É possível observar que o conjunto de amostras do caso A aproxima-se bem de uma distribuição lognormal, com seus extremos ligados pelo primeiro e terceiro quartis. Ocorre uma divergência entre a curva de dados e a extrapolação para valores teóricos altos da Lognormal. 
Esta divergência poderia ser explicada pela necessidade de medição de um maior conjunto de dados, pois a lognormal converge mais lentamente para zero do que o conjunto de dados com 4000 amostras aquisitadas. Outra explicação possível é que os grandes valores de $S_{L I I}$, que ocorrem com baixa probabilidade, sejam caracterizados por um comportamento menos universal do que o sugerido pela distribuição Lognormal. De fato, este tipo de distribuição é encontrada, também, nas pequenas escalas do movimento turbulento (48).

Assim, os resultados obtidos sugerem que poderia haver uma similitude entre as menores estruturas de fuligem e o campo de movimento turbulento. Em outras palavras, a distribuição de $\bar{f}_{v}$ acontece em cascata, das maiores escalas para as menores escalas, como é previsto para o movimento turbulento pela teoria de Kolmogorov (48). Os resultados dos quantis na zona de esteira para o caso B apresentados na Fig. 4.22 (b) mostram um desvio da distribuição de fuligem em relação a distribuição Lognormal. Este caso merece uma análise um pouco mais minuciosa, não feita aqui.
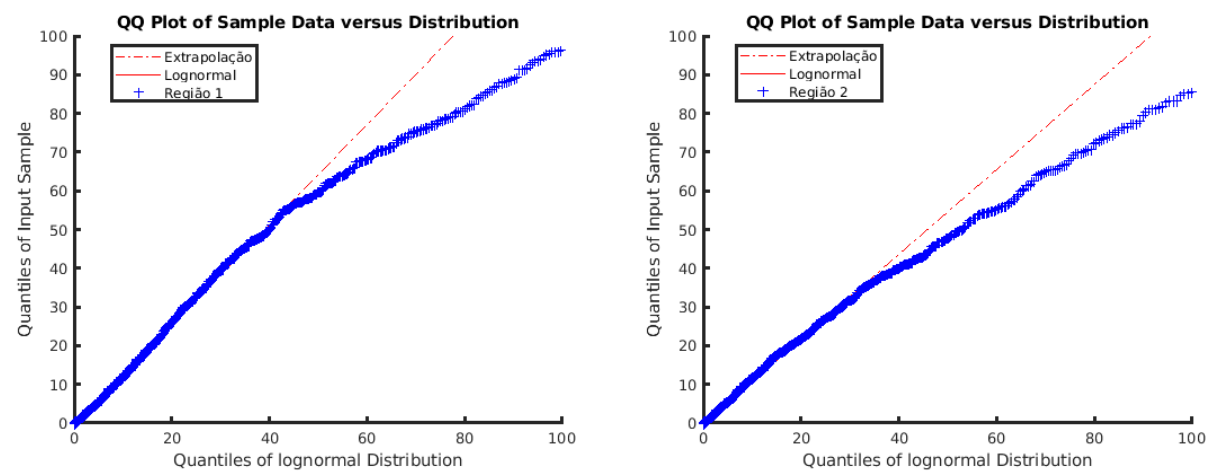

(a) Caso A.
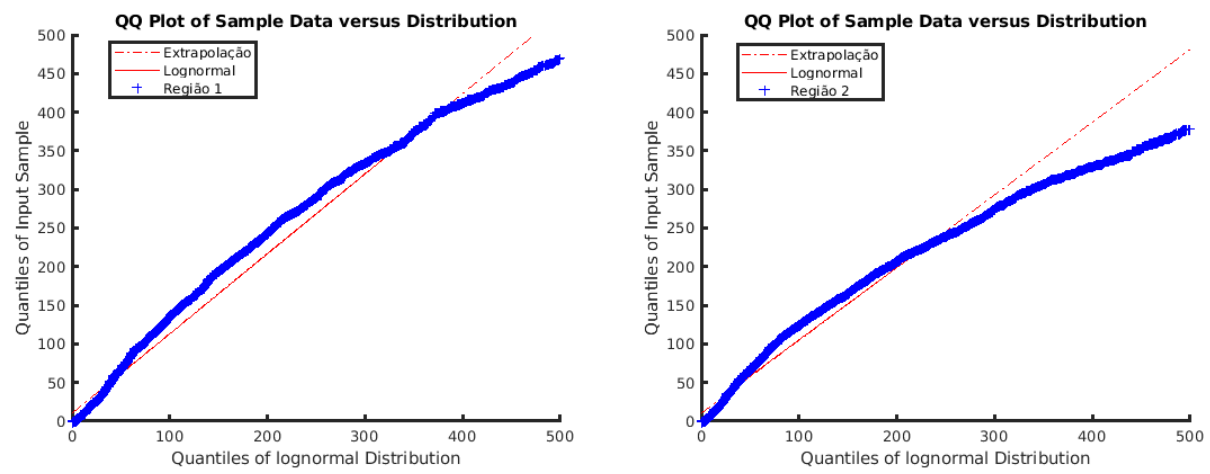

(b) Caso B.

Figura 4.22: Quantis da função de distribuição de probabilidade da fuligem em $400 \mathrm{~nm}$ delay na zona de esteira para os casos estudados.

Os resultados de estatísticas aqui apresentados concomitam para a re- 
presentação do comportamento da distribuição de fuligem por uma função densidade probabilidade lognormal para o caso A. Na Fig. 4.23, é apresentada a PDF obtida a partir da estimativa paramétrica das medidas obtidas nas cinco regiões de interesse estudadas. Esta figura consolida os histogramas apresentados acima, e também os resultados reportados na Tabela 4.5, ilustrando as diferentes distribuições de probabilidade observadas.

Enfim, as Tabelas 4.5 e 4.6 apresentam, para fins de referência, os valores das médias e desvios padrões calculados nas 5 regiões de análise definidos na Fig. 4.16 .

Tabela 4.5: Médias e desvios padrão aritmética e logarítmica das regiões 1, 2, 3, 4 e 5 estudadas para o Caso A.

\begin{tabular}{|c|c|c|c|c|}
\hline \multicolumn{5}{|c|}{ Caso A } \\
\hline Região & $S_{L I I}[\mathrm{u} . \mathrm{a}]$ & $\sigma_{L I I}$ & $\log _{S_{L I I}^{-}}[\mathrm{u} . \mathrm{a}]$ & $\log _{\sigma_{L I I}}$ \\
\hline 1 & 64,49 & 39,67 & 2,65 & 1,24 \\
2 & 59,57 & 28,02 & 3,89 & 0,45 \\
3 & 58,16 & 28,38 & 0,83 & 1,75 \\
4 & 51,97 & 14,91 & 2,83 & 1,02 \\
5 & 55,55 & 15,13 & 2,00 & 1,09 \\
\hline
\end{tabular}

Tabela 4.6: Médias e desvios padrão aritmética e logarítmica das regiões 1, 2, 3, 4 e 5 estudadas para o Caso B.

\begin{tabular}{|c|c|c|c|c|}
\hline \multicolumn{5}{|c|}{ Caso B } \\
\hline Região & $S_{L I I}[\mathrm{u} . \mathrm{a}]$ & $\sigma_{L I I}$ & $\log _{S_{L I I}^{-}}[\mathrm{u} . \mathrm{a}]$ & $\log _{\sigma_{L I I}}$ \\
\hline 1 & 236,5 & 276,8 & 4,15 & 1,28 \\
2 & 196,2 & 183,0 & 3,95 & 1,21 \\
3 & 328,0 & 238,2 & 5,26 & 0,77 \\
4 & 280,2 & 247,1 & 4,83 & 0,97 \\
5 & 236,7 & 169,7 & 4,76 & 0,84 \\
\hline
\end{tabular}




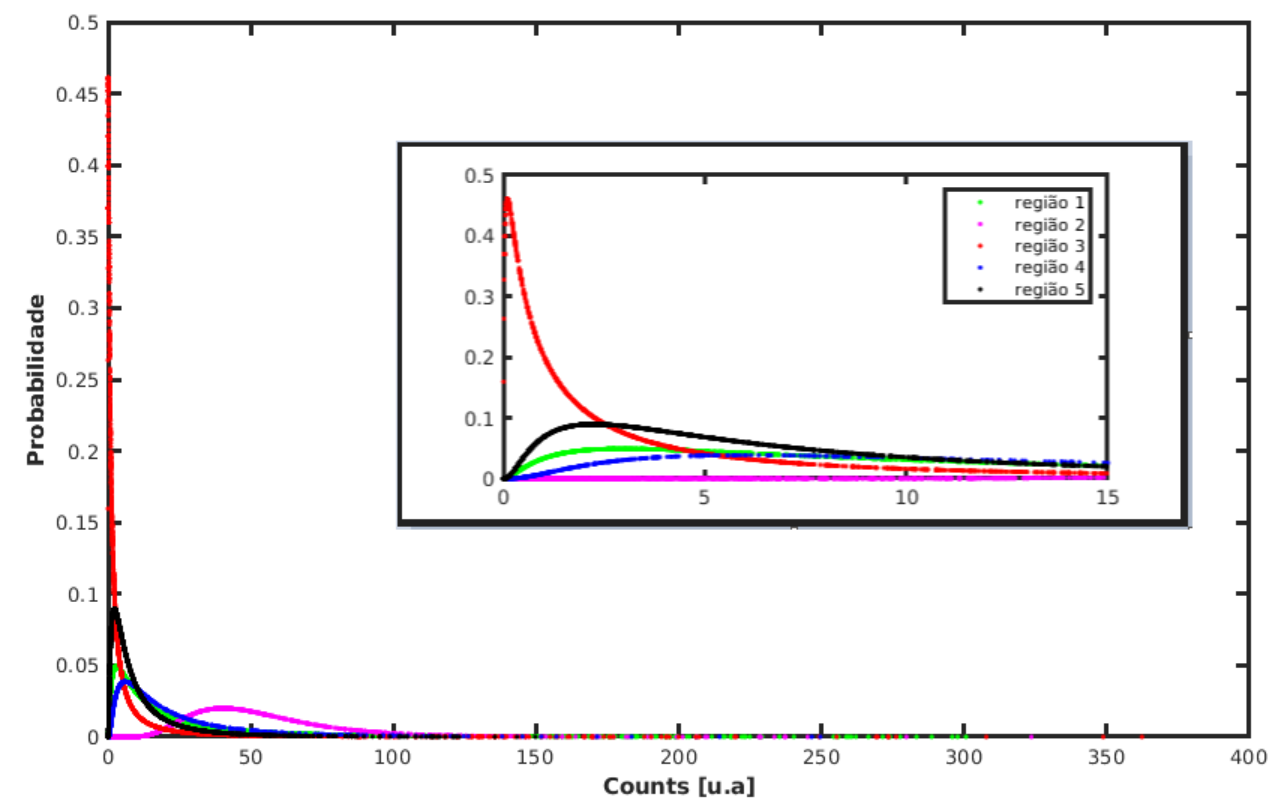

Figura 4.23: Função densidade probabilidade da distribuição de fuligem, sinal $400 \mathrm{~nm}$ delay, nas regiões apresentadas na Fig. 4.16 para o Caso A. 


\section{Conclusões e Perspectivas}

Neste trabalho, foram apresentados os principais resultados experimentais obtidos na caracterização da distribuição da estrutura de fuligem em chamas turbulentas de etileno e ar num queimador do tipo bluff-body. Para este fim, as medidas realizadas no presente estudo empregaram as técnicas de diagnóstico laser, incandescência induzida por laser e extinção da luz. A distribuição de fuligem e de HPA foi evidenciada pela detecção em duas bandas espectrais.

As principais conclusões do estudo são:

- A fração volumétrica de fuligem integral foi medida. Observou-se que, em alturas mais baixas da chama (proximo a saída do jato combustível), a extinção do laser é quase completa, o que sugere uma maior concentração de fuligem nessa região. De fato, foi encontrado maior valor de fração volumétrica de fuligem nessa região (1 ppm). O alto carregamento de fuligem pela chama e a mudança frequente da espessura do caminho óptico são responsáveis pela atenuação intermitente do laser.

- O campo médio de intermitência dos dois casos estudados mostrou que uma maior concentração das partículas de fuligem e HPA ocorre na direção radial ao redor do jato central com o aumento da vazão, sugerindo um maior valor da fração volumétrica de fuligem. De fato, o incremento da distribuição espacial da fuligem repercutiu num grande incremento do índice de intermitência.

- A análise estatística do caso de menor vazão de combustível mostrou que a distribuição de fuligem obtida é melhor parametrizada pela distribuição lognormal. Isto indica que o processo que gera fuligem acontece em cascata das maiores escalas para menores escalas do movimento turbulento. No caso de maior vazão de combustível, para o qual existe uma reminiscência de estrutura de chama laminar, não foi possível identificar uma distribuição de probabilidade paramétrica que aproxime as medições.

As principais perspectivas abertas pelo presente estudo são:

- Determinar a correlação entre $f_{v}$ e HPA, individualizando o sinal de HPA através da relação entre os sinais de prompt (HPA + fuligem) e delay (fuligem). 
- Utilizar ferramentas de estatísticas para investigar mais a fundo as funções densidade de probabilidade medidas, de modo a apoiar a criação de novos modelos.

- Utilizar outras técnicas de diagnóstico disponíveis no laboratório (velocimetria de imagem de partículas, PLIF do radical $\mathrm{OH}$ ) para realizar uma caracterização mais completa do processo de formação de fuligem. 


\section{Referências bibliográficas}

[1] MINISTÉRIO DE MINAS E ENERGIA. Balanço energético nacional, Ano Base 2017, Disponivel em: < https : //ben.epe.gov.br/ >, Acesso em: 13 de Maio de 2018

[2] MINISTÉRIO DO MEIO AMBIENTE. Conselho nacional do meio ambiente, Resolução № 382, de 26 de Dezembro de 2006, Disponivel em: < http : //www2.mma.gov.br/port/conama/res/res06/res38206.pdf >, Acesso em: 30 de Agosto de 2018

[3] WANG, F.; FRENKLACH, J. A detailed kinetic modeling study of aromatics formation in laminar premixed acetylene and ethylene flames, Combustion and Flame, 10: 384-393, 1997

[4] ENVIRONMENT PROTECTION AGENCY. Changes in particulate matter, Disponivel em: $<$ https : //19january2017snapshot.epa.gov/climate - impacts/climate impacts - human - health.html >, Acesso em: 20 Maio 2018

[5] BOURDREL, T.; BIND, M.-A.; BÉJOT, Y.; MOREL, O.; ARGACHA, J.-F. Cardiovascular effects of air pollution, Archives of Cardiovascular Diseases, 110(11):634-642, 2017

[6] MICHELSEN, H. A.; SCHUlZ, C.; SMAllWOOD, G. J.; WILL, S. Laser-induced incandescence: Particulate diagnostics for combustion, atmospheric, and industrial applications, Progress in Energy and Combustion Science, 51:2-48, 2015

[7] Desgroux, P.; Mercier, X.; THOMSON, K. A. Study of the formation of soot and its precursors in flames using optical diagnostics, Proceedings of the Combustion Institute, 34(1): 1713-1738, 2013

[8] SVELTO, O. Principles of lasers, editor: Springer, $5^{\text {th }} e d ., 2010$

[9] KOHSE-HÖINGHAUS, K.; JEFFRIES, J. B. Applied combustion diagnostics, 1.ed. New York: Taylor and Francis, v I, 2002 
[10] LAW, C. K. Chapter 3 - Chemistry of pollutant formation, Combustion Physics, 84-140, 2006

[11] ANDRADE, F. O.; FIGUEIRA DA SIlvA, L. F.; MORA, A. Large eddy simulation of turbulent premixed combustion at moderate Damköhler numbers stabilized in a high-speed flow, Combustion Science and Technology, 183(7):645 - 664, 2011

[12] WANG. H. Formation of nascent soot and other condensed-phase materials in flames, Proceedings of the Combustion Institute, 33(1): 41 67,2011

[13] MODEST, M. F. Radiative heat transfer - Chapter 1 - Fundamentals of thermal radiation, $3^{\text {th }} e d .: 1-30,2013$

[14] ZHAO, H.; LADOMMATOS, N. Optical diagnostics for soot and temperature measurement in diesel engines, Progress in Energy and Combustion Science, 24(3):221-255, 1998

[15] PACÍfico, A. L.; SANTOS, F. D. T.; YANAGIHARA, J. I.; DOS SANTOS, L. R.; BARRETA, L. G.; SBAMPATO, M. E.; FUKUMASU, N. K.; RODRIGUES, N. A. S.; LACAVA, P. T. Curso técnicas avançadas de diagnóstico em combustão, 2015 International Combustion Institute Summer School (ICISS), 2015

[16] MICHELSEN, H. A. ET.AL. Modeling laser-induced incandescence of soot: a summary and comparison of LII models, Applied Physics B, 87(3):503-521, 2007

[17] SCHUlZ, C.; KOCK, B.; HOFMANN, M.; MICHELSEN, H. A.; WILL, S.; BOUGIE, B.; SUNTZ, R.; SMALLWOOD, G. Laserinduced incandescence: recent trends and current questions, Applied Physics B, 83: 333-354, 2006

[18] FILIPPOV, A. V.; ZURITA, M.; ROSNER, D.E. Fractal-like aggregates: Relation between morphology and physical properties, Journal of Colloid and Interface Science, 229(1):261-273, 2000

[19] LIU, F.; YANG, M.; HILL, F. A.; SNELlinG, D. R.; SMALLWOOD, G.J. Influence of polydisperse distributions of both primary particle and aggregate size on soot temperature in lowfluence LII, Applied Physics B, 83(3):383, 2006 
[20] YON, J.; OUF, F.-X.; HEBERT, D.; MITCHELL, J. B.; TEUSCHER, N.; LE GARREC, J.-L.; BESCONDE, A.; BAUMANN, W.; OURDANI, D.; BIZZIEN, T.; PEREZ, J. Investigation of soot oxidation by coupling LII, SAXS and scattering measurements, Combustion and Flame, 190:441-453, 2018

[21] ESCUdero, F.; Fuentes, A.; CONSAlvi, J.-L.; LiU, F.; DEMARCO, R. Unified behavior of soot production and radiative heat transfer in ethylene, propane and butane axisymmetric laminar diffusion flames at different oxygen indices, Fuel, 183:668-679, 2016

[22] ROPER, F. G. The prediction of laminar jet diffusion flame sizes: Part I. Theoretical model, Combustion and Flame, 29:219 - 226, 1977

[23] LESCHOWSKI, M.; THOMSON, K. A.; SNELlinG, D. R.; SCHULZ, C.; SMALLWOOD, G. J. Combination of LII and extinction measurements for determination of soot volume fraction and estimation of soot maturity in non-premixed laminar flames, Applied Physics B, 119(4):685-696, 2015

[24] BLADH, H.; OLOfSSOn, N-E.; ET. Al. Probing the smallest soot particles in low-sooting premixed flames using laser-induced incandescence, Proceedings of the Combustion Institute, 35(2):1843 1850,2015

[25] QUAY, B.; LEE, T.-W.; NI, T.; SANTORO, R. J. Spatially resolved measurements of soot volume fraction using laser-induced incandescence, Combustion and Flame, 97:384 - 392, 1994

[26] DALly, B.; MASRI, A.; BARLOW, R.; FIECHTNER, G. Instantaneous and mean compositional structure of bluff-body stabilized nonpremixed flames, Combustion and Flame, 114(1):119-148, 1998

[27] HUANG, R. F.; LIN, C. L. Characteristic modes and thermal structure of nonpremixed circular-disc stabilized flames, Combustion Science and Technology, 100:123-139, 1994

[28] ESQUIVA-DANO, I.; NGUYEN, H. T.; ESCUDIE, D. Influence of a bluff-body's shape on the stabilization regime of non-premixed flames, Combustion and Flame, 127(4):2167-2180, 2001

[29] CAEtano, N.; FigueirA DA SILVA, L. F. A comparative experimental study of turbulent non premixed flames stabilized by 
a bluff-body burner, Experimental Thermal and Fluid Science, 63:20-33, 2015

[30] FRANZELli, B.; SCOUFlAIRE, P.; CANDEL, S. Timeresolved spatial patterns and interactions of soot, $\mathrm{PAH}$ and $\mathrm{OH}$ in a turbulent diffusion flame, Proceedings of the Combustion Institute, 35(2):1921 - 1929, 2015

[31] KUMAR, P.; MISHRA, D. P. Characterization of bluff-body stabilized LPG jet diffusion flame with N2 dilution, Energy Conversion and Management, 49(10):2698 - 2703,2008

[32] MUEller, M. E.; CHAN, Q. N; ET. AL. Experimental and computational study of soot evolution in a turbulent nonpremixed bluff body ethylene flame, Combustion and Flame, 160(7):1298 - 1309, 2013

[33] LEE, S.-E.; TURNS, S. R.; SANTORO, R. J. Measurements of soot, $\mathrm{OH}$, and $\mathrm{PAH}$ concentrations in turbulent ethylene/air jet flames, Combustion and Flame, 156(12):2264 - 2275, 2009

[34] NARAYANASWAMY, V.; CLEMENS, V.T. Simultaneous LII and PIV measurements in the soot formation region of turbulent non-premixed jet flames, Proceedings of the Combustion Institute, 34(1):1540 - 7489, 2013

[35] MAHMOUD, S.M; NATHAN, G.J; MEDWELL, P. R; DALLY, B. B; ALWAHABI, Z. T Simultaneous planar measurements of temperature and soot volume fraction in a turbulent non-premixed jet flame, Proceedings of the Combustion Institute, 35(2):1931 - 1938, 2015

[36] KemPF, A.; GeuRTS, B.; MA, T.; PETTIT, M.; STEIN, O. Quality issues in combustion LES, J. Sci. Comput, 49:51-64, 2011

[37] FLUIDAT on the Net Bronkhorst. Conversor de vazão mássica, Disponivel em: < https : //www.fluidat.com/default.asp >, Acesso em: 30 Maio 2018

[38] CHANG, H.; CHARAlampopoulos, T. T. Determination of the wavelength dependence of refractive indices of flame soot, Proceedings of the Royal Society of London A: Mathematical, Physical and Engineering Sciences, 430(1880):577 - 591, 1990 
[39] MELTON, L. A Soot diagnostics based on laser heating, Appl. Opt., 23(13):2201 - 2208, 1984

[40] AXElsson, B.; COllin, R.; BengtSson, P.-E. Laserinduced incandescence for soot particle size and volume fraction measurements using on-line extinction calibration, Applied Physics B, 72(3):367 - 372, 2001

[41] CRUZ VILLANUEVA, J. J. Estudo experimental da distribuição de fuligem e de hidrocarbonetos aromáticos policíclicos em chamas laminares não pré-misturadas de etileno e de ar, $\mathrm{PhD}$ thesis, Pontifícia Universidade Católica do Rio de Janeiro, 2018

[42] CAETANO, N. R. Estudo experimental de chamas turbulentas não pré-misturadas empregando simultaneamente as técnicas de diagnóstico laser PLIF e PIV, PhD thesis, Pontifícia Universidade Católica do Rio de Janeiro, 2012

[43] LAKOWICZ, J. R Principles os fluorescence spectroscopy, 3.ed. [S.I]: Springer, 2010

[44] VANDER WAL, R. L.; JENSEN, K. A.; CHOI, M. Y. Simultaneous laser-induced emission of soot and polycyclic aromatic hydrocarbons within a gas-jet diffusion flame, Combustion and Flame, 109(3):399-414, 1997

[45] BOUVIER., Y. et al. Molecular species adsorbed on soot particles issued from low sooting methane and acetylene laminar flames: A laser-based experiment., Proceedings of the Combustion Institute, 31(1):841 - 849, 2007

[46] OGER, B. Soot characterisation in diesel engines using laserinduced incandescence, $\mathrm{PhD}$ thesis, Faculdade de Ciência e Engenharia Universidade de Brighton, 223, 2012

[47] NETO, A.S. ET ALL III Escola de primavera em transição e turbulência, 2002

[48] POPE, S.B. Turbulent flows, 1.ed. United Kingdom: Cambridge University Press, 2000

[49] CRUZ VILlanUEVA, J.J.; FIGUEIRA DA SILVA, L.F. Study of the Turbulent Velocity Field in the Near Wake of a Bluff Body, Flow, Turbulence and Combustion, 97(3):715 - 728,2016 
[50] KLINE, S. J; MCCLINTOCK, F. A. Describing uncertanties in single-sample experiments, Mechanical Engineering, 75(1):3 - 8,1953

[51] DURRET, R. Probability: theory and examples, Cambridge University Press, $3^{\text {th }} e d ., 2010$

[52] VANDER WAL, R. L; TICICH, T. M; STEPHENS, A. B. Optical and microscopy investigation of soot structure alterations by laserinduced, Applied Physics B, 67(1):115 - 123, 1998

[53] SNELLING, D. et al. A calibration-independent laser-induced incandescence technique for soot measurement by detecting absolute light intensity, Applied Optics, 44: 6773 - 6785,2005

[54] ZIZAK, G. et al. Detection of aromatic hydrocarbons in the exhaust gases of a gasoline I.C. engine by laser induced fluorescence technique, Recent Results Developments in Applied Spectroscopy, 1:17 - 24,1996

[55] QAMAR, N. et al. Soot volume fraction in a piloted turbulent jet non-premixed flame of natural gas, Combustion and Flame, 156: 1339 1347, 2009. 